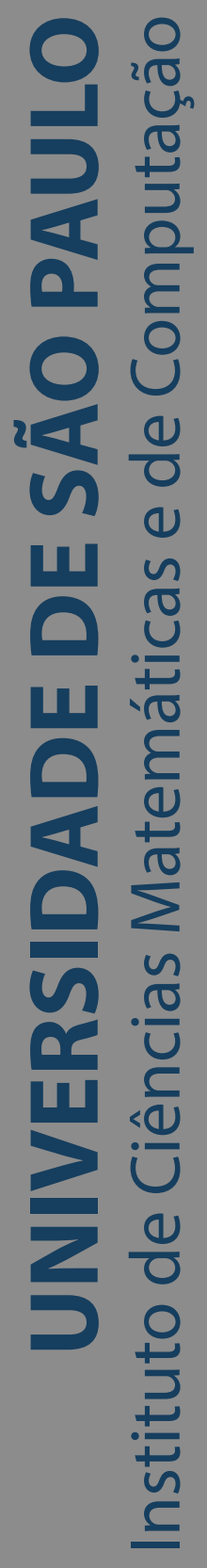

\title{
Análise da disseminação de dados em redes FANET
}

\section{Rayner de Melo Pires}

Tese de Doutorado do Programa de Pós-Graduação em Ciências de Computação e Matemática Computacional (PPG-CCMC) 

Data de Depósito:

Assinatura:

Rayner de Melo Pires

\section{Análise da disseminação de dados em redes FANET}

Tese apresentada ao Instituto de Ciências Matemáticas e de Computação - ICMC-USP, como parte dos requisitos para obtenção do título de Doutor em Ciências - Ciências de Computação e Matemática Computacional. VERSÃO REVISADA

Área de Concentração: Ciências de Computação e Matemática Computacional

Orientadora: Profa. Dra. Kalinka Regina Lucas Jaquie Castelo Branco

Coorientadora: Profa. Dra. Cristina Dutra de Aguiar Ciferri 
Ficha catalográfica elaborada pela Biblioteca Prof. Achille Bassi e Seção Técnica de Informática, ICMC/USP, com os dados inseridos pelo(a) autor(a)

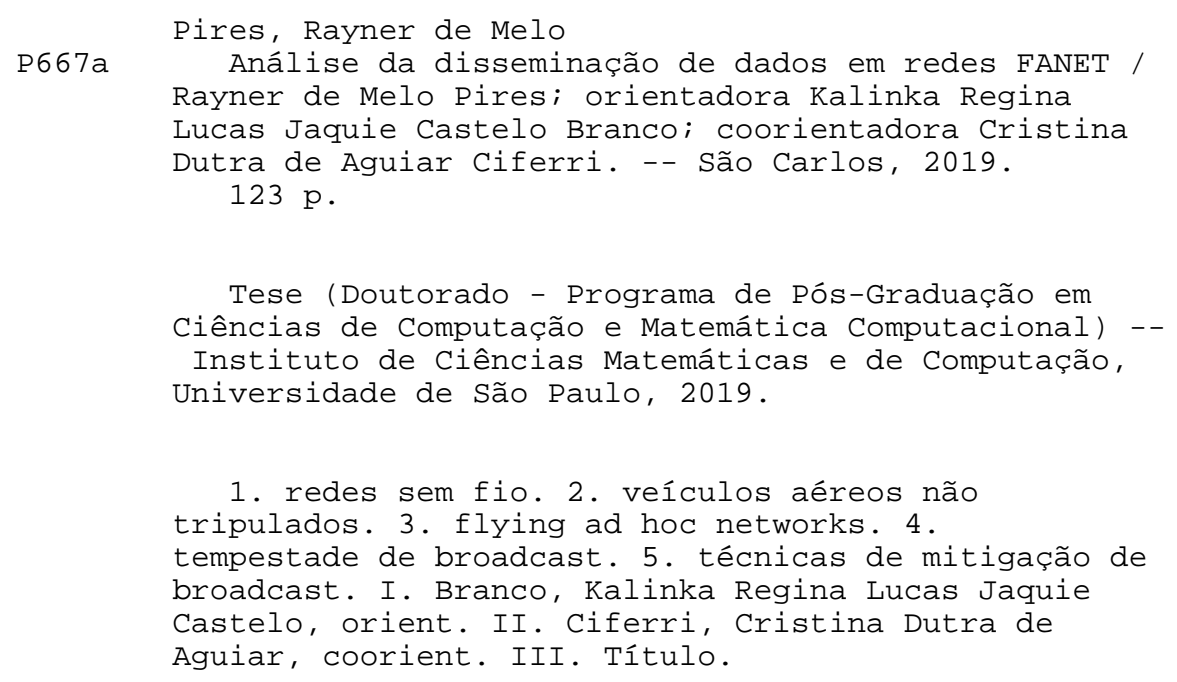

Bibliotecários responsáveis pela estrutura de catalogação da publicação de acordo com a AACR2: 


\section{Rayner de Melo Pires}

\section{Analysis of data dissemination in FANET networks}

Thesis submitted to the Institute of Mathematics and Computer Sciences - ICMC-USP - in accordance with the requirements of the Computer and Mathematical Sciences Graduate Program, for the degree of Doctor in Science. FINAL VERSION

Concentration Area: Computer Science and Computational Mathematics

Advisor: Profa. Dra. Kalinka Regina Lucas Jaquie Castelo Branco

Co-advisor: Profa. Dra. Cristina Dutra de Aguiar Ciferri

\section{USP - São Carlos}

May 2019 



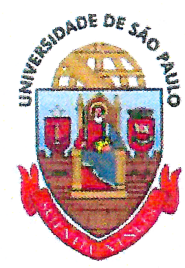

Ata de defesa de Tese do(a) Senhor(a) Rayner de Melo Pires no Programa: Ciências de Computação e Matemática Computacional, do(a) Instituto de Clências Matemáticas e de Computação da Universidade de São Paulo.

Aos 22 dias do mês de março de 2019, no(a) Sala 4-112 do ICMC-USP realizou-se a Defesa da Tese do(a) Senhor(a) Rayner de Melo Pires, apresentada para a obtenção do título de Doutor intitulada:

"Análise da disseminação de dados em redes FANET"

Após declarada aberta a sessão, o(a) Sr(a) Presidente passa a palavra ao candidato para exposição e a seguir aos examinadores para as devidas arguições que se desenvolvem nos termos regimentais. Em seguida, a Comissão Julgador: proclama o resultado:

$\begin{array}{llll}\text { Nome dos Participantes da Banca } & \text { Função } & \text { Sigla da CPG } & \text { Resultado } \\ \text { Kalinka Regina Lucas Jaquie Castelo Branco } & \text { Presidente } & \text { ICMC - USP } & \text { Não Votante } \\ \text { Rosana Teresinha Vaccare Braga } & \text { Titular } & \text { ICMC - USP } & \text { Aprovado } \\ \text { Roberto Santos Inoue } & \text { Titular } & \text { UFSCar - Externo } & \text { Aprovado } \\ \text { Paulo Sergio Martins Pedro } & \text { Titular } & \text { UNICAMP - Externo Aprovado }\end{array}$

Resultado Final: Aprovado

Parecer da Comissão Julgadora*

Eu, Geraldo de Souza Miranda

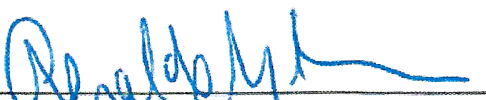
lavrei a presente ata, que assino juntamente com os(as) Senhores(as) exahtinadorés. Sâo Carlos, aos 22 dias do mês de março de 2019.

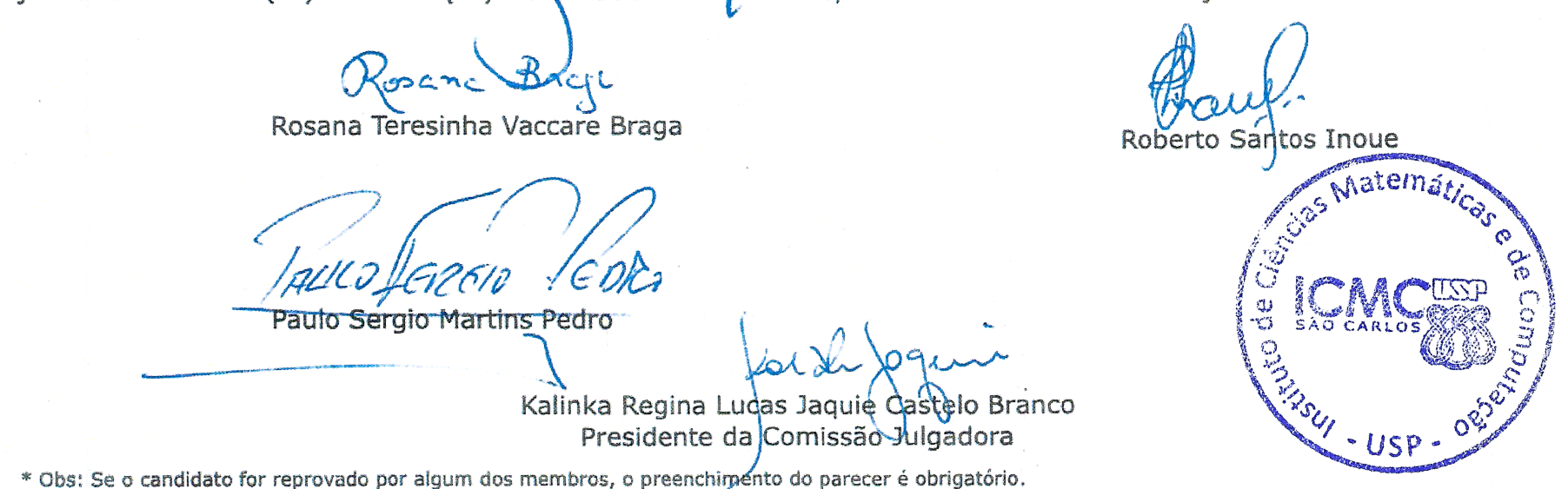

A defesa foi homologada pela Comissão de Pós-Graduação em $28 / 03 / 19$ e, portanto, o(a) aluno(a) faz jus ac título de Doutor em Ciências obtido no Programa Ciências de Cómputáção e Matemática Computacional. Aprovado "ad referendum" da $C P 6$ om 22,03119
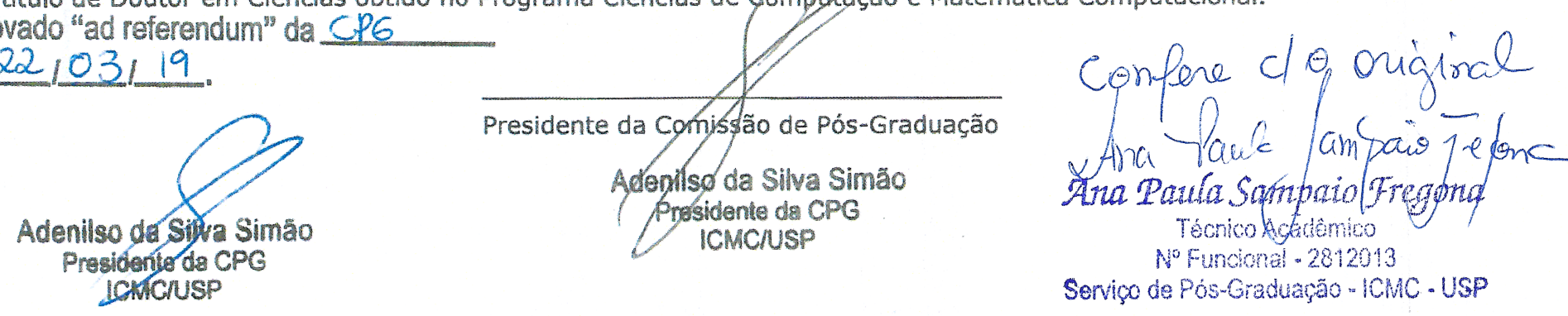

Dedico este trabalho àqueles que sempre me amaram e me apoiaram incondicionalmente, minha família! 

Quero expressar minha gratidão a todos os que me ajudaram direta ou indiretamente na realização desta tese.

Agradeço à Professora Kalinka Castelo Branco pela valiosa orientação e encorajamento em todas as fases do meu doutorado. Com certeza suas lições e contribuições influenciarão minha carreira.

Agradeço aos amigos de laboratório Emerson Marconato, Rodolfo Chiaramonte e Sergio Zumpano pela disponibilidade de sempre e grandes ajudas na realização deste trabalho.

Aos amigos que levo para a vida, Daniel Pigatto, João Vítor Fontes, Mariana Rodrigues e Natássya Barlate, meu obrigado pela parceria de laboratório, pelas ajudas no trabalho, pelos momentos de teimosia que nos enriqueceram muito e pelos muitos momentos de lazer. Também cresci profissionalmente e pessoalmente com vocês.

Sou grato ao ICMC/USP pela oportunidade de ter passado alguns anos da minha vida neste instituto, pela infraestrutura fornecida, pela qualidade do ensino e pelo suporte de toda sua equipe.

Sou grato à CAPES pelo apoio financeiro fornecido por meio do programa PROEX.

E por último, mas não menos importante, agradeço à minha família pelo apoio, pelo amor e pela compreensão com as minhas ausências enquanto estudava. 

"Educação é uma descoberta progressiva de nossa própria ignorância."

(Will Durant) 



\section{RESUMO}

PIRES, R. M. Análise da disseminação de dados em redes FANET. 2019. 123 p. Tese (Doutorado em Ciências - Ciências de Computação e Matemática Computacional) Instituto de Ciências Matemáticas e de Computação, Universidade de São Paulo, São Carlos - SP, 2019.

Os veículos aéreos não tripulados (VANTs) vêm apresentando destaque crescente no setor aeronáutico mundial, tanto no desenvolvimento dos mesmos quanto nas diferentes aplicações desses veículos, devido ao seu grande potencial de utilização. Em muitas aplicações, a utilização de múltiplos VANTs apresenta várias vantagens sobre um VANT sozinho. No entanto, o agrupamento pode experimentar problemas inerentes à comunicação sem fio, podendo originar novos problemas como inviabilizar a coordenação e a execução cooperativa de uma missão, por exemplo. Em um cenário não colaborativo, VANTs com algum nível de autonomia e que partilhem do mesmo espaço aéreo também deverão ser capazes de trocar informações entre si, principalmente informações sobre posicionamento e rota de voo, e também estarão suscetíveis aos distúrbios da comunicação sem fio. Para balancear as vantagens e as desvantagens, esses robôs precisarão se comunicar cientes das restrições e utilizando a rede de modo otimizado, por meio da aplicação de algoritmos que equilibrem adequadamente técnicas de difusão de informações e técnicas de mitigação de retransmissões. Neste projeto de doutorado foi feita a investigação sobre o método de disseminação de dados, por meio de broadcasting, em uma rede móvel ad hoc entre VANTs, denominada Flying Ad hoc Networks (FANETs). FANETs são um novo paradigma que pode superar as restrições de missões de um único VANT. As FANETs são compostas por vários VANTs que cooperam para realizar alguma missão crítica (por exemplo, uma missão de busca e resgate). Para manter a coordenação, todos os VANTs devem continuamente enviar ou retransmitir mensagens através do canal sem fio para garantir que todos os membros da rede saibam o estado da rede. Geralmente, a troca de dados necessários para manter a sincronização da missão exige o uso de broadcast para que todos os membros da rede possam recebê-los. No entanto, quando essa troca de mensagens é feita arbitrariamente, isso pode causar o problema da tempestade de broadcast (BSP), levando o meio sem fio a um estado inoperante. Apesar de alguns esforços relatados na literatura para o provimento de técnicas gerais de mitigação do problema BSP, o desafio de agregar novas informações ou conhecimento a receptores que estejam voando, ao invés de apenas espalhar os dados na rede, tem recebido menos atenção. Nesta tese, além de demonstrar que o problema BSP intensifica a contenção de rede à medida que o número de VANTs aumenta, também foi criado um método que se prova mais eficiente que os existentes até então. Tal técnica, denominada de Algoritmo Baseado em Vizinhança Dinâmica para o Problema da Tempestade de 
Broadcast (DNA-BSP), foi desenvolvida e validada com base em experimentos de mundo real e em simulações computacionais. Ele pode mitigar o problema BSP, que é um desafio real nas FANETs, reduzindo a redundância de mensagens em mais de $98 \%$ e tornando a entrega de mensagens $99,5 \%$ mais rápida do que no cenário de flooding, superando as técnicas gerais de mitigação do BSP quando aplicado em FANETs. Os resultados detalhados neste texto também poderão orientar trabalhos futuros ao fornecer informações úteis para o planejamento e otimização de redes ad hoc móveis para VANTs.

Palavras-chave: redes sem fio; veículos aéreos não tripulados; flying ad hoc networks; tempestade de broadcast; técnicas de mitigação de broadcast

"O presente trabalho foi realizado com apoio da Coordenação de Aperfeiçoamento de Pessoal de Nível Superior - Brasil (CAPES) - Código de Financiamento 001". 


\section{ABSTRACT}

PIRES, R. M. Analysis of data dissemination in FANET networks. 2019. 123 p. Tese (Doutorado em Ciências - Ciências de Computação e Matemática Computacional) Instituto de Ciências Matemáticas e de Computação, Universidade de São Paulo, São Carlos - SP, 2019.

Unmanned aerial vehicles (UAVs) have been showing increasing notoriety in the global aviation scene, both on their development and on the different applications for these vehicles, due to their high potential of use. In many applications, using multiple UAVs has several advantages over a single UAV. However, a cluster of UAVs may experience issues inherent to wireless communication, which may lead to new complications such as making mission coordination and cooperative execution impractible. In a non-collaborative scenario, UAVs with some level of autonomy which share the same airspace should also be able to exchange information among themselves, especially positioning and flight path information, and may also be susceptible to wireless communication disturbances. These robots have to use the network fairly and should communicate under restrictions, appropriately adjusting techniques that disseminate information and that mitigate broadcasts, in order to balance the advantages and disadvantages of being a group. This $\mathrm{Ph}$.D. research investigates how broadcasting is used to disseminate data throughout ad hoc mobile networks between UAVs called Flying Ad hoc Networks (FANETs). FANETs are a new paradigm that can overcome the mission constraints of single UAVs. FANETs are composed of several UAVs that cooperate to accomplish a critical mission (e.g., hazardous area monitoring). Aiming to maintain UAVs' coordination, all aircraft must continuously retransmit or relay messages through the wireless channel to assure that every member knows the FANET status. However, when this message exchange is done blindly, it may cause the broadcast storm problem (BSP), leading the wireless medium to a dysfunctional state. Despite some efforts reported in the literature for providing general techniques to mitigate the broadcast storm problem, the challenge of aggregating new information or knowledge to receivers, instead of just spreading the information in the network, has received less attention. In this research, it has been proved that the broadcast storm problem causes network contention as the number of UAVs increases, and the innovative Dynamic Neighborhood-based Algorithm for the Broadcast Storm Problem (DNA-BSP) has been provided as a countermeasure, which was developed and validated based on computer simulations and outdoor experiments. It can mitigate the broadcast storm problem, which is a real challenge in FANETs, reducing message redundancy in more than $98 \%$, and making message delivery $99,5 \%$ faster than in flooding scenario, outperforming classical broadcast storm mitigation techniques when applied in FANETs. Our detailed results can also guide future researches and provide 
useful insights for engineers planning and optimizing mission-critical mobile ad hoc network with support of UAVs.

Keywords: wireless networks; unmanned aerial vehicles; flying ad hoc networks; broadcast storm; broadcast mitigation techniques. 


\section{LISTA DE ILUSTRAÇÕES}

Figura 1 - Sistema de Aeronave Não Tripulada . . . . . . . . . . . . . . . . . 32

Figura 2 - Ilustração de uma rede FANET . . . . . . . . . . . . . . 36

Figura 3 - Comparação entre MANET, VANET e FANET . . . . . . . . . . . . . 36

Figura 4 - Protótipo para experimentos de campo . . . . . . . . . . . . 60

Figura 5 - Topologias de rede dos experimentos . . . . . . . . . . . . 60

Figura 6 - Resultados dos experimentos na topologia 1. . . . . . . . . . 63

Figura 7 - Resultados dos experimentos na topologia 2. . . . . . . . . . 65

Figura 8 - Resultados dos experimentos na topologia 3. . . . . . . . . . 67

Figura 9 - Mecanismos de propagação de ondas de rádio. . . . . . . . . . . . 72

Figura 10 - Comparação de modelos de propagação na topologia 1 . . . . . . . 75

Figura 11 - Comparação de modelos de propagação na topologia 2 . . . . . . . . 76

Figura 12 - Comparação de modelos de propagação na topologia 3 . . . . . . . . 77

Figura 13 - Trajetória 3D dos VANTs . . . . . . . . . . . . . . . . 80

Figura 14 - Variação da velocidade dos VANTs . . . . . . . . . . . . . . . . . 80

Figura 15 - Quantidade de mensagens recebidas na simulação do flooding . . . . 86

Figura 16 - Diagrama de fluxo da retransmissão . . . . . . . . . . . . . . 88

Figura 17 - Quantidade de mensagens retransmitidas na simulação do flooding 89

Figura 18 - Alcance e atraso fim-a-fim na simulação do flooding . . . . . . . . . . 90

Figura 19 - Ciclo vicioso causado pelas retransmissões no flooding . . . . . . . . 91

Figura 20 - Utilização de memória pela lista de mensagens . . . . . . . . . . . 96

Figura 21 - Comparação dos algoritmos, com quatro VANTs estáticos . . . . . . . 98

Figura 22 - Comparação dos algoritmos, com mais de três VANTs móveis . . . . . 100 

Algoritmo 1 - Simple Counter-based . . . . . . . . . . . . . 56

Algoritmo 2 - Fixed Probability-based . . . . . . . . . . . . . 57

Algoritmo 3 - Dynamic Probability-based . . . . . . . . . . . . . 58

Algoritmo 4 - Dynamic neighborhood-based, parte I . . . . . . . . . . . . 95

Algoritmo 5 - Dynamic neighborhood-based, parte II . . . . . . . . . . . . 97 

Tabela 1 - Categorização dos trabalhos relacionados . . . . . . . . . . . 52

Tabela 2 - Planejamento dos experimentos . . . . . . . . . . . . . 61

Tabela 3 - Informação recebida em campo vs. simulação . . . . . . . . . 78

Tabela 4 - Parâmetros da simulação do algoritmo de flooding. . . . . . . . . . 84

Tabela 5 - Parâmetros do sistema. . . . . . . . . . . . . . . . . 85

Tabela 6 - Redundância causada pelo flooding . . . . . . . . . . . . . 87 

AP Access Point

BSP Broadcast Storm Problem

CSMA/CA Carrier Sense Multiple Access with Collision Avoidance

CSMA/CD Carrier Sense Multiple Access with Collision Detection

DSRC Dedicated Short Range Communication

FANET Flying Ad hoc Network

GCS Ground Control Station

GPS Global Positioning System

ID identificador

IP Internet Protocol

MAC $\quad$ Medium Access Control

MANET Mobile Ad hoc Network

MIMO Multiple-Input Multiple-Output

RSS Received Signal Strenght

RTS/CTS Request to Send/Clear to Send

TCP Transmission Control Protocol

TTL Time-To-Live

UAS Unmanned Aircraft System

UAV Unmanned Aerial Vehicle

UDP User Datagram Protocol

VANET Vehicle Ad hoc Network

VANT Veículo Aéreo Não Tripulado

WSN Wireless Sensor Network

DNA-BSP Dynamic Neighborhood-based Algorithm for the Broadcast Storm Problem 



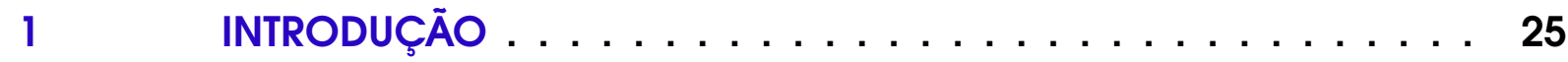

1.1 Motivação e caracterização do problema . . . . . . . . . 26

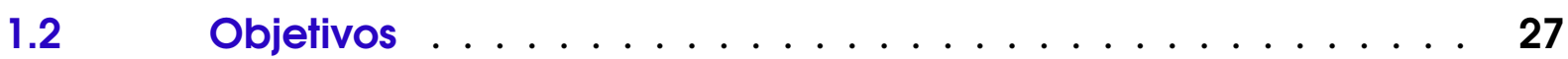

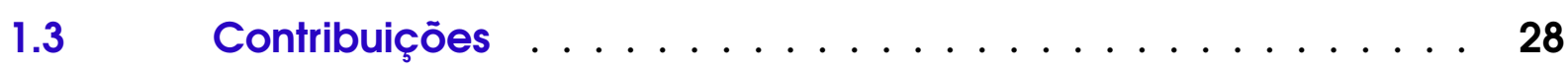

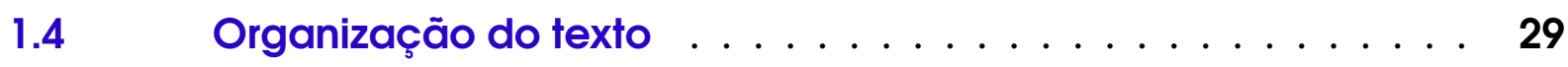

2 REFERENCIAL TEÓRICO $\ldots \ldots \ldots \ldots \ldots \ldots \ldots \ldots$

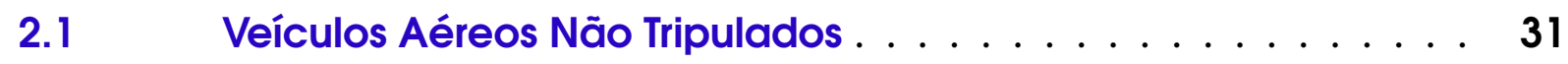

2.2 A rede FANET - Flying Ad hoc Network . . . . . . . . . . . 35

2.3 Desafios da difusão de informação em FANETs . . . . . . . . . 37

2.3.1 Disseminação de dados . . . . . . . . . . . . . . . . . . 37

2.3.2 Broadcasting em redes ad hoc . . . . . . . . . . . . . 38

$2.4 \quad$ O problema da tempestade de broadcast (BSP) . . . . . . . 39

2.5 Consideraçōes finais . . . . . . . . . . . . . . . . 41

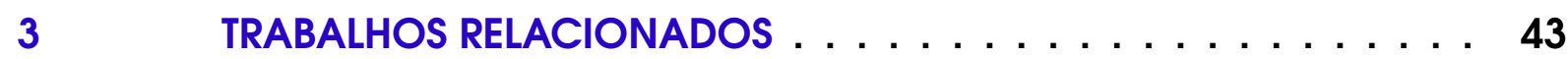

3.1 Controle de retransmissöes em redes ad hoc . . . . . . . 43

$3.2 \quad$ Consideraçōes finais . . . . . . . . . . . . . . . 53

4 EXPERIMENTAÇĀO DE TÉCNICAS EXISTENTES . . . . . . . . . 55

4.1 Técnicas de mitigação de broadcasts . . . . . . . . . . 55

$4.2 \quad$ Experimentos de campo . . . . . . . . . . . . . . . 59

$4.3 \quad$ Resultados da topologia $1 \ldots \ldots \ldots$. . . . . . . . 62

$4.4 \quad$ Resultados da topologia $2 \ldots \ldots \ldots \ldots \ldots$

$4.5 \quad$ Resultados da topologia $3 \ldots \ldots \ldots \ldots$. . . . . . . . 64

$4.6 \quad$ Considerações finais . . . . . . . . . . . . . . 66

5 DETERMINAÇÃO DO AMBIENTE DE SIMULAÇĀO . . . . . . . . . 69

5.1 Definição de simulação computacional . . . . . . . . . . 69

5.2 Características do meio sem fio e da propagação de ondas de rádio . . . . . . . . . . . . . . . . . . . 71

5.3 Determinação do modelo de propagação . . . . . . . . . . 73

5.4 Determinação do modelo de mobilidade . . . . . . . . 78

$5.5 \quad$ Consideraçōes finais . . . . . . . . . . . . . 81 
6 SIMULAÇÃO DO ALGORITMO DE FLOODING . . . . . . . . . . 83

6.1 Resultados da redundância de dados . . . . . . . . . . . . . . 84

6.2 Resultados do alcance da informação . . . . . . . . . . . 88

6.3 Considerações finais . . . . . . . . . . . . . . . . . 92

7 SOLUÇÃO PARA O CONTROLE DO BSP EM FANETS: O ALGORITMO

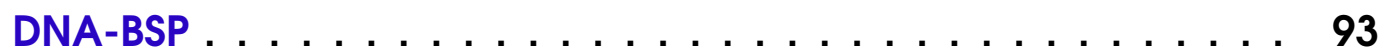

$7.1 \quad$ Resultados do Algoritmo DNA-BSP . . . . . . . . . . . . . . 97

7.2 Considerações finais . . . . . . . . . . . . . . . . 101

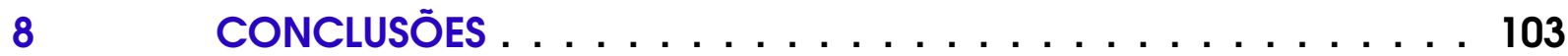

$8.1 \quad$ Limitações . . . . . . . . . . . . . . . . . . . . . 104

8.2 Dificuldades encontradas . . . . . . . . . . . . . . . 105

8.3 Contribuições . . . . . . . . . . . . . . . . 106

8.4 Trabalhos futuros . . . . . . . . . . . . . . . . . . . . . . . 107

8.5 Declaração de autoria . . . . . . . . . . . . . . . . . 108

8.6 Lista de publicações . . . . . . . . . . . . . . . . 108

8.6.1 Artigo aceito para publicação . . . . . . . . . . . . 108

8.6.2 Artigos publicados . . . . . . . . . . . . . . 108

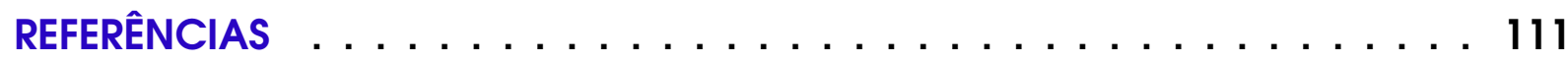




\section{1}

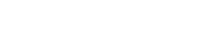

\section{INTRODUÇÃO}

Broadcasting é uma técnica importante e bem estabelecida para disseminar ou difundir dados em redes de computadores como as Redes de Sensores Sem Fio (Wireless Sensor Network (WSN)) e as Redes Móveis Ad hoc (Mobile Ad hoc Networks (MANETs)), em que os nodos enviam a mesma informação simultaneamente para todos seus vizinhos, seja por um programa em alto nível (como uma operação broadcast na Message Passing Interface (MPI)) ou por uma operação de baixo nível na rede (como broadcast nas camadas de rede ou enlace do Ethernet). Em protocolos de roteamento para redes ad hoc $^{1}$, o broadcasting é fundamental pois faz parte tanto da fase de descoberta, que é responsável por encontrar um caminho de comunicação para rotear os dados da aplicação de um nodo de origem para um ou mais nodos de destino, quanto da fase de manutenção de rotas, quando os nodos trocam pacotes de saudação para coletar informações vizinhas. Além disso, o broadcasting também é utilizado para disseminar mensagens de emergência ou de alerta em cenários de acidentes de trânsito ou desastres naturais, por exemplo. Em condições tão adversas, um mecanismo eficiente de broadcast é vital e pode ser a única maneira possível de disseminar informações cruciais (REINA et al., 2015).

Como todos os nodos compartilham o mesmo meio sem fio, o acesso simultâneo por muitos nodos ao mesmo tempo pode causar uma inundação de broadcasts e causar deterioração do desempenho em redes ad hoc sem fio. A inundação da rede causada por broadcasts redundantes e excessivos, bem como a decorrente contenção da rede e colisão de pacotes, são conhecidos coletivamente como o problema da tempestade de broadcasts (Broadcast Storm Problem (BSP)).

1 Rede ad hoc de comunicação é uma rede de computadores criada com o objetivo de cumprir um certo propósito, sem a necessidade de equipamentos de infraestrutura, como, por exemplo, switches e roteadores. Os membros da rede ficam responsáveis pelas tarefas de gerenciamento da rede e encaminhamento ou roteamento de pacotes. 
Enquanto o BSP é um problema bem conhecido em redes móveis ad hoc sem fio, nenhum estudo encontrado na literatura o considera no cenário de redes de comunicação entre Veículos Aéreos Não Tripulados (VANTs), em que os nodos se movimentam em alta velocidade, com altitudes diferentes e em um plano inerentemente tridimensional, contrariamente ao cenário das MANETs e VANETs (Vehicle Ad hoc Networks).

Nos últimos anos as pesquisas relacionadas com o controle do problema BSP em redes móveis ad hoc têm crescido significativamente (TSENG et al., 2002; TSENG; NI; SHIH, 2003; STOJMENOVIC; WU, 2004; MOHAMMED; OULD-KHAOUA; MACKENZIE, 2007; MOHAMMED et al., 2007; WISITPONGPHAN et al., 2007; MOHAMMED; OULDKHAOUA; MACKENZIE, 2008; MOHAMMED; OULD-KHAOUA; MACKENZIE, 2009; KUMAR; DAVE, 2013; SCHWARTZ; SCHOLTEN; HAVINGA, 2013; NAJAFZADEH et al., 2013; KUMAR; RAMASWAMI, 2014; MENEGUETTE et al., 2014; MENEGUETTE; VILLAS, 2014; MYLONAS et al., 2015; REINA et al., 2015; PIRES et al., 2016; KARAM, 2016; FEUKEU; SNYMAN, 2018).

Linhas de pesquisa que utilizam VANTs como objeto de estudo (VALAVANIS, 2007; ZHANG; KOVACS, 2012; KIM et al., 2012; TUNA; NEFZI; CONTE, 2014; HAYAT; YANMAZ; MUZAFFAR, 2016; BUJARI et al., 2017; KHAN et al., 2017; YANMAZ et al., 2017; MA, 2017; SHAKHATREH et al., 2018) têm considerado o agrupamento de VANTs um tópico importante a ser pesquisado para a realização de missões como, por exemplo, busca e resgate, detecção de alvos, gerenciamento de desastres naturais, mapeamento de locais desconhecidos, transporte cooperativo de objetos, entrega de medicamentos em regiões inacessíveis, monitoramento de multidões, monitoramento de fronteiras, coleta de dados sensoreados e/ou distribuídos geograficamente, retransmissão de comunicações ou reconexão de partições desconexas, controle de formação, agricultura de precisão, dentre outros.

Por meio de notícias em sites, jornais e TV é notável também a proliferação mundial desses robôs, com aplicações de uso civil e recreativo (TRINDADE JR; JORGE; AGUIAR, 2004; DRONEIMAGES, 2013; GAZETA DO POVO, 2014; MUNDOGEO, 2015; SKYDRONE, 2015; REUTERS, 2015). Desse modo, é iminente a ocupação do espaço aéreo por estes dispositivos, o que exige não só regulamentação, mas também tecnologias capazes de coordenar e gerenciar essa utilização simultânea e autônoma do espaço aéreo e do meio de comunicação, seja ele segregado ou não segregado.

\subsection{Motivação e caracterização do problema}

Elementos como a crescente quantidade de dados trocados entre aeronaves e estações de controle terrestres (Ground Control Station (GCS)), o aumento da quantidade de aeronaves tripuladas compartilhando o mesmo espaço aéreo e a entrada progressiva 
das aeronaves não tripuladas na disputa por esse espaço aéreo têm demandado uma arquitetura de rede diferenciada, com habilidades como as prometidas pelas redes Flying Ad hoc Network (FANET). As pesquisas nesta área buscam alternativas de tipos de link de dados, desenvolvem ou melhoram algoritmos de roteamento para redes ad hoc e até mesmo tentam integrar diferentes plataformas de voo para prover uma cobertura de sinal mais ampla.

A necessidade do aprimoramento da comunicação ad hoc entre múltiplos VANTs e das soluções para o controle e a mitigação do problema BSP motivam essa pesquisa.

O objetivo principal deste trabalho de doutorado é investigar e modelar os problemas causadores de contenção em uma FANET e discutir soluções mais adequadas para minimizar ou impedir sua ocorrência.

Pretende-se com isso obter soluções mais apropriadas para a comunicação autônoma eficiente entre robôs voadores. O desenvolvimento deste projeto deverá viabilizar uma comunicação mais confiável para missões com maior complexidade a serem executadas por agrupamentos de VANTs. Permitirá também a evolução de outras pesquisas que estão em andamento no mesmo laboratório e em laboratórios parceiros.

Visto isso, a questão científica deste doutorado pode ser colocada como a seguir:

- Como permitir a utilização de broadcast como modo de disseminação de informações em uma rede FANET estabelecida com "componentes de prateleira" sem que essa rede fique contida ou inutilizável?

A hipótese para solucionar essa lacuna da literatura é por meio de um método computacional que permita a realização do broadcast por aplicações que o demandem, mas que o faça de maneira controlada, levando em consideração informações sobre a rede e os dados sendo trocados, sem que seja necessária, para este controle, a intervenção por um elemento externo ou descentralizado na rede.

\subsection{Objetivos}

O objetivo principal deste trabalho é contribuir para o avanço da utilização de múltiplos VANTs em missões em que uma FANET se faça necessária, investigando e modelando os problemas causadores de contenção da rede, discutindo as soluções existentes para outros tipos de rede e fornecendo um método de controle de retransmissões de mensagens broadcast, específico para as redes FANETs, que seja capaz de amenizar os efeitos do problema BSP e permitir um melhor aproveitamento da rede.

O aproveitamento diz respeito à largura de banda do canal sem fio disponibilizada para a troca de dados coletados numa missão para a qual a FANET tenha sido concebida, 
bem como aos tempos de resposta e ao alcance das mensagens dentro da área da rede.

Como existem trabalhos na literatura sobre esse tópico em outras modalidades de rede, pode ser listado como objetivo secundário o levantamento destes trabalhos e a seleção, por empirismo, de técnicas que possam contribuir para a criação do método almejado neste doutorado.

\subsection{Contribuições}

A principal contribuição desta tese de doutorado é a concepção do algoritmo Dynamic Neighborhood-based Algorithm for the Broadcast Storm Problem para redes FANETs. Esse algoritmo vai de encontro ao objetivo desta tese, fornecendo um método de mitigação de broadcasts eficiente, capaz de amenizar os efeitos do problema BSP de modo distribuído e permitindo um melhor aproveitamento da rede.

Durante o processo da pesquisa e para a criação deste algoritmo, outras contribuições relevantes também foram obtidas:

- Levantamento de técnicas de controle de broadcast para redes ad hoc sem fio com nodos móveis no plano 2D (PIRES et al., 2016);

- Um protótipo de host para a comunicação ad hoc sem fio em redes FANETs (PIRES et al., 2016);

- Adaptação dos algoritmos da literatura para o cenário dos sistemas embarcados em aeronaves não tripuladas de pequeno porte (PIRES et al., 2016);

- Análise das vantagens e desvantagens de cada técnica de mitigação (PIRES et al., 2016);

- Análise da influência de uma camada de segurança na camada de aplicação da comunicação (ARNOSTI; PIRES; BRANCO, 2017);

- Integração entre um simulador de voo e leis da física e o simulador de redes, com geração automática de códigos (MARCONATO et al., 2017);

- Análise e escolha dos modelos de mobilidade de nodos e propagação de ondas mais apropriado para o cenário das redes FANETs;

- Quantificação do problema da tempestade de broadcast em cenário realista de FANETs;

Como última contribuição fica o ambiente de simulação computacional definido neste trabalho e descrito neste texto, que será disponibilizado para que novas pesquisas neste campo possam ser realizadas de maneira confiável e de modo mais célere. 


\subsection{Organização do texto}

O Capítulo 2 apresenta os principais conceitos relacionados aos veículos aéreos não tripulados e a rede móvel ad hoc formada pelo agrupamento destes robôs aéreos. Também é encontrado neste capítulo uma discussão sobre os desafios da disseminação de informações neste tipo de rede dinâmica.

O Capítulo 3 vislumbra o estado da arte neste tópico de pesquisa, listando os principais trabalhos que estão relacionados com o problema deste doutorado, bem como discutindo seus resultados.

No Capítulo 4 estão descritos os algoritmos selecionados para experimentação em campo, a descrição desses experimentos e os resultados encontrados, que serviram de base para a criação do ambiente de simulação e como métricas para a avaliação do algoritmo criado.

O Capítulo 5 apresenta uma breve discussão sobre a definição de simulação computacional, sobre as decisões dos modelos de mobilidade para os VANTs e de propagação de ondas para o meio de transmissão sem fio.

O Capítulo 6 apresenta os resultados da simulação do algoritmo de flooding e discute sobre seu impacto negativo no desempenho da rede.

O algoritmo Dynamic Neighborhood-based Algorithm for the Broadcast Storm Problem é apresentado e discutido no Capítulo 7 e o resultado da sua simulação é comparado com os resultados dos algoritmos da literatura, mostrando os ganhos alcançados com a abordagem mais adequada para a rede FANET.

O Capítulo 8 faz a conclusão desta tese, apresentando também a produção bibliográfica fruto desta pesquisa e as sugestões para trabalhos futuros. 

Um sistema embarcado é um sistema microprocessado em que seu processador é completamente encapsulado ou dedicado ao dispositivo ou sistema o qual ele monitora ou controla. Exemplos são smartphones, dispositivos de entretenimento digital doméstico, caixas eletrônicos bancários, impressoras, computadores de bordo em automóveis, placas de trânsito eletrônicas, equipamentos médicos, robôs, veículos autônomos e, essencialmente, qualquer coisa com um microprocessador que não é considerada um "computador" mas que desempenha algum tipo de função usando computação (FISHER; FARABOSCHI; YOUNG, 2005).

Estes sistemas são considerados críticos - ou de segurança crítica - quando eventos de falha podem acarretar perdas de vidas humanas, prejuízos ao ambiente ou perdas de ativos de alto valor. Por isso, requisitos como segurança e confiabilidade são mais importantes nessas aplicações do que desempenho. Alguns exemplos de sistemas embarcados críticos são equipamentos de cuidados médicos, plantas nucleares, armamentos, linhas de trens, carros e aviões (ARMOUSH; SALEWSKI; KOWALEWSKI, 2009; JANUZAJ et al., 2010). Os VANTs são também um exemplo típico de sistema embarcado crítico.

Esse capítulo faz uma introdução sobre essa classe de veículo autônomo e a contextualização da rede de comunicação composta por vários desses veículos, a FANET.

\subsection{Veículos Aéreos Não Tripulados}

Um Veículo Aéreo Não Tripulado (ou, em inglês, Unmanned Aerial Vehicle (UAV)) se difere de uma aeronave tripulada em muitos aspectos além do fato de não ter um piloto a bordo. Um VANT pode atuar por períodos de tempo mais longos do que um piloto conseguiria, com segurança, operar uma aeronave (DONLEY; SCHWARTZ, 2009). Eles podem ser utilizados na agricultura de precisão, no monitoramento ambiental, na 
coleta de dados científicos e têm sido utilizados amplamente em missões militares (em questões de segurança nacional) (USA Army UAS Center of Excelence, 2010).

Esses veículos vêm apresentando destaque crescente no setor aeronáutico mundial, tanto no desenvolvimento dos mesmos quanto nas diferentes aplicações em que podem ser empregados. Tais aeronaves possuem potencial de utilização, em várias aplicações, superior ao das aeronaves tripuladas convencionais. Têm surgido na última década diversas iniciativas de uso de VANTs em aplicações civis, como no monitoramento ambiental e na agricultura (ZHANG; KOVACS, 2012). Um dos principais fatores geradores dessas iniciativas é o baixo custo de aquisição e operação de VANTs, particularmente os civis de tamanho reduzido (BRANCO et al., 2011).

O VANT faz parte de um conjunto maior, formado pela própria aeronave e sua carga, pelos subsistemas de controle e pelos elementos de comunicação. Esse conjunto é conhecido como Sistema de Aeronave Não Tripulada (SANT), ou em inglês Unmanned Aircraft System (UAS)), como ilustrado na Figura 1.

Figura 1 - Sistema de Aeronave Não Tripulada

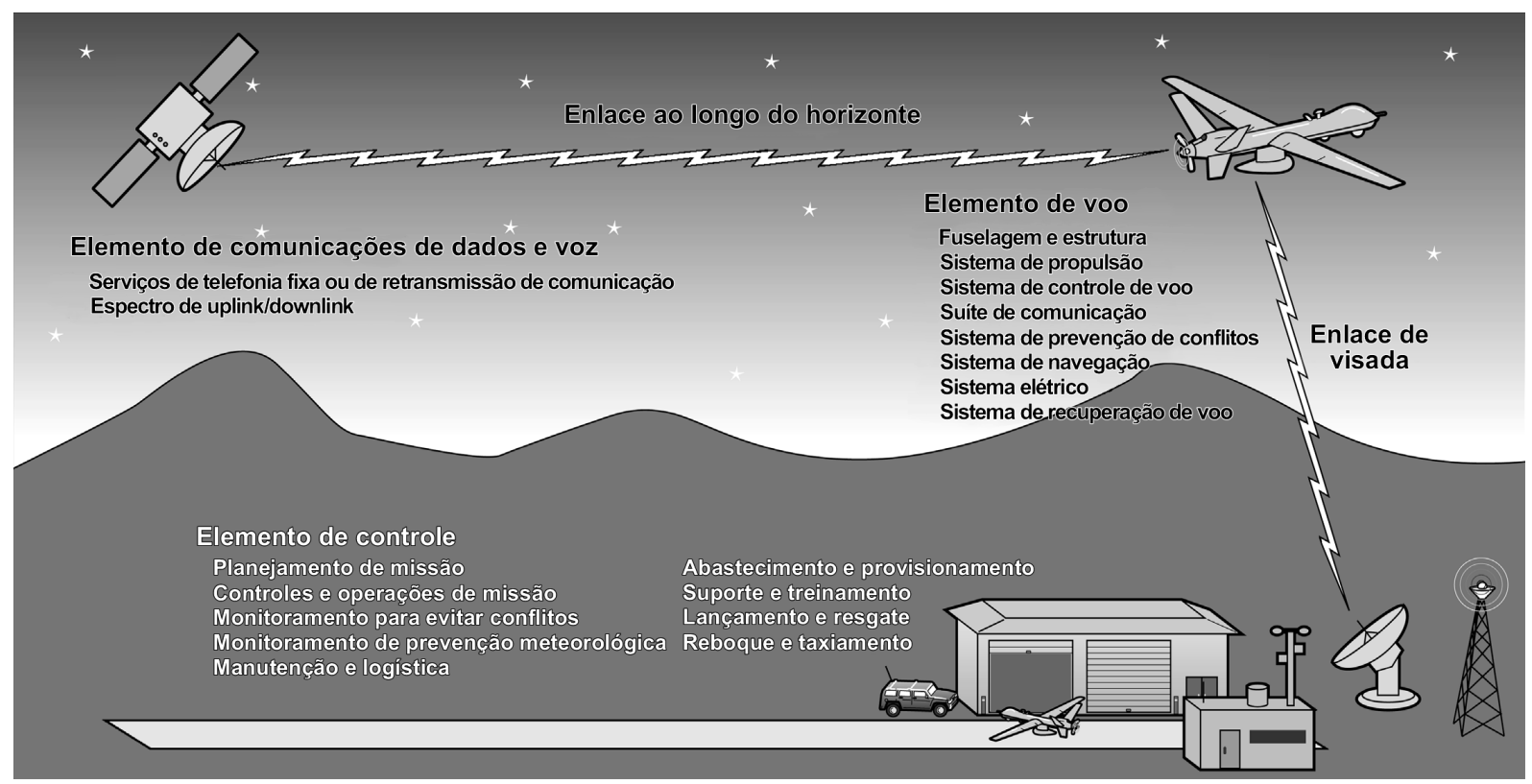

Fonte: Adaptada de USA Government Accountability Office (2008).

Em um SANT, a comunicação entre a aeronave e sua base é infraestruturada. Essa comunicação pode requerer hardwares caros e também limitar o afastamento da aeronave, devido à interrupção do link de comunicação, limitando, assim, a área de cobertura da missão.

Algumas aeronaves podem voar de forma autônoma, seguindo uma trajetória de voo pré-programada (baseada em uma grid ou uma sequência de waypoints) (TRINDADE JR et al., 2002; TRINDADE JR et al., 2010), enquanto outras voam recebendo comandos 
a partir de estações de controle terrestres operadas por pilotos, sendo chamadas, então, de aeronaves remotamente pilotadas. A estação de controle pode ser implementada em smartphones, tablets, laptops, em salas com tecnologias específicas para pilotagem remota ou até redes de estações de trabalho (estações de controle distribuídas) (PIRES; CHAVES; BRANCO, 2014).

A aeronave pode variar não apenas em tamanho, mas também na forma, no tipo de propulsão e no desempenho. A interface homem-máquina (ou homem-robô) pode variar desde um joystick até uma interface de usuário tangível (por exemplo, uma mesa tangível com realidade aumentada). O desempenho dos links de comunicação e o tipo de carga também são muito importantes para cumprir a missão destinada ao sistema (DONLEY; SCHWARTZ, 2009; USA Army UAS Center of Excelence, 2010).

Com relação aos VANTs, toda sua aviônica ${ }^{1}$ está, evidentemente, embarcada na aeronave. O uso de sistemas embarcados em aeronaves, tripuladas ou não, é inevitável, haja vista que muitos dados são coletados e tratados, além da possibilidade de existirem muitos dispositivos envolvidos em sua operação durante todo o tempo de voo. Esse trabalho seria inviável de ser feito confiavelmente por humanos sem sistemas dedicados que gerenciassem tanta informação.

Uma das questões importantes que norteiam os VANTs refere-se à estrutura para a comunicação desses robôs. Em sistemas ou missões com múltiplos VANTs, a comunicação é crucial para a cooperação e colaboração entre as aeronaves.

Veículos aéreos não tripulados têm sido empregados em missões estratégicas, difíceis, perigosas ou de tempo real, como campos de guerra (FINN; SCHEDING, 2010), por exemplo.

Em cenários do mundo real em que vários VANTs autônomos são empregados para realizar missões em grupo, os sistemas das aeronaves colaboram uns com os outros para atingir objetivos comuns por meio da troca de informações sobre o progresso da missão ou de localização em tempo real. Em muitas aplicações, um agrupamento de VANTs apresenta várias vantagens, tais como a maior agilidade e rapidez na execução de tarefas como detecção de inimigo ou de alvo, monitoramento de multidões, no balanceamento de recursos e decentralização de informações (PARRISH; EDELSTEIN-KESHET, 1999), bem como sensoriamento de grandes áreas, obtenção e processamento de informações geograficamente distribuídas, reconexão de porções desconexas etc. No entanto, o agrupamento pode diminuir a mobilidade do grupo ou atrapalhar a comunicação sem fio. Para equilibrar as vantagens e desvantagens, algumas decisões que otimizem o tamanho do grupo, a disposição, a estratégia de deslocamento e o modo de comunicação precisam

1 Designa-se por aviônica toda a eletrônica a bordo dos aviões. O termo provém de AVIation electrONICS. Neste grupo de equipamentos incluem-se os sistemas de navegação e comunicação, piloto automático e os sistemas de controle de voo. 
ser tomadas (CONRADT; ROPER, 2003; COUZIN et al., 2005).

Para melhores tomadas de decisão, a comunicação é um fator fundamental na dinâmica que determina a forma e o tamanho do grupo. Em (AREM; DRIEL; VISSER, 2006; KIM et al., 2012), os autores demonstraram que uma estratégia de comunicação deve ser adotada para aumentar a capacidade de manobra e a eficiência no deslocamento de agentes móveis. Consequentemente, um método de comunicação apropriado é essencial para explorar o benefício de um agrupamento de VANTs que trabalham em um esquema de divisão de tarefas.

A inserção de comunicação direta entre os membros do grupo, entretanto, acarreta novos problemas. Dado um grupo e seus membros, o ruído e a interferência aumentam de acordo com o crescimento do tamanho do grupo. Uma solução intuitiva consiste em aumentar a intensidade do sinal sem fio. No entanto, essa abordagem resulta em outros problemas: aumento de interferência e exposição de informações internas (KIM; SEO, 2012).

Em aplicações militares ou escoltas seguras, sabe-se que um agrupamento de maior tamanho tem diversas vantagens em termos de extensão do alcance na detecção de alvos, na identificação de inimigos e na proteção das aeronaves mais importantes, geralmente localizados no centro do grupo. Os membros do grupo compartilham suas informações com outros membros por meio de comunicações sem fio e a interferência é, sobretudo, um dos principais fatores que afetam significativamente o desempenho da comunicação (RAPPAPORT, 2001), como a vazão de dados ou o atraso na comunicação.

A segurança da formação e da comunicação é uma questão importante para veículos tripulados visto que pilotos humanos realizam a navegação de acordo com a formação determinada por missões estratégicas. Os parâmetros de comunicação correspondentes são determinados adaptativamente para suportar os requisitos da formação. A comunicação no cenário dos veículos não tripulados pode ser considerada ainda mais essencial, porque os veículos não tripulados são controlados por inteligência autônoma com base na informação que é detectada e entregue por meio dessas comunicações.

Como o grau de utilidade das informações depende fortemente do desempenho da rede, a comunicação tem papel fundamental na dinâmica dos VANTs. Além disso, a comunicação de longo alcance, como, por exemplo, a comunicação via satélite, é mais suscetível à espionagem, o que pode incorrer em ataques como Man-in-the-Middle, de disfarce ou de repetição de mensagens (KIM; SEO, 2012). Assim, a comunicação local diretamente com a vizinhança é mais apropriada em diversas aplicações de VANTs, particularmente em aplicações militares. É este tipo de comunicação que norteia o desenvolvimento dessa pesquisa de doutorado. A seção a seguir apresenta a definição e faz uma explicação sobre esse tópico. 


\subsection{A rede FANET - Flying Ad hoc Network}

Em comparação com um único VANT, existem diversas vantagens em estabelecer e utilizar um sistema com múltiplos VANTs. Elas podem ser enumeradas, como a seguir (BEKMEZCI; SAHINGOZ; TEMEL, 2013):

- Custo - A aquisição e manutenção de várias aeronaves pequenas é mais barata que um grande VANT de porte equivalente ao grupo formado pelos pequenos aviões;

- Escalabilidade - A utilização de um VANT grande aumenta muito pouco a área de cobertura. Entretanto, múltiplos VANTs aumentam a escalabilidade da operação facilmente;

- Resiliência - Na ocorrência de uma falha em um VANT, a possibilidade de "sobrevivência" ou continuidade da execução de uma missão multi-VANT é muito maior do que em uma missão na qual o VANT que falha é o único executor;

- Rapidez - Uma missão pode ser realizada mais rapidamente se suas tarefas forem distribuídas entre VANTs diferentes;

- Maior discrição - Sistemas multi-VANT produzem áreas de reflexão em radar muito pequenas, o que é crucial em aplicações militares.

Apesar das vantagens supracitadas, existem desafios singulares a serem vencidos num sistema multi-VANT, como é o caso da comunicação, o tópico de pesquisa deste doutorado.

Dada a restrição da utilização de uma comunicação infraestruturada, a alternativa para um sistema multi-VANTs é estabelecer uma rede ad hoc entre as aeronaves. Deste modo, as aeronaves comunicam-se entre si e a conexão do grupo à estação (ou estações) de base pode ser feita por intermédio de apenas um dos integrantes do grupo (ou momentaneamente, por alguns deles), que age como um gateway na rede. Esse cenário é ilustrado na Figura 2.

Este tipo de rede é referenciado na literatura por meio de diferentes nomenclaturas, como UAV Network, UAV Ad hoc networks (UAANETs), Aeronautical Ad hoc Network, Airborne Communication Networks e UAS MANET. Entretanto, este tipo de rede só foi devidamente caracterizado e diferenciado de outras redes móveis ad hoc no trabalho de Bekmezci, Sahingoz e Temel (2013). O termo sugerido pelos autores é Flying Ad hoc Network (FANET). Desde então, diversos outros trabalhos também o tem adotado (SAHINGOZ, 2013; TEMEL; BEKMEZCi, 2013; BEKMEZCI; ERMIS; KAPLAN, 2014; CHIARAMONTE; BRANCO, 2014; MARCONATO et al., 2014; RAZZAQI; MUSTAQIM; KHAWAJA, 2014; SAHINGOZ, 2014; SHARMA; KUMAR, 2014; ABDULLA et al. , 2015; 
Figura 2 - Ilustração de uma rede de comunicação entre VANTs. A possibilidade de comunicação entre todas as aeronaves e todas as estações de base permite estender a capacidade de um sistema multi-VANTs para executar missões.

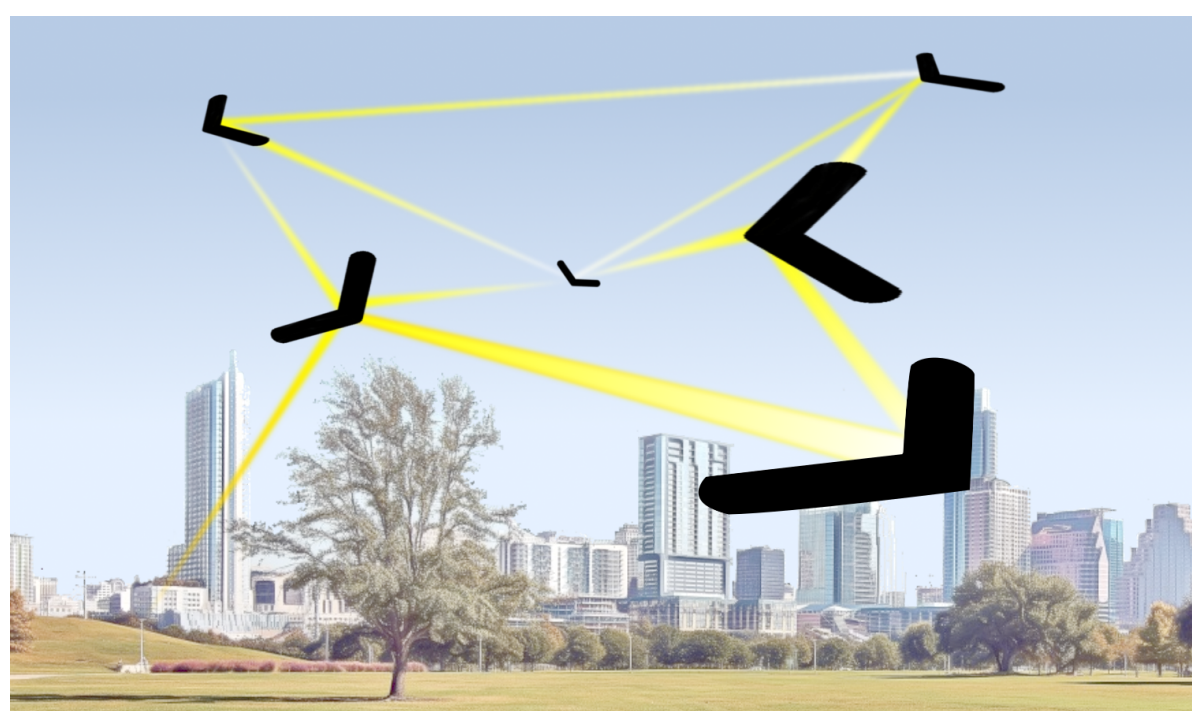

Fonte: Elaborada pelo autor.

MARCONATO et al., 2016; PIRES et al., 2016; MARCONATO et al., 2017) e este é o termo utilizado no decorrer deste texto.

Uma rede FANET pode ser vista como uma especificidade de MANET e VANET, como ilustrado na Figura 3. Essa subclassificação se dá em função das diferenças que surgem no cenário aéreo e as restrições que são impostas por este ambiente dinâmico como maior grau de mobilidade, mudança de terreno, condições do canal, falha de nodos, e demandas dinâmicas da missão (BEKMEZCI; SAHINGOZ; TEMEL, 2013).

Figura 3 - Comparação entre MANET, VANET e FANET.

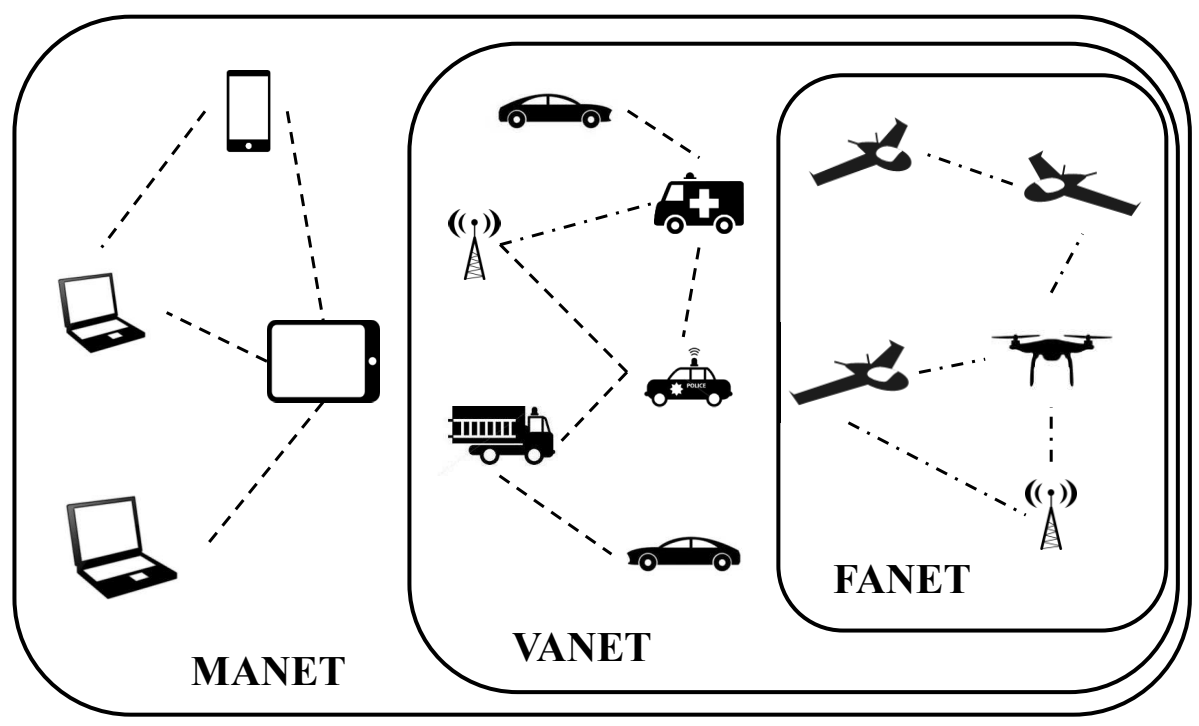

Fonte: Pires et al. (2016). 
Devido ao maior grau de mobilidade, a topologia da rede também se altera com maior frequência. Além disso, os nodos dessa rede podem precisar estabelecer, além de uma conexão ad hoc entre si, uma conexão com uma estação de comando e controle em solo, a GCS, como acontece em missões em que dados são coletados por uma rede de sensores e são enviados para um servidor, ou quando a GCS precisa gerenciar o cumprimento da missão, por exemplo. Outras diferenças acentuadas que podem ser enumeradas são (BEKMEZCI; SAHINGOZ; TEMEL, 2013) a velocidade de movimentação, as diferenças de altitude, a densidade dos nodos na rede, a distância entre os nodos, o padrão de movimentação em três dimensões e a variedade de sensores embarcados nesses nodos. Essas características podem requerer, e normalmente requerem, estratégias de troca de dados diferentes para cada nodo, o que é investigado nesta tese.

\subsection{Desafios da difusão de informação em FANETs}

\subsubsection{Disseminação de dados}

Disseminação de dados é o processo pelo qual dados ou requisições são roteados em uma rede. Em uma FANET, os dados coletados pelos VANTs podem ser comunicados à GCS ou a qualquer outro nodo interessado nos dados para ajudar na realização da missão. O nodo que gera dados é chamado de fonte e o conjunto dos dados a serem relatados é chamado de evento. Um nodo que está interessado em um evento e busca informações sobre ele é chamado de coletor.

Os eventos podem alcançar coletores usando dois modelos de tráfego: o modelo de coleta de dados, ou o de disseminação (difusão) de dados (MURTHY; MANOJ, 2004). No modelo de coleta de dados, a fonte envia os dados coletados, periodicamente ou sob demanda, para uma entidade de coleta que irá processá-los.

A difusão de dados, por outro lado, consiste em um processo em duas etapas: de propagação de interesse e propagação de dados. Um interesse é um descritor para um tipo específico de dados ou evento no qual um nodo está interessado, como sinal anticolisão, fatias do mapa da região sobrevoada ou alvos encontrados. Para cada evento em que um coletor está interessado, ele transmite seu interesse para seus vizinhos e periodicamente renova seu interesse. O interesse é propagado pela rede e cada nodo mantém um cache de interesse de todos os eventos a serem relatados. Quando um evento é detectado, ele é relatado aos nodos que estejam listados no cache de interesse. Essa é a ideia central da disseminação de dados.

Na literatura, diversos são os algoritmos encontrados para realizar esta tarefa (REINA et al., 2015; HAYAT; YANMAZ; MUZAFFAR, 2016), alguns simples e outros com propósito de eficiência e de uso de inteligência para o roteamento de dados e interesses 
em ambientes controlados.

O algoritmo mais clássico e genérico é o flooding (ou inundação). É o modo mais antigo de se disseminar dados em redes ad hoc e é com base nele que foram propostos os primeiros algoritmos de roteamento para comunicação ad hoc (PERKINS; BHAGWAT, 1994; HO et al., 1999). Nesse algoritmo, cada nodo que recebe um pacote o retransmite se a contagem máxima de saltos do pacote (Time-To-Live (TTL)) não for atingida e o nodo em si não for o destino do pacote. Este é, portanto, um protocolo simples que não requer nenhuma manutenção de topologia ou algoritmos de descoberta de rotas em qualquer nodo. Ele dissemina dados rapidamente em uma rede na qual a largura de banda não seja escassa e os links não estejam propensos a perdas. Mas o flooding em redes ad hoc sem fio causa a disseminação duplicada de dados (HEINZELMAN; KULIK; BALAKRISHNAN, 1999 apud MURTHY; MANOJ, 2004), seja porque um nodo recebe cópias do mesmo evento de muitos de seus vizinhos, ou porque o mesmo evento pode ser detectado por mais de um nodo devido à sobreposição de regiões de cobertura do sinal.

\subsubsection{Broadcasting em redes ad hoc}

Uma rede móvel ad hoc (MANET) consiste em um conjunto de hosts móveis que podem se comunicar uns com os outros e movimentar-se livremente. Não existe um ponto de acesso para a comunicação neste tipo de rede. Por causa de algumas limitações como potência do rádio, utilização de um só canal ou economia de energia, um host móvel pode não ser capaz de comunicar-se com outros hosts diretamente, por meio de um único salto (ou single-hop). Sendo assim, a comunicação entre vários hosts móveis torna-se multi-hop, na qual os pacotes enviados por um remetente são retransmitidos por vários nodos intermediários até que chegue ao host destinatário (TSENG et al., 2002).

É comum a utilização de broadcasting em uma rede para solucionar diversos problemas. Particularmente em uma MANET, devido à mobilidade dos hosts e a consequente mudança na topologia da rede, mensagens de broadcast são prováveis de acontecer com maior frequência (HAAS; PEARLMAN, 2001; JOHNSON; MALTZ; BROCH, 2001), para a execução de tarefas como envio de informações de movimentação do host, anúncio de presença para evitar colisões, envio de informações sobre o ambiente local, envio de sinal de alarme, encontrar uma rota para um host particular etc.

Em uma MANET, os hosts têm transceptores com capacidade de evitar colisões de pacotes (Carrier Sense Multiple Access with Collision Avoidance (CSMA/CA)), mas, por serem transceptores sem fio, não possuem capacidade de detectar a ocorrência de colisões de pacote (Carrier Sense Multiple Access with Collision Detection (CSMA/CD)) (TANENBAUM, 2003; BOUKERCHE, 2008; KUROSE; ROSS, 2012b). Além disso, manter uma sincronização numa rede com tal mobilidade é uma tarefa improvável de se ter 
sucesso. Sendo assim, fazer transmissões por meio de flooding (ou inundação) é a solução mais direta.

Se a densidade de nodos nessa rede é alta, é muito provável que estes nodos estejam próximos uns dos outros. Deste modo, como a propagação do sinal de rádio é omnidirecional, uma mesma região deve estar coberta pelo sinal de vários nodos, o que acarreta três problemas: retransmissões redundantes (e então, desnecessárias), contenção do meio de transmissão e muita colisão de pacotes - pois o diálogo Request to Send/Clear to Send (RTS/CTS) não é aplicável em redes ad hoc devido ao problema de congestionamento que ele induz (RAY; CARRUTHERS; STAROBINSKI, 2003).

A adoção de broadcasting para disseminação de informação em uma rede dinâmica como as MANETs é uma solução coerente, mas a utilização de flooding como método é um problema. A diferença entre as duas técnicas é que o flooding tem por objetivo atingir todos os nodos alcançáveis na rede (ou em uma área de interesse da rede) e o broadcast tem por objetivo entregar uma mensagem a todos os nodos alcançáveis na rede, no máximo, uma vez, o que evita a redundância de pacotes na rede e seus consequentes problemas. Entretanto, em redes ad hoc sem fio em que nodos precisam de outros nodos intermediários para se comunicarem, não há uma solução final para o desafio de disseminar dados por meio de broadcast e, ao mesmo tempo, assegurar que não ocorra redundância de dados. A próxima seção discute sobre esse desafio e seu princípio de dualidade, a Seção 4.1 apresenta as principais soluções da literatura e no Capítulo 7 pode ser encontrada a solução desenvolvida nesta pesquisa de doutorado.

\subsection{O problema da tempestade de broadcast (BSP)}

Os problemas associados à redundância excessiva causada pelo flooding de mensagens são coletivamente conhecidos como o problema da tempestade de broadcasts (Broadcast Storm Problem (BSP)) (TSENG et al., 2002).

Apesar deste problema ser bem conhecido em MANETs sem fio, não foram encontrados trabalhos relacionados ao tema que o considere em redes ad hoc entre VANTs, que possuem dinâmicas e propriedades distintas.

A alta mobilidade dos nodos é uma das características mais distintas de FANETs e isso ocasiona novos problemas relacionados à comunicação. Por causa dessa alta mobilidade e das variações de distância entre os nodos, frequentemente acontecem flutuações na qualidade dos links de comunicação. Uma das principais características da rede FANET, no tocante à comunicação, é a intermitência da conexão causada pela variação de qualidade ou interrupção dos links. Isso, por sua vez, acarreta problemas nas rotas da camada de rede localizada diretamente acima da camada de enlace. A busca repetitiva por caminhos na rede após cada entrega de pacote torna-se exaustiva 
e pode acarretar o problema BSP, por isso não é ideal a manutenção de uma tabela de roteamento neste tipo de rede.

Fatores como o crescente volume de dados trafegados entre aeronaves e suas estações de base, o crescente número de aeronaves tripuladas que disputam o espaço aéreo, e a progressiva entrada das aeronaves não tripuladas na disputa por esse espaço têm demandado uma arquitetura de rede diferenciada como a viabilizada pelas FANETs. As pesquisas nessa área buscam soluções para o controle e mitigação de broadcast storm (TSENG et al., 2002; TSENG; NI; SHIH, 2003; WISITPONGPHAN et al., 2007; MOHAMMED; OULD-KHAOUA; MACKENZIE, 2007; MOHAMMED; OULD-KHAOUA; MACKENZIE, 2008; MOHAMMED; OULD-KHAOUA; MACKENZIE, 2009; KUMAR; DAVE, 2013; MENEGUETTE et al., 2014; MYLONAS et al., 2015; PIRES et al., 2016; FEUKEU; SNYMAN, 2018), testam a utilização de tipos alternativos de links de dados (CHAPMAN et al., 2007; FUCHS et al., 2007; KARRAS et al., 2008; WENZHUN; YONGSHENG; XIANGYANG, 2008; TEMEL; BEKMEZCi, 2013; HARTMANN; STEUP, 2013; CHANDRASEKHARAN et al., 2016; MARCONATO et al., 2016), desenvolvem ou aprimoram algoritmos de roteamento em redes ad hoc (GU et al., 2000; HYLAND et al., 2007; LAI et al., 2009; SHI; LUO, 2012; SHIRANI et al., 2012; QUISPE; GALAN, 2014; ZHENG et al., 2014; ROSATI et al., 2015; SINGH; VERMA, 2015; TAREQUE; HOSSAIN; ATIQUZZAMAN, 2015; YASSEIN; DAMER, 2016; GANKHUYAG; SHRESTHA; YOO, 2017; OUBBATI et al., 2017; JIANG; HAN, 2018; NAYYAR, 2018) e até buscam integrar diferentes plataformas aéreas para prover uma maior cobertura de sinal (VALAVANIS, 2007; LOON, 2011; FACEBOOK, 2014; CHANDRASEKHARAN et al., 2016).

À medida que os VANTs se tornam operacionalmente mais eficientes e seguros, a duração da bateria se expande e as restrições regulatórias se reduzem, novos modelos de negócios começarão a se desenvolver, impulsionando assim a demanda que está atualmente latente. Como resultado, a agência federal de aviação dos EUA (Federal Aviation Administration (FAA)) prevê um cenário com taxas de crescimento anual cumulativo de sistemas comerciais de VANTs de até 46\% (FEDERAL AVIATION ADMINISTRATION, 2018). Uma das principais preocupações neste compartilhamento de espaço aéreo é que o tráfego de uma rede FANET deve ser distribuído de tal forma que não atrapalhe os voos comerciais ou a comunicação entre os nodos que voam em altas altitudes.

No contexto da comunicação por broadcast em redes ad hoc sem fio, muitas pesquisas em protocolos confiáveis de disseminação de dados são realizadas para MANETs e VANETs e também podem ser derivadas para FANETs. Devido a contínua variação na densidade da rede, esses protocolos devem suportar um alto grau de escalabilidade. Em redes esparsas, os protocolos incorporam mecanismos store-carry-forward para aproveitar a mobilidade de veículos a fim de aumentar o alcance das mensagens. Em redes densas, as técnicas de mitigação são projetadas para impedir o BSP, mas ainda não alcança- 
ram soluções ótimas para disseminação usando antenas omnidirecionais (SCHWARTZ; SCHOLTEN; HAVINGA, 2013).

\subsection{Considerações finais}

Nesse capítulo foi feita uma revisão do referencial teórico sobre o tema que norteia esta pesquisa de doutorado. Foram introduzidos conceitos sobre sistemas embarcados críticos e suas ligações com os veículos aéreos não tripulados. Em seguida, a relevância da utilização de múltiplos VANTs foi abordada, bem como foi apresentada a principal técnica de disseminação de dados em redes como a composta por VANTs. A rede formada por nodos voadores foi apresentada na seção sobre FANETs e, por último, foram expostos os desafios de se difundir dados nessas redes. Uma das metas deste trabalho é apresentar os desafios da disseminação de informação em FANETs por meio de broadcast. Até onde se sabe, não foi encontrada nenhuma ocorrência na literatura de resultados de BSP em simulação realista de FANET com antenas omnidirecionais. O próximo capítulo apresenta o estado da arte da disseminação de dados em FANETs. A pesquisa está descrita em detalhes ao longo do capítulo. 



\section{3}

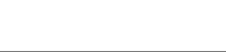

\section{TRABALHOS RELACIONADOS}

Vários estudos já foram realizados por pesquisadores (TSENG et al., 2002; TSENG; NI; SHIH, 2003; WISITPONGPHAN et al., 2007; MOHAMMED; OULD-KHAOUA; MACKENZIE, 2007; MOHAMMED; OULD-KHAOUA; MACKENZIE, 2008; MOHAMMED; OULD-KHAOUA; MACKENZIE, 2009; KUMAR; DAVE, 2013; MENEGUETTE et al., 2014; MYLONAS et al., 2015; REINA et al., 2015; HAYAT; YANMAZ; MUZAFFAR, 2016; PIRES et al., 2016; FEUKEU; SNYMAN, 2018) para investigar a comunicação em redes ad hoc e amenizar o problema BSP por meio de análises teóricas e simulações. Esta seção apresenta, em ordem cronológica, algumas das abordagens populares no tema.

\subsection{Controle de retransmissões em redes ad hoc}

Tseng et al. (2002) investigaram a abordagem do flooding usando modelagem teórica e avaliações de simulação. Os resultados numéricos mostram que uma única retransmissão é capaz de aumentar até $41 \%$ a área de cobertura de uma mensagem com apenas uma retransmissão, mas a redundância é incrementada, em média, em $61 \%$ para cada área de cobertura adicional. Neste trabalho, os autores concluem que as retransmissões por meio de flooding são capazes de degradar bastante o desempenho da rede e recomendam que soluções que utilizem retransmissões por meio de flooding sejam utilizadas com cautela, porque o aumento no alcance deve-se a altos custos em termos de largura de banda e consumo de energia.

O flooding oferece a vantagem de aumentar o alcance das mensagens em redes pouco densas em relação a outros mecanismos de disseminação que utilizam broadcast (TSENG et al., 2002; WILLIAMS; CAMP, 2002). Contudo, em redes mais densas, acaba gerando duplicações excessivas de mensagens, colisão de pacotes e contenção de rede, ou seja, o denominado problema BSP. 
A principal abordagem para resolver o problema da tempestade de broadcast em MANETs concentra-se em como reduzir a quantidade de retransmissões redundantes. Isso pode ser obtido evitando que um subconjunto dos nodos da rede façam a retransmissão. Existem vários trabalhos na literatura que utilizam diferentes técnicas de controle de redundância em comunicações via broadcast, como apresentado na revisão de Reina et al. (2015). Todos os trabalhos que utilizam a abordagem de mitigação podem ser classificados em uma das categorias gerais sugeridas em (TSENG et al., 2002): técnicas baseadas em contador, baseadas em probabilidade, baseadas em distância, baseadas na localização e baseadas em agrupamento.

Os métodos com a métrica mais simplista contam a quantidade de cópias recebidas de uma mensagem e utilizam um limiar para decidir se essa mensagem deve ser retransmitida ou descartada.

Os métodos baseados em probabilidade utilizam um valor de probabilidade predeterminado, ao invés de um contador, como limiar para decidir sobre a retransmissão. Eles são uma modificação do método de flooding e se equiparam ao último quando o limiar é igual a $100 \%$.

Os métodos baseados em distância e localização avaliam a área adicional que uma retransmissão pode alcançar. Para decidir sobre a retransmissão de uma mensagem, um retransmissor calcula a distância dos receptores com relação à sua própria e compara com o limiar, que é predefinido com o intuito de que as retransmissões aumentem o alcance das mensagens. A análise da distância é feita com apoio de posicionamento global Global Positioning System (GPS) ou pela intensidade do sinal dos nodos vizinhos (WILLIAMS; CAMP, 2002).

Um agrupamento é formado por um conjunto de nodos no qual somente um deles funciona como gateway - o responsável por encaminhar as mensagens de todo o grupo. Os métodos baseados em agrupamento não permitem que outros membros do grupo, além do gateway, retransmitam mensagens. O único membro que retransmite utiliza, então, algum dos outros métodos para decidir quais mensagens são retransmitidas ou são descartadas. O agrupamento (ou clusterização) tem como características próprias a diminuição do raio de alcance em um único salto, o aumento no número de saltos, o aumento no atraso fim-a-fim e a diminuição da contenção da rede (BOUKERCHE, 2008).

Tseng et al. (2002) propuseram vários métodos para reduzir retransmissões redundantes e diferenciar o tempo de retransmissão para amenizar o problema BSP. No método baseado em contador proposto por eles, o nodo cancela a retransmissão e descarta o pacote caso ele receba várias cópias da mesma mensagem. Ao receber uma mensagem de broadcast pela primeira vez, ao invés de retransmiti-la imediatamente, o nodo começa a aguardar por um período aleatório de avaliação. Se um nodo receber várias cópias daquela mensagem durante o intervalo de espera e o número de cópias recebidas for 
maior que um limite, a retransmissão é cancelada. A ideia deste algoritmo é minimizar as retransmissões excessivas de mensagens em áreas onde haja sobreposição de sinal, que é uma das causas de duplicações de mensagens, como discutido na Seção 2.3.

No ano seguinte, Tseng, Ni e Shih (2003) propuseram um sistema adaptativo para resolver o problema do valor fixo do limiar do contador. O limiar do contador pode ser descrito como o número máximo de cópias da mesma mensagem permitida antes de retransmitir a mensagem. Um limite baixo pode reduzir bastante o número de nodos retransmitindo. No entanto, o alcance das mensagens diminui muito em redes esparsas. Por outro lado, um limite alto pode garantir alcance maior, mas ao custo de um grande número de nodos retransmitindo. Para resolver o problema acima, os autores introduziram uma função adaptativa para o limite do contador que leva em consideração o número de nodos vizinhos, ou seja, o valor do limiar do contador varia com base no número de nodos vizinhos ao nodo de origem. Essa função permitiu resultados melhores do que no trabalho anterior, mas para calcular dinamicamente o número de nodos vizinhos eles utilizaram a troca periódica de mensagens de saudação, conhecidas como HELLO, por meio do algoritmo de roteamento ad hoc.

As abordagens de broadcasting podem exigir informações diferentes da vizinhança, o que é refletido no conteúdo das mensagens enviadas pelos nodos quando eles se movem, reagem às alterações na topologia, alteram o status da atividade ou simplesmente enviam periodicamente mensagens de atualização. Uma mensagem HELLO geralmente contém, além do seu próprio ID, sua posição, um bit para status de grupo dominante (um bit informando aos vizinhos se o nodo se considera ou não em um grupo dominante), uma lista de vizinhos adjacentes (vizinhos de um salto) e a quantidade de vizinhos conhecidos (STOJMENOVIC; WU, 2004). Outro conteúdo também é possível, como uma lista de vizinhos adjacentes e suas posições, uma lista de vizinhos de dois saltos ou até mesmo informações globais da rede (STOJMENOVIC; WU, 2004).

O uso de mensagens HELLO é uma técnica conhecida hoje por sobrecarregar a rede ad hoc, justamente porque essas mensagens são comumente distribuídas utilizando o método flooding. Como alternativa, o trabalho (TSENG; NI; SHIH, 2003) poderia ter determinado a localização relativa dos nodos vizinhos utilizando coordenadas GPS, calculando atrasos de mensagens recebidas ou medindo a intensidade do sinal recebido (Received Signal Strenght (RSS)), por exemplo.

Em 2004, Gerla e Yi (2004) investigaram a comunicação entre grupos de veículos autônomos. Desde este ano já se notava a motivação em agrupar veículos autônomos para realizar missões civis complexas ou de risco, como situações de emergência, desastres naturais, interligação de regiões isoladas ou monitoramento de multidões, por exemplo. Neste trabalho, eles adotam um cenário em que há ilhas de sensores separadas geograficamente, cujos dados devem ser coletados por grupos de VANTs. Cada grupo 
se dirige para uma ilha e coleta as informações de forma cooperativa. Esses grupos precisam de um link de backbone eficiente para enviar dados sensoreados para uma estação terrestre, para trocar dados entre os grupos, para navegação e, mais amplamente, para realizar a missão complexa de forma autônoma.

Gerla e Yi (2004) definiram que a comunicação entre todos os VANTs se realizaria de forma ad hoc e hierarquizada. Nessa comunicação, os membros responsáveis por representar um grupo se comunicam através de multicast. Assim que dados chegam ao nodo representante, esse ficaria responsável por disseminar estes dados dentro do grupo, adotando qualquer técnica eficiente de broadcast. Diferentes frequências foram consideradas para os diferentes tipos de links, para evitar problemas de interferência de sinais e otimizar a utilização dos meios de comunicação. Para esse ambiente de comunicação, os autores criaram um protocolo de roteamento chamado Multicast-enabled Landmark Ad hoc Routing protocol (M-LANMAR), capaz de rotear informações para os membros representantes de cada grupo considerando a mobilidade dentro do grupo e dos diferentes grupos, otimizando a tabela de rotas dos nodos.

Para as simulações computacionais eles utilizaram o simulador de redes QualNet e adotaram o IEEE 802.11 DCF como protocolo para a camada de enlace, com banda de 2 Mbps. O modelo de propagação de ondas adotado para o canal é o modelo two-ray path loss. O modelo de mobilidade dos nodos não foi especificado.

Os resultados apresentados mostram que o M-LANMAR associado com o protocolo de transporte próprio para multicasts chamado Reliable Adaptive Lightweight Multicast protocol (RALM) garantem uma taxa de entrega de pacotes de 100\%. Quando associado ao protocolo User Datagram Protocol (UDP), a taxa média de entrega cai para próximo de 50\%. Contudo, é com o UDP que o M-LANMAR obtém as melhores taxas de vazão, devido à ausência do mecanismo de controle de congestionamento nesse protocolo de transporte.

Este trabalho de Gerla e Yi (2004) está focado numa solução para a troca de dados orientada à uma missão. Para a viabilização da comunicação entre grupos, ele oferece como solução um protocolo de roteamento multicast. Nele não é avaliada a qualidade da comunicação entre VANTs do mesmo grupo, nem propostas soluções para problemas que ocorrem numa disseminação via broadcast, como o problema BSP que é considerado neste trabalho de doutorado.

O trabalho de Webber e Hiromoto (2006) examina o voo em formação de VANTs do ponto de vista de redes, ou seja, considerando os problemas de comunicação pertinentes em um grupo de VANTs com comportamento coordenado. O objetivo desse trabalho foi investigar as restrições de rede para manter um voo em formação com mais de duas aeronaves, em que a correção de posicionamentos é realizada com a troca de informações de localizações dos outros nodos da formação. Todos os nodos possuem as 
identificações dos membros do grupo e o líder é o responsável por manter e coordenar as rotas de voo com todos os outros VANTs. Deste modo, os modelos de comunicação são $(1: M)$ e $(M: 1)$.

$\mathrm{Na}$ inicialização do grupo, os nodos seguidores requisitam e recebem a rota do líder, calculam suas próprias rotas com base no seu posicionamento dentro do grupo e devolvem ao líder as suas próprias rotas, para que este saiba, durante todo o voo, qual VANT está ou não acompanhando a formação. O líder está posicionado no centro da formação e os outros nodos estão espalhados equidistantes em torno do líder, em um círculo de 240 metros de raio.

Webber e Hiromoto (2006) utilizaram o simulador de redes NS2 para realizar as simulações computacionais. Nele, o protocolo de roteamento escolhido foi o Ad hoc On-Demand Distance Vector (AODV). O modelo de propagação utilizado foi o shadowing propagation model, que foi parametrizado para proporcionar uma probabilidade de $50 \%$ de um pacote ser recebido quando um VANT estivesse no raio de formação de 240 metros. Esse valor é fixo e está representando a potência da antena de transmissão.

A comunicação entre os VANTs aconteceu com a troca de pacotes de dados de 512 bytes, a uma taxa de $2 \mathrm{~Hz}$ ( 2 pacotes por segundo). Cada nodo possuía um buffer de 50 pacotes (ou 25 segundos).

O modelo de mobilidade que Webber e Hiromoto (2006) inseriram no simulador é derivado do Reference Point Group Mobility Model (HONG et al., 1999) e uma simplificação do Structured Group Mobility Model (BLAKELY; LOWEKAMP, 2004) - ou Spring Mobility Model.

A avaliação dessa rede foi feita com duas métricas: o número de pacotes perdidos e a razão entre pacotes perdidos e pacotes enviados. O número de VANTs na rede variou de 5 a 19. Os autores afirmam que o congestionamento da rede é realmente muito sério e preocupante neste cenário e puderam perceber mediante seus resultados que o AODV introduziu ainda mais congestionamento na rede para refazer rotas que tinham sido invalidadas, além de sugerirem que parâmetros como a potência das antenas e o tamanho do raio de formação possam ser modificados para melhorar a entrega de pacotes e, consequentemente, a qualidade da rede.

Apesar das métricas adotadas serem valorosas, esse trabalho ainda não considera outras também importantes para garantir uma qualidade de serviço nessa rede, como vazão da rede, por exemplo. Outra limitação do trabalho de Webber e Hiromoto (2006), assim como no de Gerla e Yi (2004), é que os nodos se movimentam apenas em duas dimensões. Talvez isso seja uma limitação das plataformas utilizadas, mas um ambiente realista de simulação de FANETs deve considerar a mobilidade dos VANTs em três dimensões, bem como as características físicas da propagação tridimensionalmente, ao 
invés de modelos que definem a propagação de forma não realista, em duas dimensões.

Keshavarz-Haddad, Ribeiro e Riedi (2006) propuseram uma variante do método baseado em contador para o controle do BSP em redes ad hoc, chamada de metodologia de broadcast baseado em cores. O algoritmo usa $n$ cores, em que o valor de $n$ é o mesmo que o valor do limite do contador nos algoritmos citados anteriormente. Cada nodo marca uma mensagem com uma cor aleatória ao retransmiti-la. Todos os nodos iniciam um temporizador aleatório quando recebem uma mensagem e registram todas as cores recebidas durante esse intervalo. Ao expirar esse tempo, os nodos produzem uma lista de cores não recebidas e só retransmitem a mensagem em espera se esta lista não estiver vazia. Os autores verificaram que o conjunto de nodos que retransmitem uma mensagem varia aleatoriamente de uma transmissão para a seguinte em função dos temporizadores. Em média, esse conjunto é menor e está contido no conjunto de nodos retransmissores do método baseado em contador, o que acaba gerando mais redundância do que o método original. Entretanto, eles perceberam que o conjunto retransmissor do método baseado em cores quase sempre produz grafos de conectividade no formato de malha, ao invés do formato em árvore, como sempre acontece com o método baseado em contador com limiar $n=2$. Eles ressaltam ainda, que conexões em malha são mais robustas a falhas nos nodos, permitem múltiplas rotas de pacotes e podem reduzir a latência, o que são características interessantes para algoritmos de roteamento em redes ad hoc.

O artigo (HAN; ROSSI; SHEN, 2007) não utiliza VANTs como objetos de estudo. Entretanto, nele é apresentado um cenário em que o controle de formação de um grupo de robôs móveis sem fio é feito de modo distribuído, em uma rede MANET e por meio da análise do sinal de rádio dos vizinhos imediatamente adjacentes. Este é um exemplo de cenário e de análise que pode ser transposto para o ambiente aéreo. $\mathrm{O}$ uso de comunicações sem fio em sistemas de controle em rede impõe novos desafios na otimização do desempenho da rede utilizada, levando em consideração restrições na largura de banda da comunicação, congestionamento e contenção dos recursos de comunicação, atraso, jitter $^{1}$, ruído, atenuação e o gerenciamento da potência do sinal de transmissão (HAN; ROSSI; SHEN, 2007). Um controle de formação de um grupo de VANTs também poderia ser construído utilizando a mesma abordagem, mas com parâmetros mais apropriados.

No algoritmo de (HAN; ROSSI; SHEN, 2007), os robôs fazem o broadcast de mensagens HELLO em intervalos regulares de 2 segundos (taxa de envio de 0,5 Hz), contendo a posição atual do robô e a direção para onde ele está se movendo. Essa informação é capturada pelos vizinhos adjacentes (em um único salto).

O algoritmo foi testado em ambiente de simulação com a ferramenta QualNet.

1 Jitter pode ser definido como a medida de variação do atraso entre pacotes sucessivos de dados. 
As camadas física e de enlace utilizaram o protocolo IEEE 802.11b, com uma taxa de transmissão de $5 \mathrm{Mbps}$, com alcance de transmissão omnidirecional de 354 metros e jitter inicial de 1 segundo. O número de robôs variou de 10 a 50, em uma área de $1 \mathrm{~km}^{2}$ e eles se movimentaram com velocidade de $1 \mathrm{~m} / \mathrm{s}$ a $10 \mathrm{~m} / \mathrm{s}$.

Os autores conduziram a simulação para avaliar o desempenho do algoritmo proposto frente a duas métricas: taxa média de entrega ao destinatário e tempo médio de entrega das mensagens ao destinatário. Quanto maior foi a velocidade de deslocamento do grupo, menor foi a taxa média de entrega. Isso pode ser explicado por perdas de pacotes devido à periodicidade fixa de broadcast de mensagens HELLO. Para conseguirem atingir bons resultados de taxa de entrega em grupos volumosos, foi necessário lidar com as restrições da rede, o que acarretou num deslocamento mais lento e acabou aumentando o tempo médio de entrega. Fica evidente, então, a influência da qualidade de serviço da rede no desempenho da realização de uma missão.

Esse é mais um trabalho investigando a aplicação de uma rede de comunicação entre robôs sem apoio de uma infraestrutura. Contudo, ele também não simula as diversidades da movimentação em um ambiente livre como o céu, em que o movimento dos robôs voadores é influenciado, além das restrições da rede, também por fatores externos como rajadas de vento e diferenças de altitudes entre os nodos, ou por fatores estruturais, como restrições de cinética para realização de manobras ou para alteração de velocidades, por exemplo.

Wisitpongphan et al. (2007) direcionaram esforços na criação de três técnicas para o controle do BSP em redes VANETs, utilizando a abordagem de probabilidade e de contador. Eles propuseram os algoritmos weighted p-persistence, slotted 1-persistence e slotted p-persistence, que dão aos veículos mais distantes da fonte do broadcast uma prioridade maior de retransmissão. Para determinar a distância do emissor da mensagem, os veículos precisam determinar sua posição utilizando GPS ou RSS. Os testes foram realizados utilizando o simulador GrooveSim, configurado para utilizar o protocolo IEEE 802.11p (ou Dedicated Short Range Communication (DSRC)), que opera na faixa $5,9 \mathrm{GHz}$, com largura de banda de $75 \mathrm{MHz}$. Os três algoritmos propostos foram utilizados para mitigar as retransmissões que já eram reduzidas, pelo fato dos autores utilizarem nesse trabalho o protocolo de disseminação chamado GrooveNet, que é projetado para disseminar mensagens dentro de uma região limitada especificada no cabeçalho das mensagens. Os resultados das simulações mostraram que os algoritmos propostos conseguiram reduzir em até 70\% a perda de pacotes e manteve o atraso fim-a-fim em níveis aceitáveis para as redes VANETs. Contudo, o cenário desse trabalho é muito específico a VANETs, como o algoritmo de roteamento e o método de disseminação e o torna improvável de ser adaptado para FANETs.

Mohammed, Ould-Khaoua e Mackenzie (2007) propõem o método Efficient 
Counter-Based Scheme (ECS) para o controle de broadcasts, que é uma combinação do método de contador simples com o de probabilidade de retransmissão. Esta combinação permite ao nodo tomar a decisão de retransmissão baseada em dois limiares estatísticos. Neste algoritmo, os nodos também aguardam um período aleatório de avaliação e contam as cópias recebidas nesse período. Quando o tempo expira, os nodos geram um valor aleatório $p$ entre 0 e 1 e tomam a decisão de retransmissão comparando a quantidade de cópias recebidas com o limite do contador e comparando $p$ com uma probabilidade de retransmissão $P=65 \%$. A mensagem em espera é retransmitida somente quando o contador $c$ e o valor $p$ são menores que seus respectivos limiares.

Mohammed, Ould-Khaoua e Mackenzie (2007) se nortearam por resultados de terceiros para definirem a probabilidade de retransmissão como $P=65 \%$. Entretanto, em (MOHAMMED; OULD-KHAOUA; MACKENZIE, 2008), os mesmos autores ajustam o método ECS propondo um novo valor de probabilidade e simulações realizadas determinaram que $P=50 \%$ é um valor melhor, que evitou mais retransmissões e acarretou um atraso fim-a-fim relativamente menor sem degradar a capacidade de alcance.

Tanto no trabalho de 2007 quanto no de 2008 os autores perceberam que as abordagens utilizadas foram pouco abrangentes e os resultados encontrados ficavam limitados ao cenário de aplicação. Por isso, Mohammed, Ould-Khaoua e Mackenzie (2009) deram continuidade ao trabalho e fizeram mais uma alteração no ECS, quando abandonaram a ideia de uma probabilidade fixa de retransmissão e propuseram uma função que calcula a probabilidade com base no número médio de vizinhos. Nesse último trabalho, entretanto, o tamanho médio da vizinhança é fixo. Este tamanho é definido com base na quantidade total de membros da rede, na área da rede e no raio de alcance do rádio transmissor. Os resultados da simulação revelaram que utilizar um limiar de probabilidade dependente da vizinhança alcançou taxas de mitigação cerca de $20 \%$ superiores do que no método baseado somente em contador, em uma rede densa, e o atraso fim-a-fim foi cerca de $26 \%$ menor sem sacrificar o alcance em redes médias a densas.

Os trabalhos (YANMAZ; KUSCHNIG; BETTSTETTER, 2013; HAYAT; YANMAZ, 2015) foram focados na investigação de métodos para aprimorar a qualidade da rede de comunicação entre VANTs.

Yanmaz, Kuschnig e Bettstetter (2013) enfatizam a aplicabilidade do padrão IEEE 802.11 para ambientes de mobilidade no plano 3D, apesar de outros trabalhos só o terem avaliado com nodos se movendo em duas dimensões. Eles propõem um rearranjo das antenas dos nodos para que a cobertura do sinal seja feita por igual nas três dimensões.

Múltiplas antenas são acopladas em um pequeno quadricóptero e também na estação de comunicação em solo e os receptores utilizam a técnica de Seleção Combinada 
Simples ${ }^{2}$ para escolher a antena com o sinal mais forte. O quadricóptero se comunica com o Access Point (AP) em solo usando o padrão IEEE 802.11a, na frequência 5,2 GHz. Esse padrão foi escolhido para evitar interferências com o sinal do controle remoto da aeronave, que utilizava a frequência $2,4 \mathrm{GHz}$.

O modelo de propagação de ondas adotado nos cálculos dos autores foi o logdistance path loss model, pois os experimentos foram realizados em espaço aberto e sem obstáculos entre o VANT e o AP. A aeronave, por sua vez, foi movimentada em torno do AP, na horizontal e com altitude fixa, e depois na vertical, com a posição horizontal fixada.

Os dados de teste utilizados na comunicação foram fornecidos por um gerador de pacotes UDP, de tamanhos fixos de 1469 bytes, para propiciar um uso completo do link da rede. O desempenho da comunicação foi medido levando em consideração a taxa de transmissão, a força do sinal recebido e o número de retransmissões de pacotes, entre outros.

Com três antenas distribuídas equidistantes, os autores conseguiram prover um padrão de irradiação de sinal uniforme em $360^{\circ}$ em torno do AP. A irradiação esférica que conseguiram estabelecer pode eliminar problemas relacionados à movimentação vertical e horizontal dos nodos simultaneamente.

Yanmaz, Kuschnig e Bettstetter (2013) ainda experimentaram a comunicação entre dois VANTs no ar, em que a orientação relativa de um avião mudava constantemente com relação ao outro. Eles mostraram que o modelo de atenuação de sinal chamado Rayleigh fading não é apropriado para um cenário de VANTs, então, com base nos resultados de (BEAULIEU; CHENG, 2005), utilizaram o Nakagami fading para calcular a função de densidade do sinal.

Para avaliar o desempenho da rede, Yanmaz, Kuschnig e Bettstetter (2013) colocaram os dois VANTs enviando, ao mesmo tempo, pacotes destinados ao AP enquanto se afastavam dele. No ponto mais distante, o número de retransmissões de pacotes foi no máximo 1 em 85\% do tempo. A melhor vazão dessa rede foi de $12 \mathrm{Mbps}$ e a vazão mínima foi de $1,52 \mathrm{Mbps}$.

O desempenho da rede entre os dois aviões não foi avaliado, nem o envio de informações para o AP por meio de múltiplos saltos ou através de broadcast. Essas capacidades multi-hop foram avaliadas posteriormente em (HAYAT; YANMAZ, 2015). Neste novo trabalho, as autoras estendem a análise para uma configuração de rede com múltiplos remetentes e com múltiplos saltos. Esta configuração representa o cenário de uma FANET, em que VANTs estão voando em formação ou cooperação e estão intermi-

2 A Combinação de Diversidades é a combinação de múltiplos sinais recebidos (diversidades) em um único sinal melhorado. A Seleção Combinada Simples é uma das técnicas possíveis, onde somente o sinal mais forte dos $N$ sinais recebidos é selecionado. 
tentemente conectados com a estação de solo. A avaliação de desempenho foi focada no provimento de cobertura com alta vazão e com imparcialidade na retransmissão dos nodos nessa rede intermitentemente conectada.

Experimentos de um único salto e de dois saltos foram conduzidos e as autoras avaliaram o desempenho da rede no modo infraestruturado - estabelecido com IEEE 802.11a e IEEE 802.11n - e no modo mesh - estabelecido com IEEE 802.11s.

Nos experimentos de único salto, foi possível perceber com os resultados, que a capacidade Multiple-Input Multiple-Output (MIMO) do padrão IEEE 802.11n proporcionou uma experiência com vazão muito maior que o padrão IEEE 802.11a.

Nos experimentos de dois saltos, Hayat e Yanmaz (2015) perceberam que o protocolo de roteamento padrão do IEEE 802.11s, o Hybrid Wireless Mesh Protocol (HWMP), teve muita influência na queda do desempenho da rede e concluíram que a métrica dele (número de saltos) não é ideal para todos os casos de rede.

Os trabalhos (YANMAZ; KUSCHNIG; BETTSTETTER, 2013) e (HAYAT; YANMAZ, 2015) utilizaram componentes de prateleira para estabelecer redes de comunicação para VANTs e fazer avaliações de desempenho e qualidade dessas redes. Contudo, esses trabalhos ainda limitaram a quantidade de nodos envolvidos ou a contínua movimentação das aeronaves. Afinal, nem todos os nodos de uma FANET são capazes de pairar no ar, como é o caso de VANTs de asa fixa, por exemplo. Isso impele que novos experimentos venham a ser realizados e novos resultados observados.

Por fim, a Tabela 1 apresenta uma categorização dos trabalhos apresentados nesta seção.

Tabela 1 - Principais características extraídas dos trabalhos relacionados nesta seção.

CARACTERÍSTICAS RELEVANTES DOS TRABALHOS

TIPO DE TRABALHO

Avaliação teórica T1, T2, T5, T6

Simulação computacional T1, T2, T3, T4, T6, T7, T8, T9, T10

Experimentação em ambiente real com T11, T12 componentes de prateleira

TIPO DE REDE

Rede multi-hop com mais de dois nodos T3, T4, T6, T7, T8, T9, T10

Padrão IEEE 802.11a/b/g/n

Padrão IEEE 802.11p T7, T11, T12

Padrão IEEE 802.11s $\mathrm{T} 7$ $\mathrm{T} 12$ 


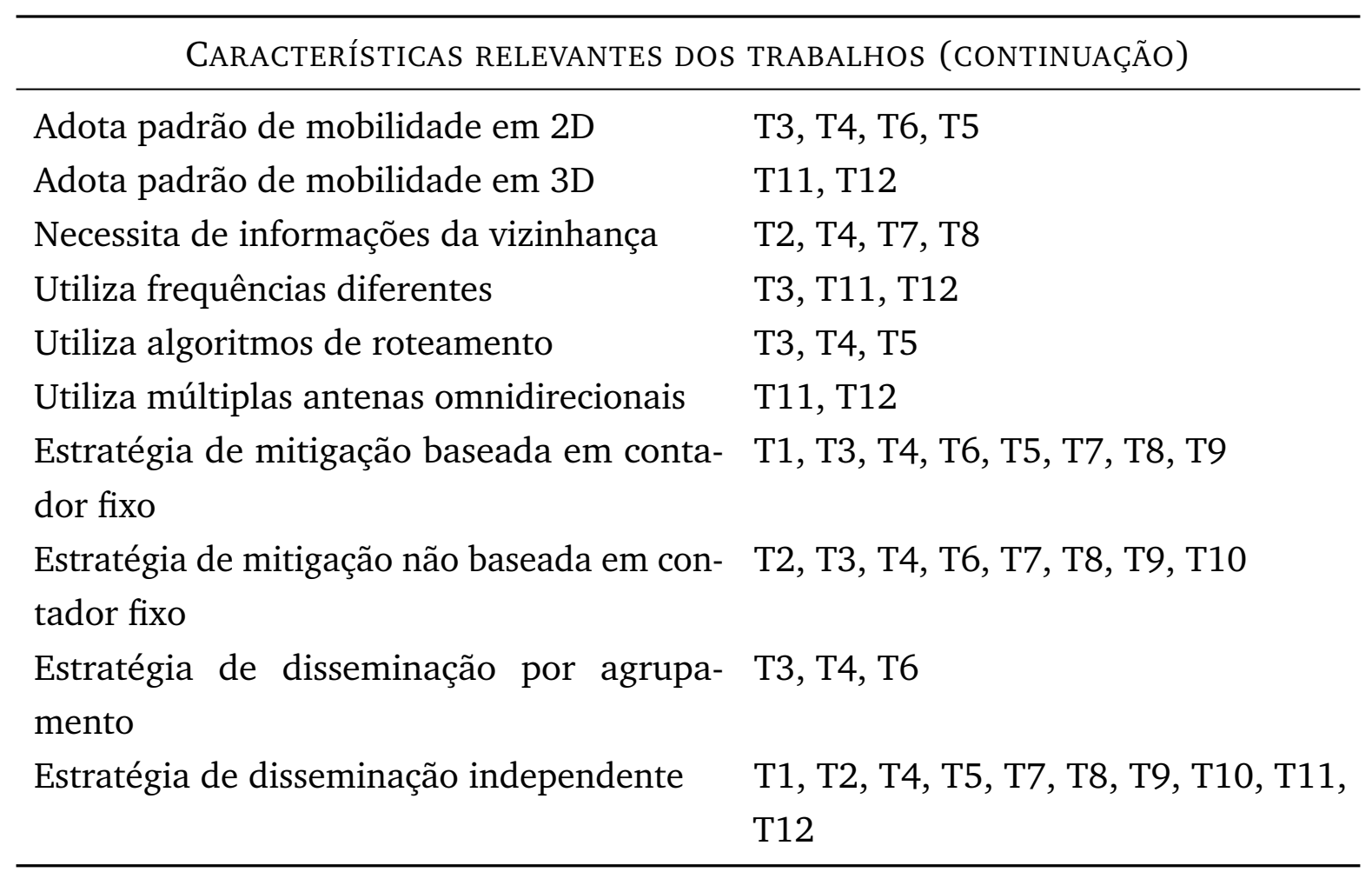

T1 (TSENG et al., 2002)

T2 (TSENG; NI; SHIH, 2003)

T3 (GERLA; YI, 2004)

T4 (WEBBER; HIROMOTO, 2006)

T5 (KESHAVARZ-HADDAD; RIBEIRO; RIEDI, 2006)

T6 (HAN; ROSSI; SHEN, 2007)

T7 (WISITPONGPHAN et al., 2007)

T8 (MOHAMMED; OULD-KHAOUA; MACKENZIE, 2007)

T9 (MOHAMMED; OULD-KHAOUA; MACKENZIE, 2008)

T10 (MOHAMMED; OULD-KHAOUA; MACKENZIE, 2009)

T11 (YANMAZ; KUSCHNIG; BETTSTETTER, 2013)

T12 (HAYAT; YANMAZ, 2015)

\subsection{Considerações finais}

A revisão bibliográfica serviu para levantar trabalhos relevantes no tema deste doutorado, mas também possibilitou enxergar pontos em abertos desses trabalhos que ainda precisam ser investigados para se garantir qualidade de serviço à uma rede FANET. Diferentemente dos estudos listados neste capítulo, nesta pesquisa de doutorado foram levados em consideração as diferentes decisões por modelos de propagação de sinal, modelos de mobilidade em três dimensões e abordagens para a disseminação de dados 
nessas redes. O próximo capítulo trata da experimentação de alguns dos trabalhos mencionados até aqui e da avaliação dos resultados obtidos em ambiente de campo. 


\section{EXPERIMENTAÇÃO DE TÉCNICAS EXISTENTES}

Todos os trabalhos citados no Capítulo 3 possuem vantagens e desvantagens. Eles geralmente buscam a combinação de métricas como vazão, alcance, latência das mensagens e a quantidade de retransmissões evitadas (ou não realizadas). Então, os trabalhos (TSENG et al., 2002; TSENG; NI; SHIH, 2003; MOHAMMED; OULD-KHAOUA; MACKENZIE, 2007; MOHAMMED; OULD-KHAOUA; MACKENZIE, 2008; MOHAMMED; OULD-KHAOUA; MACKENZIE, 2009) foram selecionados e suas técnicas experimentadas em um cenário simplista de FANET com característica multi-hop. Eles foram escolhidos como referência porque utilizam métodos estatísticos para realizar o controle de retransmissões, seus resultados foram produzidos a partir de simulação computacional e mostraram que eles diminuem a carga ${ }^{1}$ na rede mesmo não tendo informação sobre a topologia da rede. Isso se traduz em simplicidade e uso mais justo da rede. Além disso, as técnicas citadas servem ao mesmo objetivo deste trabalho e também podem operar sob condições ambientais críticas semelhantes às das FANETs.

A seguir, os algoritmos utilizados neste trabalho são apresentados, são descritos os experimentos de campo realizados e quais foram os resultados obtidos.

\subsection{Técnicas de mitigação de broadcasts}

Inicialmente foi implementada a técnica baseada em contador. Nos experimentos realizados neste trabalho, os valores de limiares adotados foram threshold $=2 \mathrm{e}$ threshold $=3$, como nos trabalhos de referência ((TSENG et al., 2002; TSENG; NI; SHIH, 2003; MOHAMMED; OULD-KHAOUA; MACKENZIE, 2007; MOHAMMED; OULDKHAOUA; MACKENZIE, 2008; MOHAMMED; OULD-KHAOUA; MACKENZIE, 2009)).

O algoritmo de Tseng et al. (2002) pausa o cronômetro toda vez que uma men-

1 Neste trabalho, o termo carga se refere à utilização do canal sem fio da rede. 
sagem redundante é recebida e, se o valor atual do contador for menor que o valor do limiar, o cronômetro é continuado. Na versão implementada aqui, o cronômetro não é interrompido quando novas mensagens chegam, nem são feitas comparações enquanto o cronômetro está ativo. Pausar o tempo para fazer computações resulta em um atraso maior na retransmissão das mensagens enfileiradas, o que não é desejável, além de usar mais recursos da CPU e, por isso, consumir mais energia, o que não é apropriado para sistemas embarcados como os utilizados em VANTs civis de pequeno porte. A única tarefa que é executada concorrentemente ao temporizador é o listener ${ }^{2}$ de novas mensagens.

A versão implementada está descrita no Algoritmo 1.

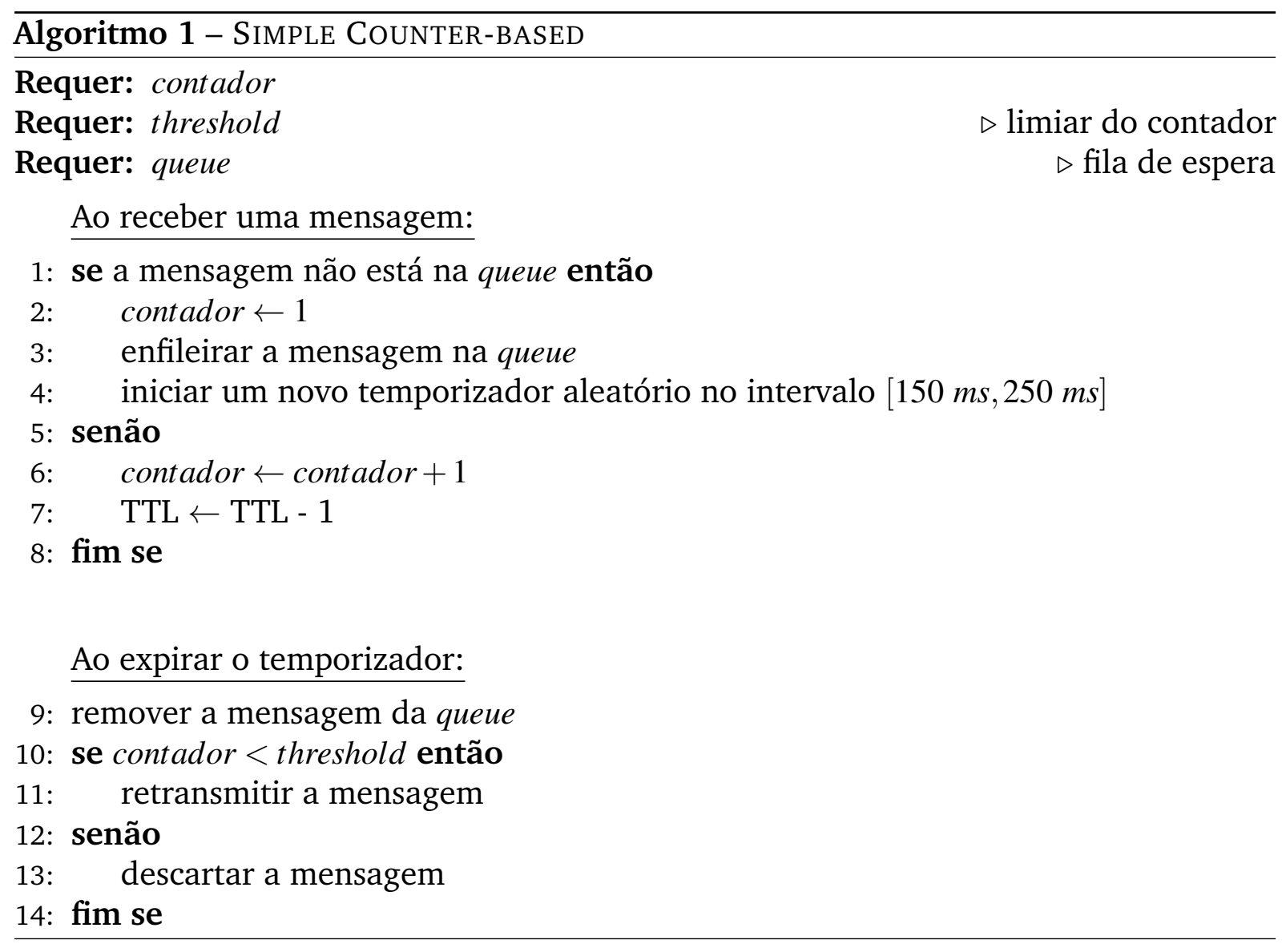

A segunda técnica implementada foi a de probabilidade fixa de retransmissão. Conforme descrito em (MOHAMMED; OULD-KHAOUA; MACKENZIE, 2007; MOHAMMED; OULD-KHAOUA; MACKENZIE, 2008), as mensagens não são retransmitidas automaticamente com base somente no valor do contador, mas também dependem de uma probabilidade de retransmissão $P$ predeterminada. A combinação das duas técnicas diminui a quantidade de mensagens redundantes, gerando menos colisão de pacotes e, portanto, um atraso fim-a-fim menor.

2 Um event listener é um procedimento ou função em um programa de computador que aguarda a ocorrência de um evento. O listener é programado para reagir a uma entrada ou sinal chamando o manipulador do evento. 
Os dois valores $P=65 \%$ ((MOHAMMED; OULD-KHAOUA; MACKENZIE, 2007)) e $P=50 \%$ ((MOHAMMED; OULD-KHAOUA; MACKENZIE, 2008)) foram escolhidos para experimentação e avaliação.

No Algoritmo 2, duas condições devem ser avaliadas antes da retransmissão de uma mensagem, decorrendo em maior eficiência em termos de retransmissões mitigadas, quando comparado com o Algoritmo 1.

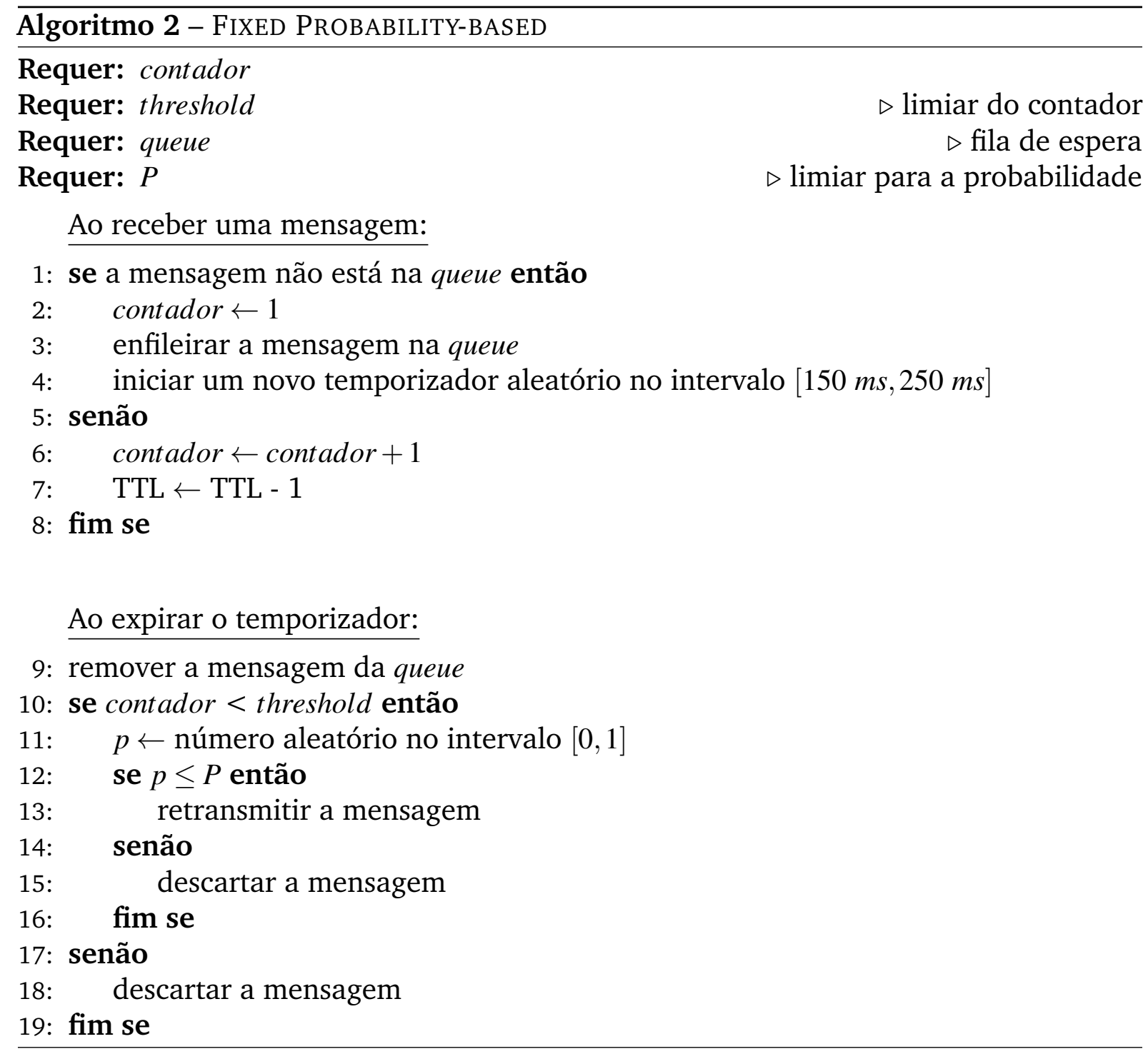

A terceira técnica implementada é uma melhoria do Algoritmo 2. De acordo com o trabalho (MOHAMMED; OULD-KHAOUA; MACKENZIE, 2009), estes valores são pouco prováveis de serem ideais para todos os casos, pois o desempenho depende também de outros parâmetros da simulação, como o tamanho da topologia, alcance de transmissão e número de vizinhos. Por isso, os autores propuseram uma função que calcula o segundo limiar com base em informações da rede. Essa função está representada na Equação (4.1):

$$
f(c)=e^{-\frac{c}{\lambda}}
$$


em que $c$ é o contador de mensagens duplicadas e $\lambda$ é uma segunda função, que estima o número de vizinhos locais.

Apesar de ser relativamente simples de descobrir o número de vizinhos usando mensagens HELLO periódicas, isso não é recomendável em redes muito dinâmicas, porque este método pode ser ineficaz se a periodicidade for baixa demais, ou inundaria a rede caso fosse frequente demais. Deste modo, Mohammed, Ould-Khaoua e Mackenzie (2009) resolveram estimar o número médio de vizinhos com base nos parâmetros de simulação, como dado pela Equação (4.2):

$$
\lambda=(N-1) \frac{\pi R^{2}}{A}
$$

Nessa equação, $N$ é o número de nodos na rede, $R$ é o alcance do sinal de rádio dos nodos e $A$ é a área total da rede.

O Algoritmo 3 foi implementado com o suporte das equações (4.1) e (4.2).

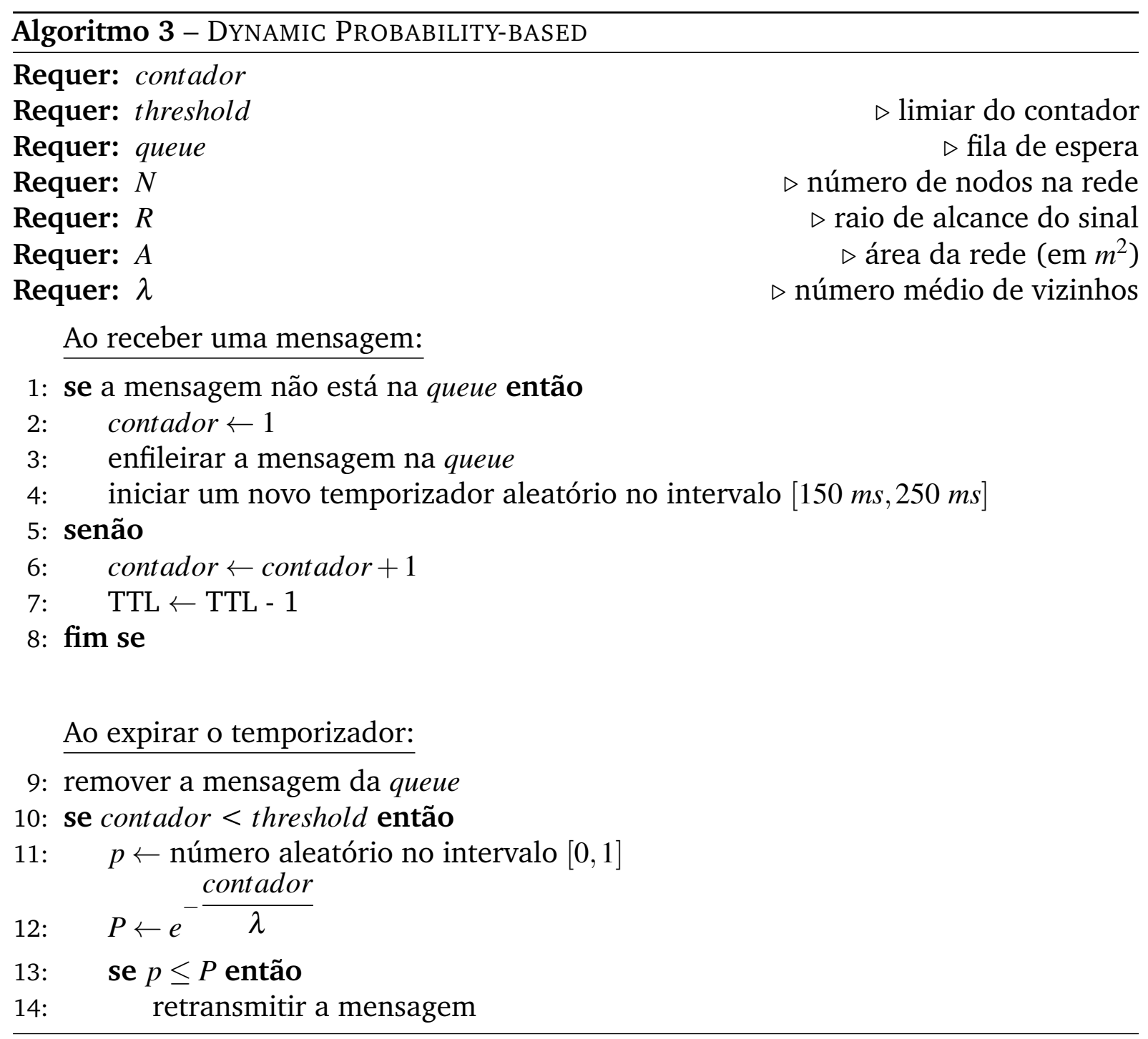




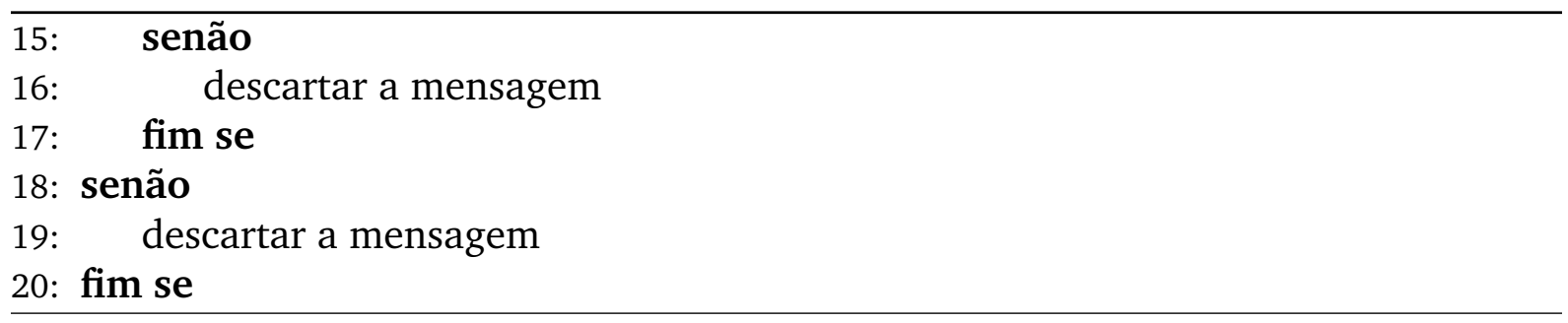

Depois que os algoritmos foram adaptados e codificados, eles foram implantados em protótipos reais e experimentados em campo.

\subsection{Experimentos de campo}

A simulação computacional da comunicação via broadcast em uma rede FANET exige um ambiente de simulação parametrizado adequadamente para que, ao final, os resultados obtidos sejam confiáveis. Com o intuito de criar um ambiente de simulação realista, experimentos de comunicação em campo foram realizados para investigar o comportamento da rede e coletar dados que serviriam de base para a parametrização do ambiente virtual.

A primeira atenção tomada foi em utilizar um hardware similar ao usado nos VANTs civis de pequeno porte. A plataforma utilizada para a prototipação foi a Gumstix Overo ${ }^{\circledR}$ Fire, um módulo computacional com um processador ARM Cortex-A8 de $720 \mathrm{MHz}$, com conexões Blueetooth, Wi-Fi e USB, e 512 MB de memória RAM. Os testes foram executados em ambiente externo aberto, com prédios distantes, algumas árvores e com pouca ou nenhuma interferência de outras redes Wi-Fi no mesmo canal. A fotografia do protótipo construído está mostrada na Figura 4.

Os experimentos consistiram em quatro placas arranjadas em três topologias, ilustradas na Figura 5, almejando abranger diferentes situações de voo em formação de um grupo de VANTs, como o esquema líder-seguidor, por exemplo. As topologias definem o número de nodos na rede, o posicionamento de cada nodo e a interconexão entre eles (FERREIRA; GALTIER; PENNA, 2002). Elas foram definidas, neste trabalho, para organizar um grupo de VANTs quadrotores que executam uma missão pré-programada autonomamente, em que dados são trocados na rede por broadcast e a velocidade e os movimentos de voo são coordenados de tal modo que a distância Euclidiana entre os nodos é mantida constante.

Na primeira topologia, os nodos 1, 2 e 3 ficaram dispostos de modo que seus sinais se sobreponham. O nodo START alcança apenas os nodos 1 e 2 , enquanto o nodo 4 está isolado, comunicando somente com o nodo 3.

Na segunda topologia, os nodos estão arranjados de modo linear. Esta disposição é importante porque ele expande a área da rede e torna a análise de alcançabilidade das 
Figura 4 - Detalhes do protótipo utilizado nos experimentos de campo. Em preto está uma bateria selada de $12 \mathrm{~V}$ e abaixo está a placa Gumstix.

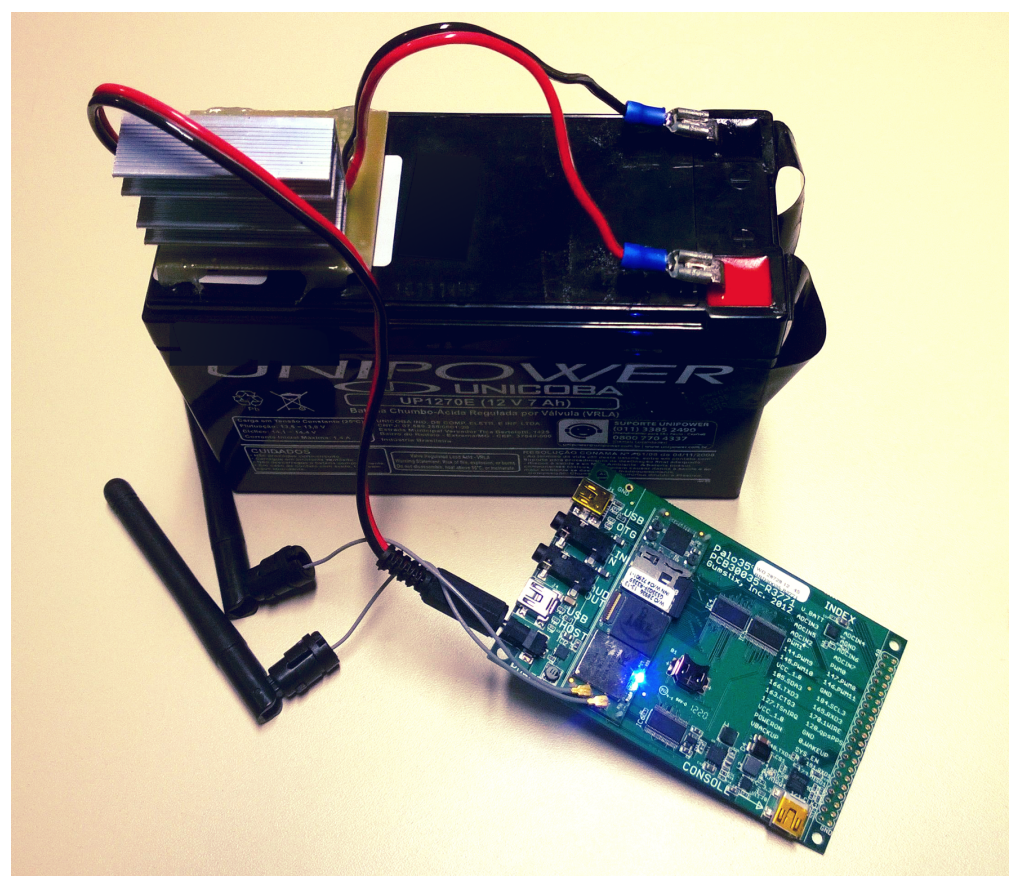

Fonte: Elaborada pelo autor.

Figura 5 - Cenário de rede adotado nos experimentos para investigar o espalhamento de informação em uma FANET composta por um nodo transmissor (Start) e quatro nodos retransmissores organizados em três diferentes topologias: (a) topologia 1 com até $80 \%$ de sobreposição de sinais, (b) topologia 2 com até $60 \%$ de sobreposição de sinais e (c) topologia 3 com 100\% de sobreposição de sinais.

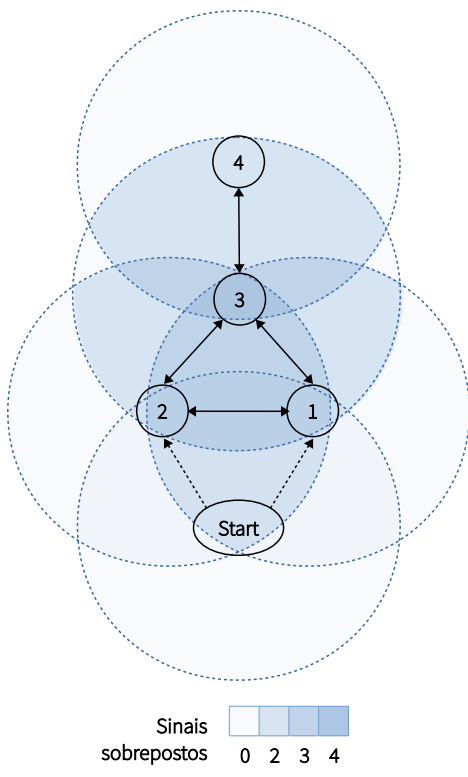

(a) Topologia 1

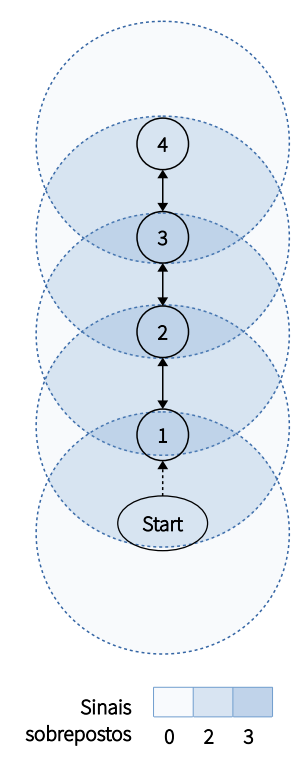

(b) Topologia 2

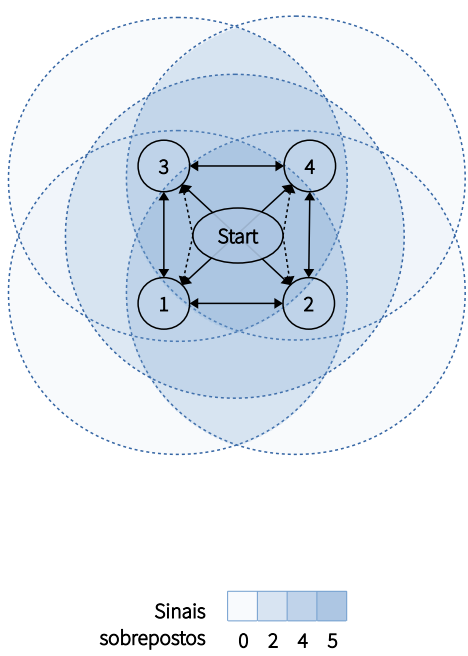

(c) Topologia 3

Fonte: Elaborada pelo autor. 
mensagens mais notória. Todas as mensagens foram enviadas pelo nodo START através do nodo 1 e alcançaram os outros nodos por meio de retransmissões de apenas um salto.

A terceira topologia representa um cenário de rede densa, na qual os nodos estão próximos uns dos outros e são capazes de receber todas as transmissões ao mesmo tempo. Nessa formação, os efeitos do BSP são mais intensos.

Em cada cenário foram executados oito experimentos, variando os thresholds e probabilidades de retransmissão. Os experimentos foram modelados conforme está apresentado na Tabela 2.

Tabela 2 - Planejamento dos experimentos de campo. $C$ é o valor do limiar do contador, $P$ é a probabilidade de retransmissão, $A$ é a área de cobertura da rede e $R$ é o alcance do sinal das placas.

\begin{tabular}{llll}
\hline & Topologia 1 & Topologia 2 & Topologia 3 \\
\hline Algoritmo 1 (Simple Counter-based) & \\
Experimento 1 & $C=2$ & $C=2$ & $C=2$ \\
Experimento 2 & $C=3$ & $C=3$ & $C=3$
\end{tabular}

Algoritmo 2 (Fixed Probability-based)

$\begin{array}{llll}\text { Experimento } 3 & C=2 & C=2 & C=2 \\ & P=65 \% & P=65 \% & P=65 \% \\ \text { Experimento } 4 & C=2 & C=2 & C=2 \\ & P=50 \% & P=50 \% & P=50 \% \\ \text { Experimento } 5 & C=3 & C=3 & C=3 \\ \text { Experimento 6 } & P=65 \% & P=65 \% & P=65 \% \\ & C=3 & C=3 & C=3 \\ & P=50 \% & P=50 \% & P=50 \%\end{array}$

Algoritmo 3 (Dynamic Probability-based)

$\begin{array}{llll}\text { Experimento } 7 & C=2 & C=2 & C=2 \\ & R=90 m & R=90 \mathrm{~m} & R=90 \mathrm{~m} \\ \text { Experimento } 8 & A=75.600 \mathrm{~m}^{2} & A=75.600 \mathrm{~m}^{2} & A=1.072 \mathrm{~m}^{2} \\ & C=3 & C=3 & C=3 \\ & R=90 \mathrm{~m} & R=90 \mathrm{~m} & R=90 \mathrm{~m} \\ & A=75.600 \mathrm{~m}^{2} & A=75.600 \mathrm{~m}^{2} & A=1.072 \mathrm{~m}^{2}\end{array}$

Em todos os experimentos o nodo START enviou 1.000 mensagens, espaçadas em intervalos de $125 \mathrm{~ms}$, simulando uma missão em que a GCS envia oito mensagens por segundo para os VANTs que compõem a FANET. Cada mensagem teve seu campo TTL definido como 8 (o dobro do número de nodos da rede), pois um número menor fazia com que algumas mensagens deixassem de ser recebidas e um número maior induzia muita redundância de mensagens na rede. 
Cada algoritmo foi avaliado usando duas métricas:

1. a quantidade de broadcasts não retransmitidos, que indica a capacidade de mitigação dos algoritmos; e

2. a porcentagem de informação recebida, com a qual pode ser mensurada a alcançabilidade das mensagens.

Os resultados dos experimentos são discutidos nas Seções 4.3, 4.4 e 4.5.

\subsection{Resultados da topologia 1}

A primeira discussão é sobre os resultados da topologia 1 (Figura 5a).

Pelo gráfico da Figura 6a pode-se observar que o Algoritmo 1 teve a melhor taxa de recebimento de mensagens, porque todos os quatro nodos receberam pelo menos 90\% das mensagens. Entretanto, esse mesmo algoritmo mitigou menos de 40\% das retransmissões realizadas por cada nodo, obtendo o pior desempenho nessa métrica, como pode ser observado nos experimentos 1 e 2 da Figura 6b. Isso deixa claro que usar somente a abordagem simples de contador - como adotado no Algoritmo 1 - não é suficiente para evitar a redundância de mensagens na rede, mesmo considerando um limiar baixo para o contador (como 2 e 3 ).

Os experimentos com os algoritmos de abordagem probabilística (algoritmos $2 \mathrm{e}$ 3) conseguiram melhores taxas de mitigação do que o primeiro algoritmo, em sacrifício de uma menor porcentagem de informação recebida. Isso acontece pois retransmissões das placas 1 e 2 induziam o contador da placa 3 a alcançar o limiar do contador, fazendo com que a última evitasse a retransmissão redundante. A placa 4 estava conectada somente à placa 3 e, por consequência, não recebeu as mensagens que foram descartadas por 3.

Analisando a Figura 6c, pode-se reiterar que os métodos probabilísticos são melhores para diminuir a redundância de dados na rede do que o método baseado simplesmente em um contador.

\subsection{Resultados da topologia 2}

A topologia 2 (Figura 5b) é a que permite, por meio dos resultados, ver mais claramente o impacto de cada algoritmo na distribuição de mensagens pela rede.

Apesar da alta porcentagem de informação recebida atingida pelo Algoritmo 1 - mais de 95\% (Figura 7a) -, a taxa de mitigação se manteve abaixo de 25\% nos dois experimentos desse algoritmo (Figura 7b). Os nodos de fronteira deslocam a 
Figura 6 - Resultados dos experimentos na topologia 1.

\section{Informação recebida}

$\square$ VANT $1 \square$ VANT $2 \square$ VANT $3 \square$ VANT 4

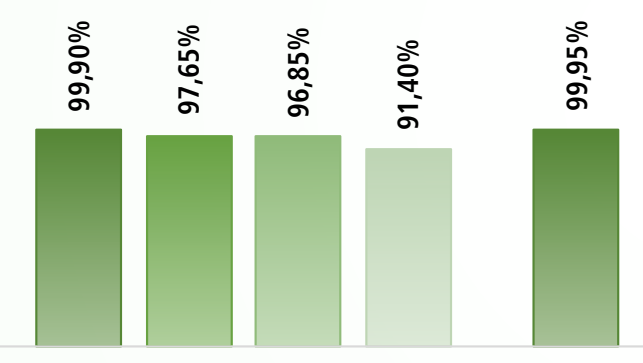

Algoritmo 1

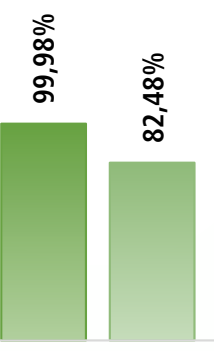

Algoritmo 2

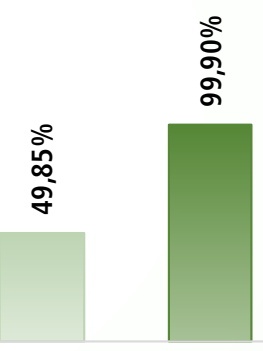

Algoritmo 3

(a) Porcentagem de informação recebida nos nodos da rede.

\section{Retransmissões evitadas}

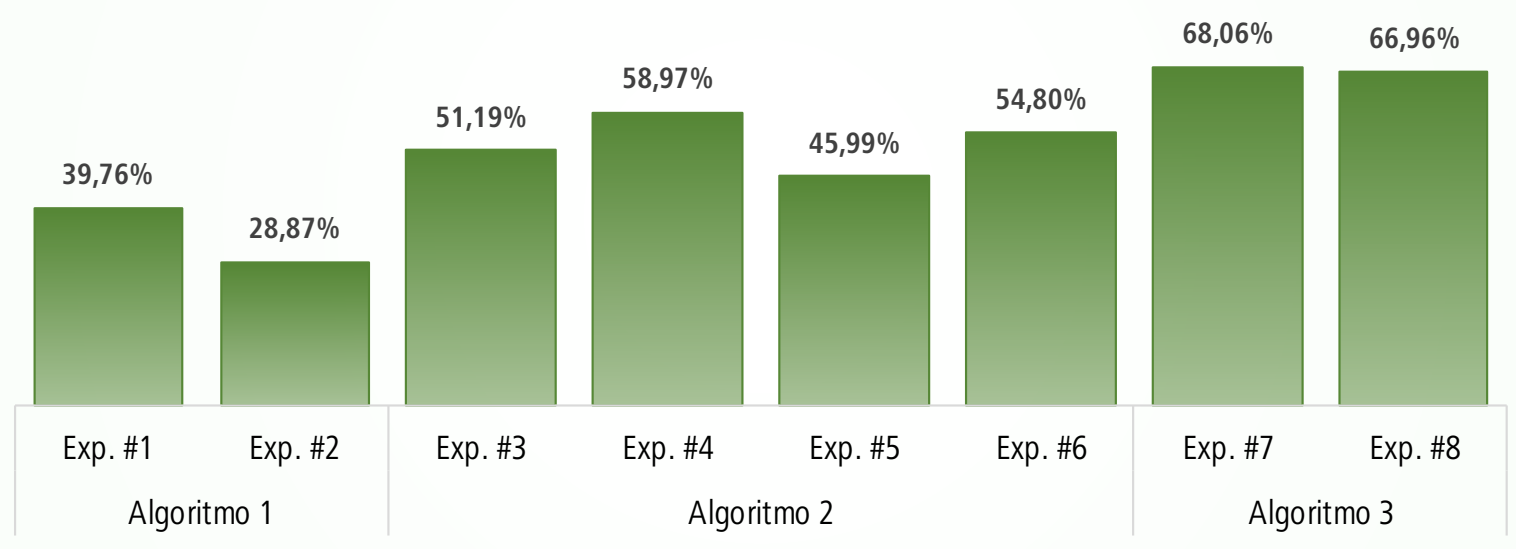

(b) Capacidade de mitigação dos algoritmos em cada experimento.

\section{Mensagens recebidas}

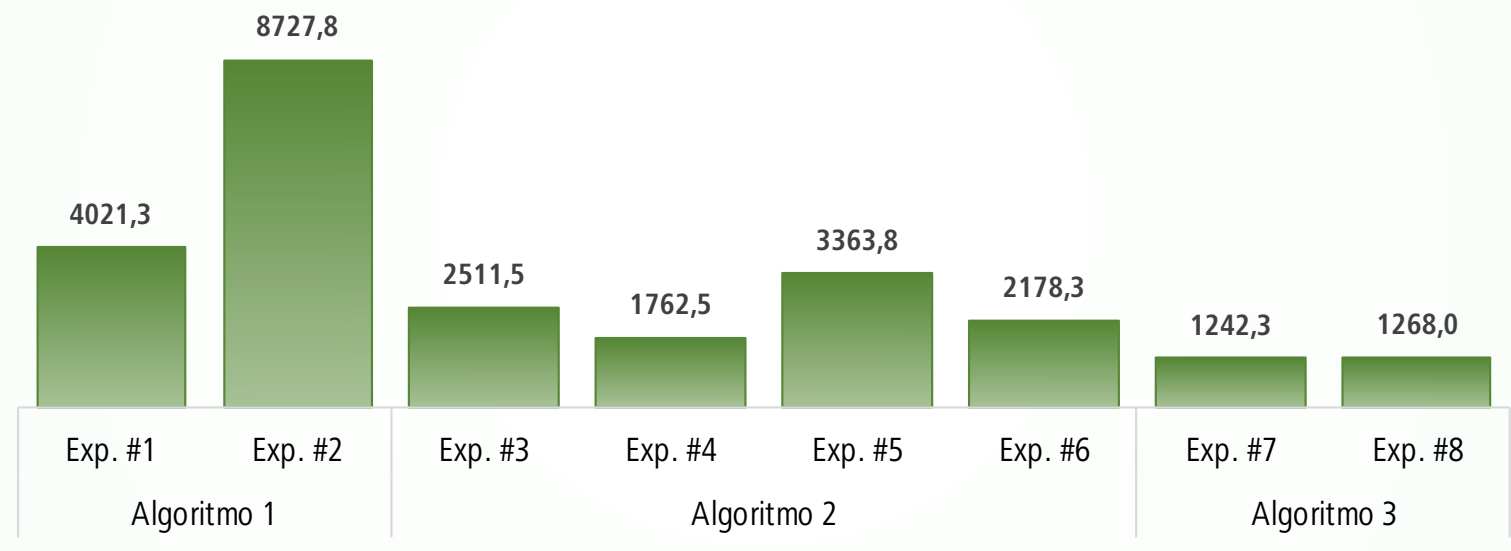

(c) Quantidade média de mensagens recebidas em cada experimento. 
média para baixo porque eles possuem somente um vizinho e, devido a isso, o valor de seus contadores não alcança o threshold, permitindo que mais mensagens sejam retransmitidas.

Em uma análise primária, o Algoritmo 1 parece ser uma abordagem aceitável para espalhar mensagens para os nodos, evitando, ainda, alguns broadcasts. Entretanto, ao analisar a redundância apresentada no gráfico da Figura $7 \mathrm{c}$, é possível observar que esse algoritmo é o mais tolerante à redundância, assim como na topologia 1.

Os algoritmos 2 e 3 tiveram uma alta eficiência - maior ou igual a $40 \%$ - e até $65 \%$ de mensagens foram mitigadas. Por outro lado, esses algoritmos não foram eficientes na disseminação de informação nessa topologia de rede. Como pode ser observado na Figura $7 \mathrm{a}$, somente $25 \%$ das placas receberam todas as mensagens. Isso aconteceu porque estes algoritmos possuem uma restrição a mais que o primeiro. Eles tiveram que considerar o valor do contador e a probabilidade de retransmissão. Por meio dos dados coletados, foi possível notar que a probabilidade média $P$ gerada pela Equação 4.1 se manteve em torno de $37 \%$, significando que a chance das mensagens serem retransmitidas era muito restritiva, resultando em uma alta taxa de mitigação, mas baixa taxa de entrega de mensagens.

\subsection{Resultados da topologia 3}

Esta topologia (Figura 5c) representa a rede de maior densidade. A área da rede é menor e os nodos estão mais próximos uns dos outros. Essa configuração permitiu a disseminação das mensagens por um caminho mais curto, em apenas um salto. Devido a isso, na topologia 3 as taxas de mitigação e de informação recebida não foram opostas, contrariamente às outras duas topologias.

O curto tempo necessário para a entrega das mensagens fez com que o contador de mensagens alcançasse o limite antes que o temporizador parasse, elevando a quantidade de mensagens descartadas e, consequentemente, das taxas de mitigação. Até $68,6 \%$ das transmissões foram mitigadas, como pode ser visto na Figura 8b.

Considerando o Algoritmo 2, nos experimentos com mesmo valor de probabilidade de retransmissão (Exp. $3 v$ s. Exp. 5 e Exp. 4 vs. Exp. 6), a diferença nas taxas de mitigação se manteve entre $10 \%$ e $11 \%$. Comparando os experimentos com mesmo valor de threshold (Exp. 3 vs. Exp. 4 e Exp. 5 vs. Exp. 6), a diferença entre as taxas de mitigação caiu para o intervalo entre $6 \%$ e 7\%. Com esta análise é possível verificar a influência da probabilidade e do contador na decisão de retransmitir ou mitigar as mensagens e reforçar o quão é decisivo ter valores bem ajustados tanto para o limiar do contador (o threshold), quanto para as variáveis das equações (4.1) e (4.2). 
Figura 7 - Resultados dos experimentos na topologia 2.

\section{Informação recebida}

$\square$ VANT $1 \square$ VANT $2 \square$ VANT $3 \square$ VANT 4

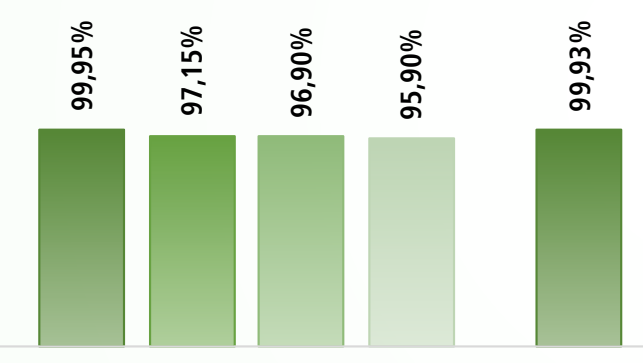

Algoritmo 1

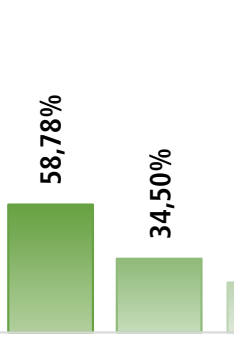

Algoritmo 2

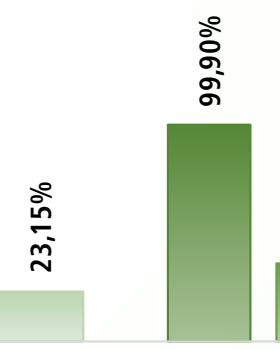

Algoritmo 3

(a) Porcentagem de informação recebida nos nodos da rede.

\section{Retransmissões evitadas}

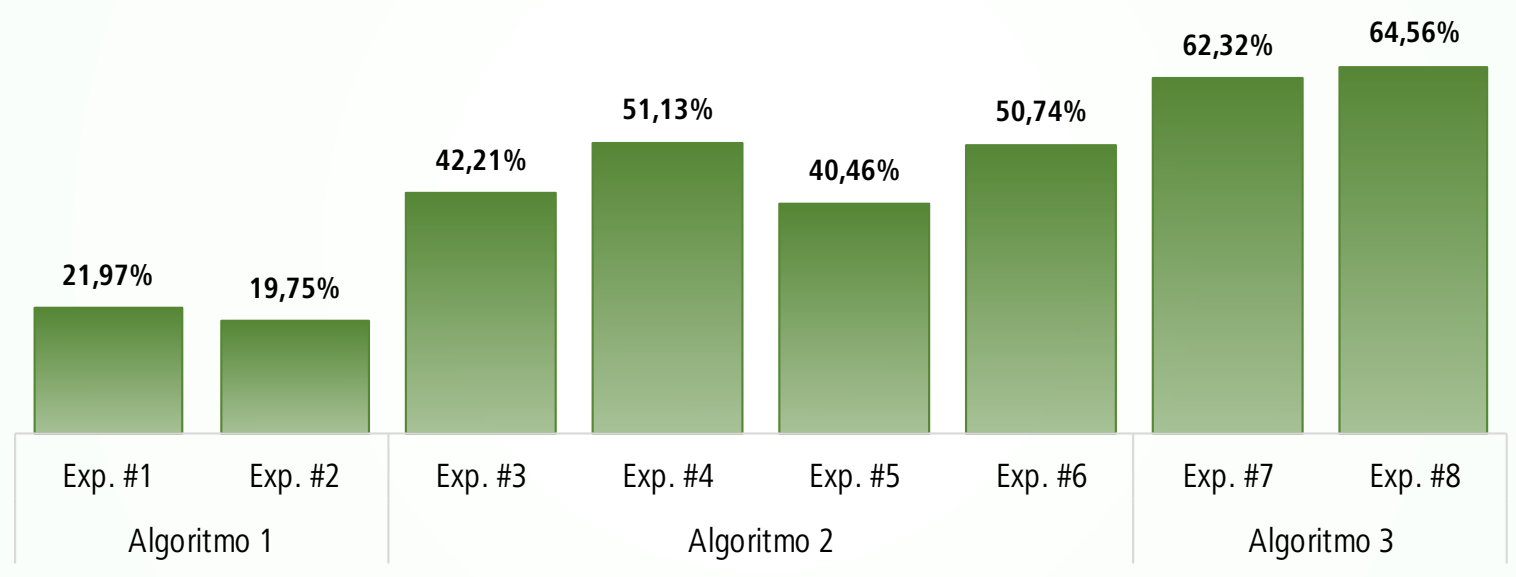

(b) Capacidade de mitigação dos algoritmos em cada experimento.

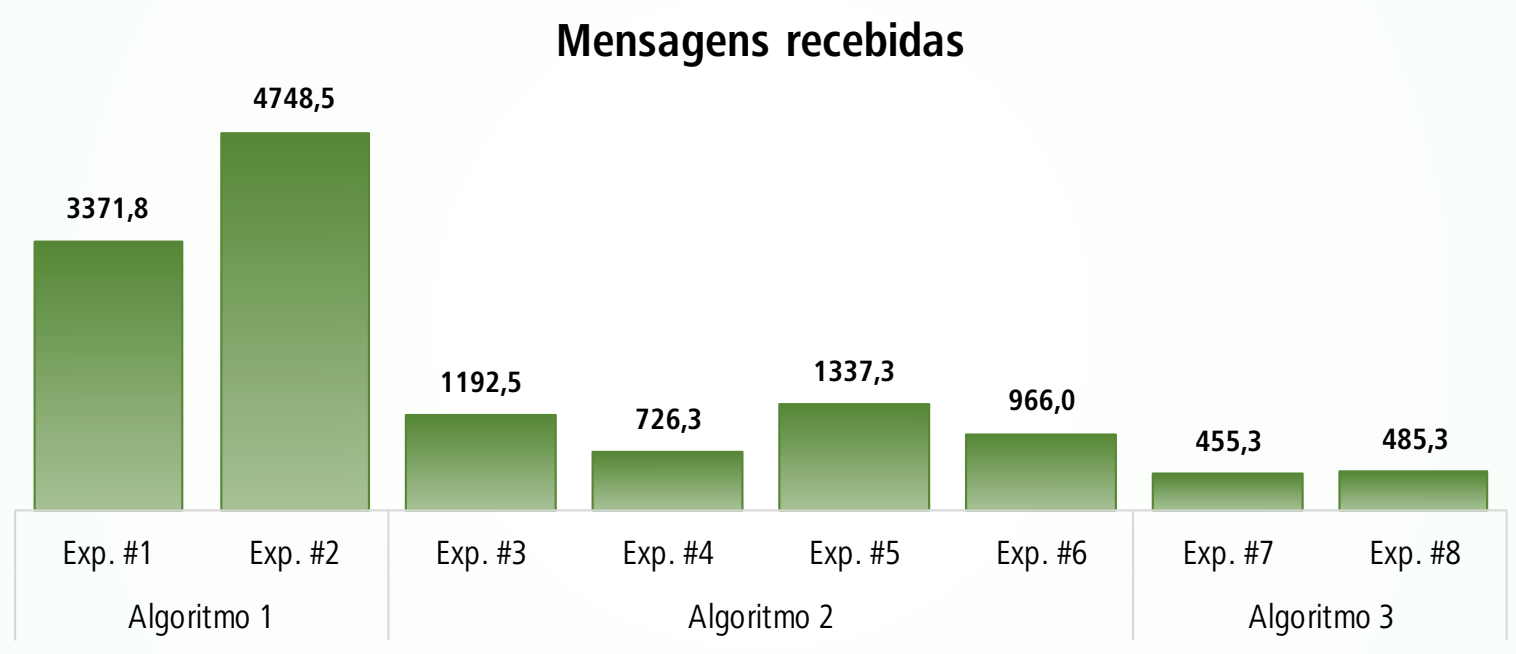

(c) Quantidade média de mensagens recebidas em cada experimento. 
Mesmo sendo a topologia na qual os algoritmos mais mitigaram mensagens, todos os quatro nodos da rede receberam mais que $99,8 \%$ das informações enviadas pelo START, como ilustrado no gráfico da Figura 8a.

Na topologia 3, os nodos de 1 a 4 estão diretamente conectados entre si e com o nodo START. Todas as mensagens originadas no nodo START foram recebidas praticamente ao mesmo tempo por todos os outros nodos da rede. Quando estes recebiam as mensagens, as armazenavam em uma lista e iniciavam um temporizador para cada uma delas. Quando o temporizador parava, pelo menos um dos nodos havia retransmitido aquela mensagem e os outros três que a receberam incrementavam o contador.

O nodo ou nodos que retransmitiam as mensagens, as removiam da lista de espera para que esta lista não aumentasse indefinidamente de tamanho, mas essa abordagem permitiu que algumas mensagens continuassem na rede até que seu TTL fosse zerado. Isso acarretou na elevada redundância de dados nessa topologia, como apresentado na Figura 8c.

\subsection{Considerações finais}

Os resultados anteriores demonstram que os algoritmos apresentam, sob iguais parametrizações, desempenhos distintos que variam de acordo com a topologia.

A topologia 1 permitiu uma análise do cenário com três VANTs voando próximos e um VANT mais afastado. Desse modo, permitiu estudar a interação de um VANT isolado com uma partição densa da rede.

A topologia 2 ilustra um voo em formação na configuração "linha de frente", na qual todos os VANTs voam próximos e ao lado uns dos outros. Os resultados dessa topologia mostraram a importância da flexibilização do threshold do contador para cada nodo da rede.

A topologia 3 representa a situação mais típica de uma rede FANET, em que os sinais de todos os nodos se sobrepõem. Ainda que essa seja a topologia mais suscetível aos efeitos do BSP, por causa do elevado número de mensagens redundantes geradas pela vizinhança, os resultados dos experimentos na topologia 3 mostraram que os algoritmos conseguiram, nesse arranjo, o melhor balanceamento entre alcançabilidade (acima de 99\%) e mitigação (acima de 40\%) de mensagens.

Para concluir, é importante ressaltar a relação observada entre a taxa de recebimento e o uso de técnicas probabilísticas. Em topologias esparsas (por exemplo, a topologia 2), uma baixa probabilidade de retransmissão garante menos mensagens redundantes na rede, mas faz com que um grande número de mensagens não seja entregue aos nodos mais distantes da fonte e isto pode ser um problema em uma comunicação de 
Figura 8 - Resultados dos experimentos na topologia 3.

\section{Informação recebida}

$\square$ VANT $1 \square$ VANT $2 \square$ VANT $3 \square$ VANT 4

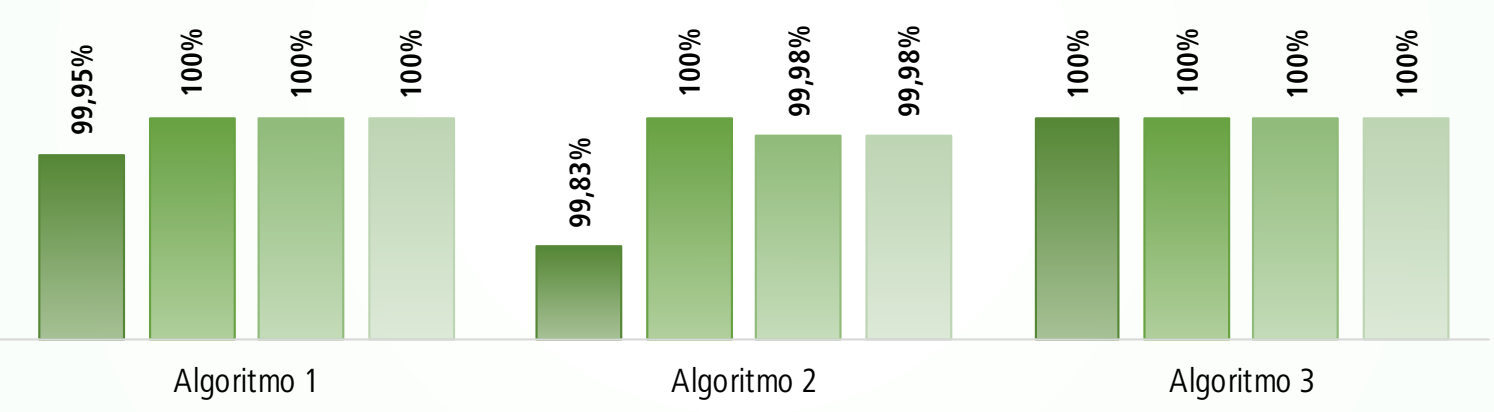

(a) Porcentagem de informação recebida nos nodos da rede.

\section{Retransmissões evitadas}

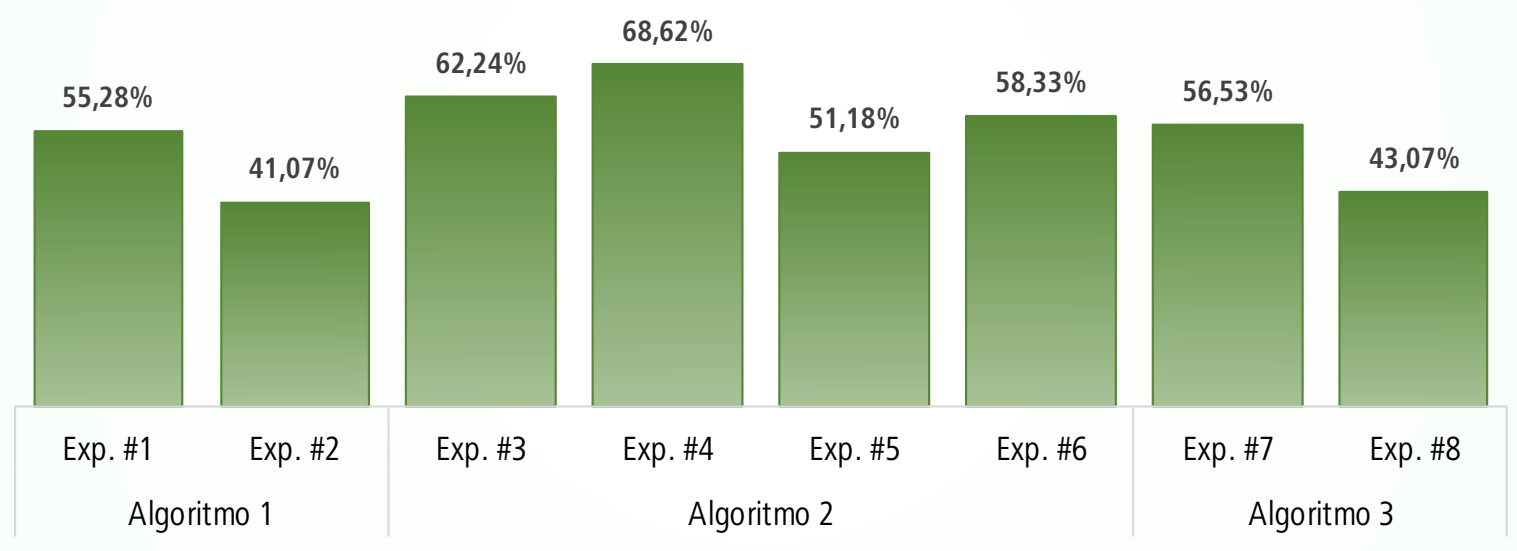

(b) Capacidade de mitigação dos algoritmos em cada experimento.

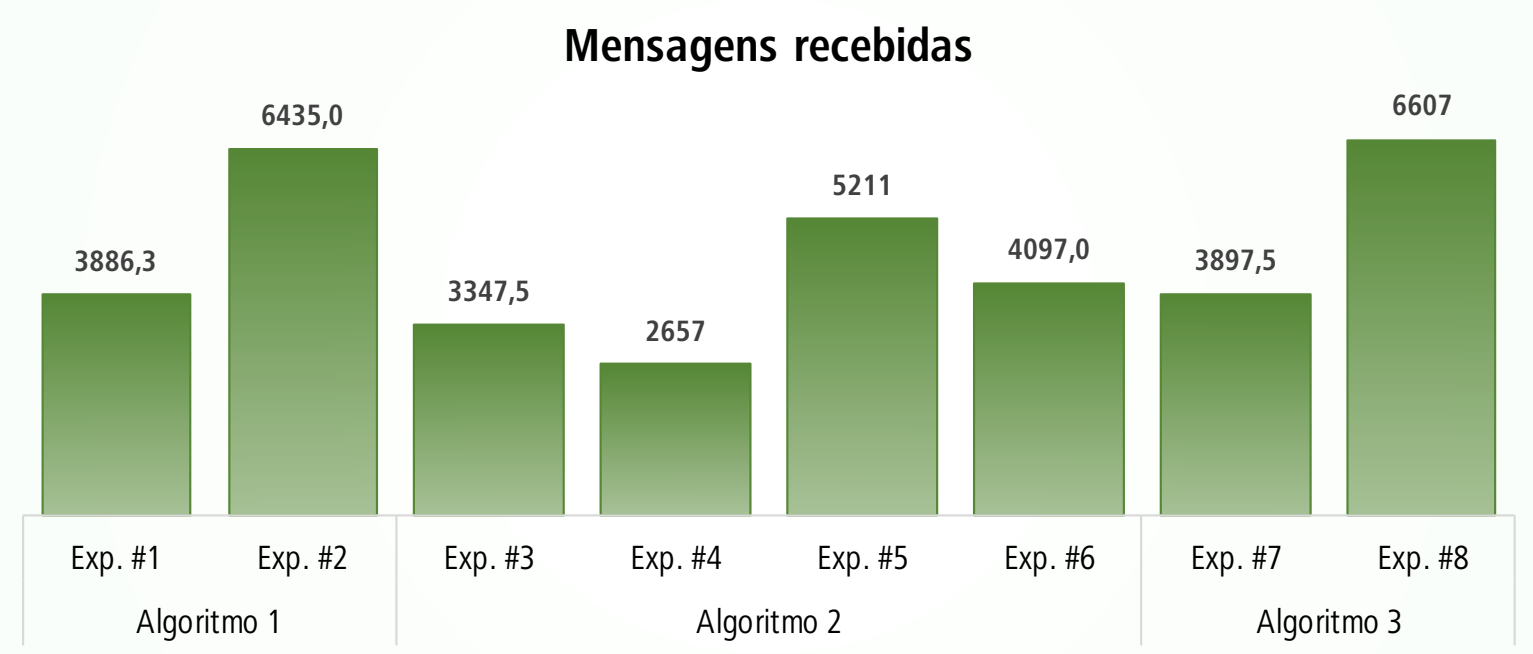

(c) Quantidade média de mensagens recebidas em cada experimento. 
um grupo de VANTs.

Também nota-se que a redundância é um sério problema causado pelo uso de broadcast em uma FANET. Dependendo do número de nodos na rede, a troca de dados pode se tornar impraticável por causa da sobrecarga causada pela redundância de dados.

Os resultados obtidos nos experimentos de campo serviram de apoio para os experimentos simulados, servindo como base para a determinação dos parâmetros do ambiente de simulação e para a avaliação dos resultados simulados. A justificativa para a simulação computacional e a definição do ambiente virtual são apresentados no Capítulo 5. Em seguida, são apresentados os resultados da demonstração do algoritmo de flooding no Capítulo 6 e da abordagem criada neste doutorado para o controle de retransmissões de broadcasts no Capítulo 7. 


\section{DETERMINAÇÃO DO AMBIENTE DE SIMULAÇÃO}

Para que a comunicação nas FANETs seja possível e confiável, uma vez que envolve fatores desafiadores como alta velocidade de movimentação, diferenças de altitude, densidade e distância entre os nodos, é necessário e importante que se faça um estudo das técnicas e problemas envolvidos nessa comunicação. Entretanto, realizar pesquisa acadêmica sobre uma rede de comunicação entre nodos voadores não é tarefa trivial, pois a ausência de infraestrutura de suporte como múltiplas aeronaves, hardware computacional que possa ser instrumentado e autorização de espaço aéreo para voo livre de interferências, podem dificultar o bom andamento do projeto.

Em virtude disso, a simulação computacional foi escolhida para viabilizar a realização da análise da comunicação nessa rede. Os resultados obtidos nos experimentos de campo permitem que as simulações sejam validadas e que a escalabilidade da rede seja confiável.

\subsection{Definição de simulação computacional}

Discorrendo filosoficamente em seu longo texto sobre o tema, Winsberg (2018) mostra diferentes pontos de vista sobre o conceito de simulação computacional. Em um sentido mais amplo, o autor define o conceito de simulações computacionais como um método compreensivo de estudar sistemas. Este processo inclui a escolha de um modelo, encontrar uma maneira de implementar esse modelo em um formato que possa ser executado em um computador, calcular a saída do algoritmo e visualizar e estudar os dados resultantes. O método inclui todo esse processo - usado para fazer inferências sobre o sistema que se tenta modelar - bem como os procedimentos usados para validar essas inferências. Muito esforço e conhecimento são necessários para decidir quais resultados de simulação são confiáveis e quais não são. 
Sob uma ótica mais restrita, simulação computacional também pode ser definida como um programa que é executado em um computador e que usa o método de passo a passo para explorar o comportamento aproximado de um modelo matemático que, geralmente, modela um sistema do mundo real (mesmo que o sistema em questão seja hipotético). Algumas vezes o passo a passo da simulação computacional é usado quando o modelo em interesse contém equações diferenciais - que especificam mudanças contínuas no tempo - que não poderiam ser resolvidas analiticamente, como, por exemplo, fenômenos físicos e biológicos, cinética química e dinâmica de fluidos (PETERSEN, 2012; WINSBERG, 2018). Contudo, é frequentemente utilizado quando o modelo original contém equações discretas - que podem ser implementadas diretamente em um algoritmo adequado para simulação - ou porque o modelo original consiste em algo melhor descrito como regras de evolução do que como equações.

É preciso destacar aqui, assim como Winsberg (2018) o faz em seu texto, que quando as equações estão sendo "discretizadas" (transformação de equações diferenciais em equações discretas), a discretização pode encontrar, na melhor das hipóteses e com o grau de precisão desejado, apenas algo que se aproxime da solução de equações contínuas.

Quando se fala de "simulação computacional" no sentido mais restrito, então, refere-se a uma implementação particular de um algoritmo em um computador específico, escrito em uma linguagem específica, usando um compilador específico, com parâmetros específicos etc. Há casos em que resultados diferentes podem ser obtidos se houver variações em qualquer um desses detalhes.

As simulações podem ser usadas para gerar compreensão sobre dados que já se possui, respondendo questões sobre como eventos do mundo real podem ter - ou como realmente tenham - acontecido. Também podem ser usadas com a finalidade de prever dados que ainda não se tem, mostrando como pode ser esperado que algum sistema do mundo real se comporte sob um conjunto particular de circunstâncias. Os modelos matemáticos e suas equações precisam satisfazer condições realistas do meio para que os resultados possam ser considerados válidos.

Para conseguir simular computacionalmente o comportamento dos algoritmos utilizados nos experimentos de campo de modo realista, é de grande importância que o hardware utilizado tenha o mesmo comportamento do hardware do mundo real.

Além disso, também é importante que o meio de transmissão tenha comportamento compatível. Os mecanismos de propagação e estimativas de perda de potência são muito importantes para projetar e implantar redes de comunicação sem fio (MURTHY; MANOJ, 2004), por isso também precisam ser compreendidos e levados em consideração ao planejar a simulação. 
Na próxima seção é apresentada uma breve explicação sobre as características da propagação de ondas de rádio utilizadas nas redes móveis sem fio, como as FANETs.

\subsection{Características do meio sem fio e da propagação de ondas de rádio}

Ondas de rádio propagam-se no ambiente, geralmente, por meio de três mecanismos (IEEE, 1997; GUAN; TURNER, 1999; RAPPAPORT, 2001; MURTHY; MANOJ, 2004):

1. Reflexão: quando a onda de rádio atinge um objeto que é muito grande comparado ao seu comprimento de onda (como a superfície da terra ou altos prédios), a onda é refletida por esse objeto;

2. Difração: esse efeito é sofrido pela onda de rádio quando ela contorna a borda de um objeto impenetrável ou passa por uma fenda, fazendo com que ela se propague em uma direção diferente. A mudança de direção da onda faz com que ela chegue a lugares atrás do objeto, que normalmente não seriam alcançados por uma transmissão fora da linha de visada;

3. Dispersão: quando se propaga por um meio com vários objetos de dimensões menores que o seu comprimento, como copas de árvores, placas de rua e postes de iluminação, por exemplo, a onda é dispersada (ou dividida em várias outras ondas mais fracas) em direções diferentes da reflexão.

Normalmente, o sinal transmitido tem uma componente direta entre o transmissor e o receptor (também conhecida como sinal na linha de visada) e outras componentes, conhecidas como componentes multipercurso, que são refletidas, difratadas e dispersas pelo ambiente.

Na Figura 9 são ilustrados os mecanismos de propagação das ondas de rádio.

Quando uma onda é recebida, a potência do sinal recebido é comumente menor que a potência de transmissão desse sinal. A perda na força do sinal (ou atenuação do sinal) se deve a fatores como path loss, fading, interferência e efeito Doppler. Estes fatores restringem o alcance, a taxa de dados e a confiabilidade da transmissão.

O path loss é a redução da densidade de energia de uma onda eletromagnética conforme essa onda propaga-se pelo espaço. É uma função da perda da potência do sinal em relação à distância. Ele pode ser expresso como a razão entre a potência do sinal transmitido e a potência do mesmo sinal recebido pelo receptor, em um determinado caminho. 
Figura 9 - Mecanismos de propagação de ondas de rádio.

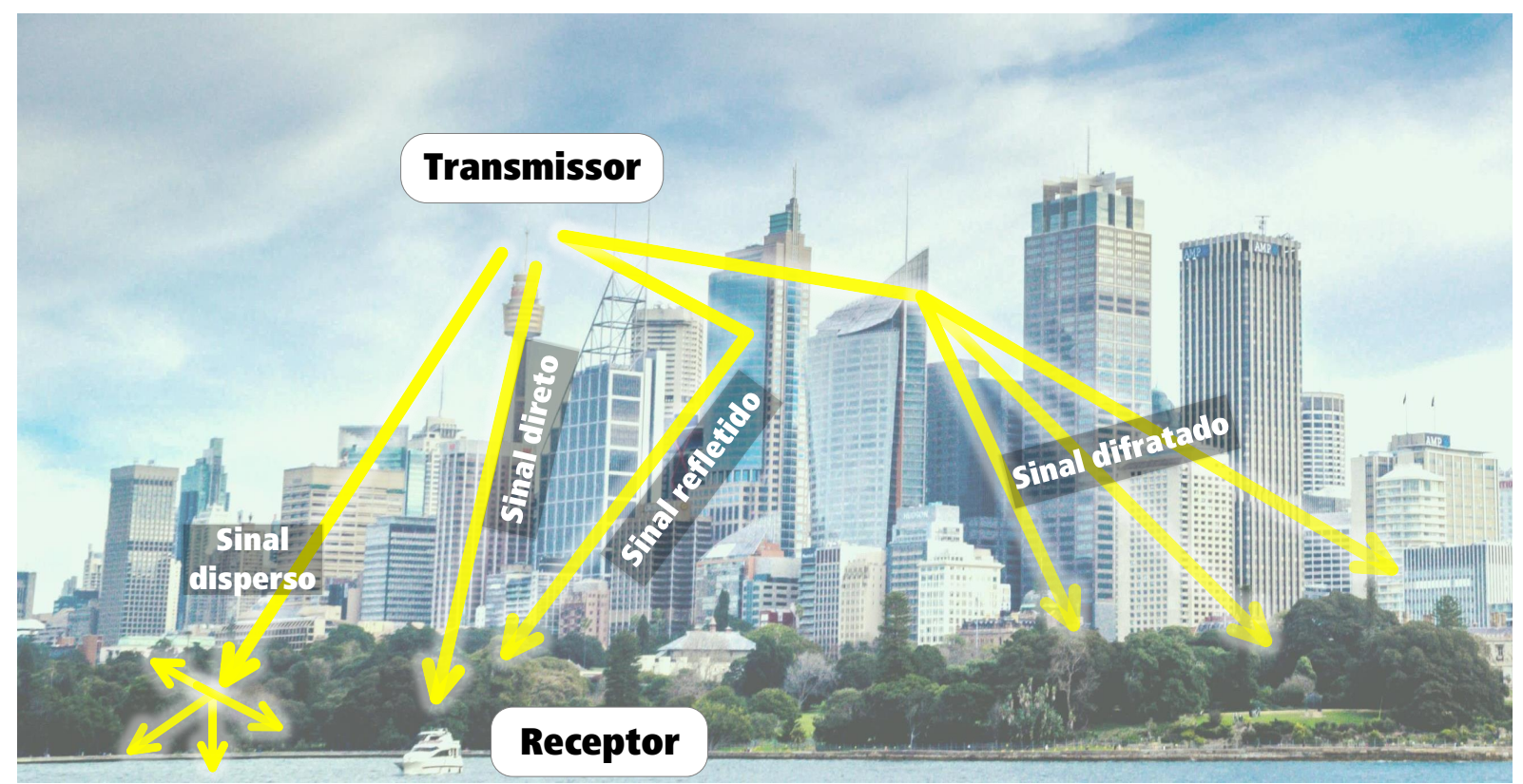

Fonte: Elaborada pelo autor.

Dois modelos de path loss muito conhecidos e utilizados em simulações computacionais são o Free Space Propagation e o Two-Ray Ground Reflection (RAPPAPORT, 2001; MURTHY; MANOJ, 2004). O primeiro assume que há apenas a componente direta do sinal entre o transmissor e o receptor. O segundo assume que há duas componentes do sinal: a direta e a refletida (ou a difratada, ou a dispersa). Outros modelos mais complexos podem ser encontrados na literatura (GUAN; TURNER, 1999; RAPPAPORT, 2001) e também estão disponíveis para uso no framework de simulação.

O fading (SIMON; ALOUINI, 2000; RAPPAPORT, 2001; MURTHY; MANOJ, 2004) faz referência às variações na força do sinal que chega no receptor. Estas podem ser flutuações rápidas na amplitude da onda, na fase, ou nos atrasos das múltiplas cópias do sinal recebido por propagação multipercursos, causados justamente pela interferência das componentes não diretas. Também podem ser variações lentas, que ocorrem quando objetos que absorvem parcialmente as transmissões estão entre o transmissor e o receptor, como paredes de prédios, por exemplo.

A interferência no sinal pode acontecer, predominantemente, de duas formas: por componentes de sinais em frequências próximas que estão fora da faixa alocada, ou pelo uso da mesma frequência de transmissão por outros tipos de sistemas, como transmissões AM/FM, por exemplo. Também pode acontecer a interferência inter-símbolos, em que a distorção no sinal recebido é causada pela dispersão temporal e a consequente sobreposição de pulsos individuais no sinal.

O efeito Doppler é a variação ou deslocamento da frequência do sinal recebido 
quando o transmissor e o receptor estão se movendo e há variação na distância entre eles. Se eles estão se movendo um em direção ao outro, então a frequência do sinal recebido será maior do que a do sinal transmitido e, se eles estão se afastando um do outro, a frequência do sinal no receptor será menor do que no transmissor.

Os modelos de propagação disponíveis no framework de simulação foram utilizados para alcançar esses quatro efeitos explicados acima. A próxima seção descreve como o modelo foi escolhido, dentre as opções disponíveis, e como ele foi parametrizado.

\subsection{Determinação do modelo de propagação}

O componente responsável por simular o meio sem fio foi configurado com base nos resultados apresentados no Capítulo 4.

O software utilizado neste trabalho para as simulações foi o OMNeT ++5.0 , um software de código fonte aberto e gratuito para uso acadêmico e educacional (VARGA, 2010), utilizado amplamente por equipes de pesquisa do mundo todo ${ }^{1}$. O OMNeT++ é uma biblioteca padrão para simulação e um framework que possibilita a criação de simuladores de redes. Ele provê uma arquitetura de componentes modulares, programados em linguagem $\mathrm{C}++$, que são agregados em componentes maiores e que facilitam a reusabilidade. Ao final, os simuladores gerados são executados em tempo discreto ${ }^{2}$ e os resultados brutos são salvos em disco para posteriores análises.

Um simulador é criado neste framework por meio da composição e associação de vários módulos, bem como da parametrização destes componentes. Os módulos são programados utilizando equações e regras de evolução, de modo que o produto tanto de suas execuções quanto de suas interações possam gerar resultados compatíveis com o esperado no mundo real. Para que esses módulos possam ser úteis na extrapolação do estudo ou previsão de casos futuros, eles podem ser parametrizados (de modo a fazer um ajuste fino nas suas propriedades) conforme a necessidade.

Os experimentos de campo apresentados no Capítulo 4 serviram para coletar dados da rede em situação realista e os resultados empíricos serviram como base para a busca da parametrização ideal (mostrada mais adiante, na Tabela 5) do meio de transmissão usado na simulação, a fim de torná-lo confiável para a pesquisa com redes FANETs em escalas maiores que a experimentada em campo.

1 Para uma lista selecionada de ferramentas e modelos de simulação para o OMNeT ++ , criados e disponibilizados por times de pesquisadores, siga até < https://omnetpp.org/download/ models-and-tools $>$.

2 Tempo discreto é o tempo não contínuo, dividido em amostras discretas. De forma geral, o período de amostragem em sistemas de tempo discreto é constante, mas em alguns contextos uma amostragem não uniforme também é usada. 
Uma rede ad hoc foi montada com quatro nodos fixados nas mesmas três topologias apresentadas na Figura 5, mantendo-se as distâncias entre os nodos e a interconexão entre eles. As placas de rede sem fio dos nodos foram parametrizadas para funcionarem como as placas utilizadas nos experimentos de campo: com o mesmo tipo de rádio e a mesma potência de transmissão. Para calibrar o meio sem fio virtual com o real, várias simulações foram executadas a fim de encontrar os parâmetros ideais para caracterizar o ambiente sem fio de modo apropriado.

Desse modo, os três algoritmos dos experimentos anteriores (Algoritmo 1, Algoritmo 2 e Algoritmo 3) foram implementados e executados com a variação dos seguintes parâmetros:

- Modelo de propagação do sinal: (i) Nakagami fading, (ii) Rician fading, (iii) Rayleigh fading, (iv) Log-Normal shadowing, (v) Two-ray ground reflection e (vi) Free space path loss;

- Potência do ruído de fundo: variada entre $-120 \mathrm{dBm}$ e $-85 \mathrm{dBm}$, com o passo de $5 \mathrm{dBm}$;

O INET framework pode ser considerado a biblioteca padrão do OMNeT ++ para simulações de redes (VARGA, 2010). Os modelos de VANTs implementados foram integrados com componentes desse framework, como toda a pilha de protocolos de rede e o modelo de propagação de ondas no meio sem fio.

Os modelos de propagação que resultaram em valores mais próximos dos experimentos de campo tiveram seus resultados comparados para que pudesse ser tomada a decisão de qual modelo adotar. Esses modelos foram o Two-ray ground reflection e o Nakagami fading. Os gráficos ilustrados nas figuras 10, 11 e 12 mostram a comparação dos resultados desses modelos nas topologias 1, 2 e 3, respectivamente, quando o ruído de fundo estava parametrizado em $-90 \mathrm{dBm}$.

Apesar das proximidades dos resultados desses modelos com os resultados de campo, escolher um deles com base nos valores absolutos não seria uma escolha racional. O ambiente do mundo real é um processo estocástico ${ }^{3}$; é impossível replicar o cenário exato de nossos experimentos reais, com interferências exatas de sinais externos, obstáculos como edifícios, árvores e postes de iluminação, a luminosidade do ambiente, a temperatura do terreno, os reflexos de onda no solo e carros em movimento, por exemplo. Esse tipo de processo é modelado e testado para operar como o ambiente real, mas não se pode usar valores absolutos porque, por natureza, eles sempre serão dependentes do meio ambiente. Portanto, a análise feita aqui considerou o comportamento dos

3 Um processo estocástico possui decisões randômicas, ou dependentes de fontes randômicas, de modo que a execução do mesmo processo múltiplas vezes sob a mesma condição pode gerar resultados diferentes. 
Figura 10 - Comparação dos resultados entre experimento de campo e os modelos de propagação Nakagami fading (NF) e Two-ray ground reflection (TRGR), na topologia 1. A métrica é a quantidade de mensagens recebidas por cada nodo.

\section{Comparação de modelos de propagação \\ (Topologia 1)}

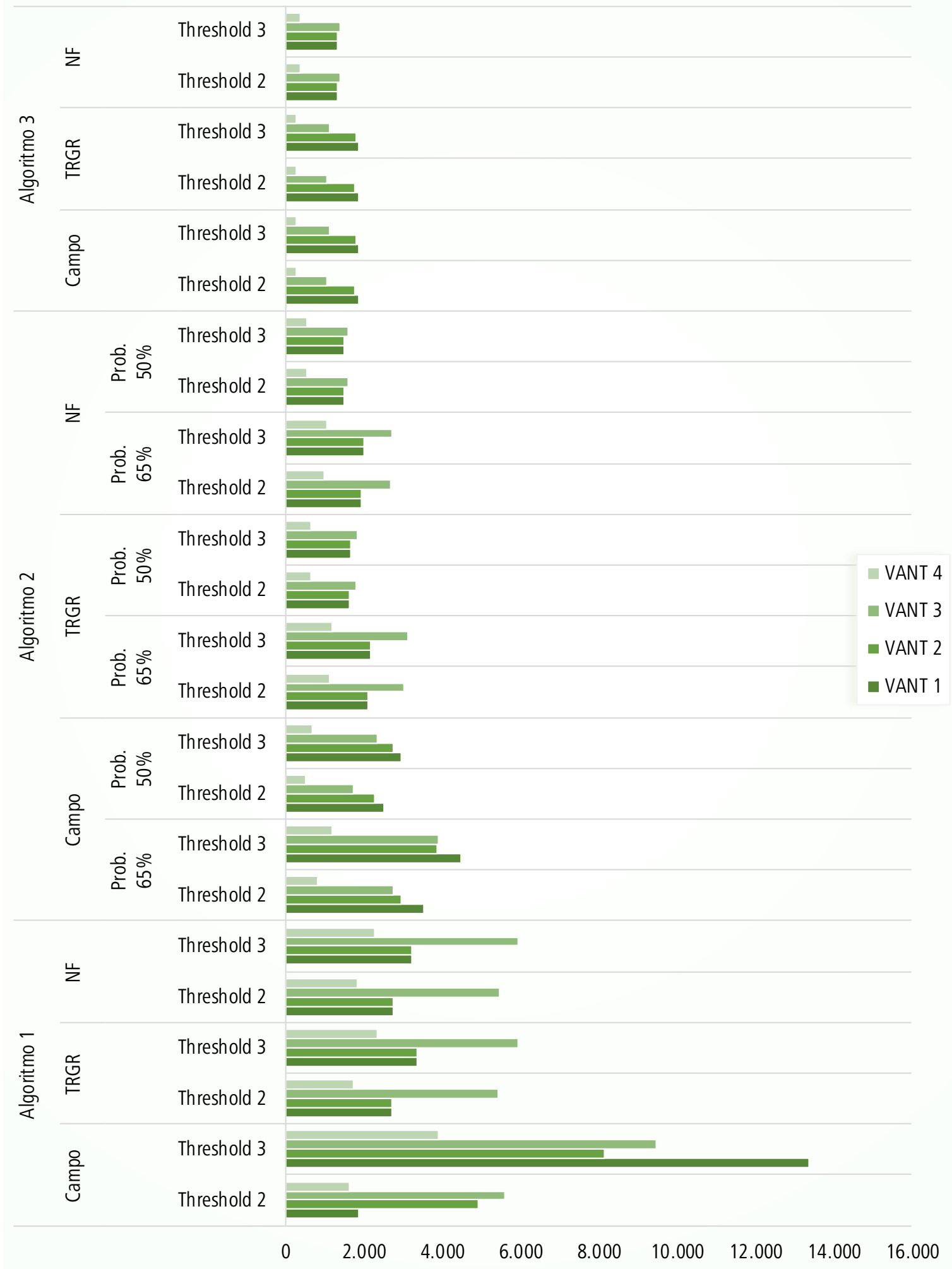


Figura 11 - Comparação dos resultados entre experimento de campo e os modelos de propagação Nakagami fading (NF) e Two-ray ground reflection (TRGR), na topologia 2. A métrica é a quantidade de mensagens recebidas por cada nodo.

\section{Comparação de modelos de propagação (Topologia 2)}

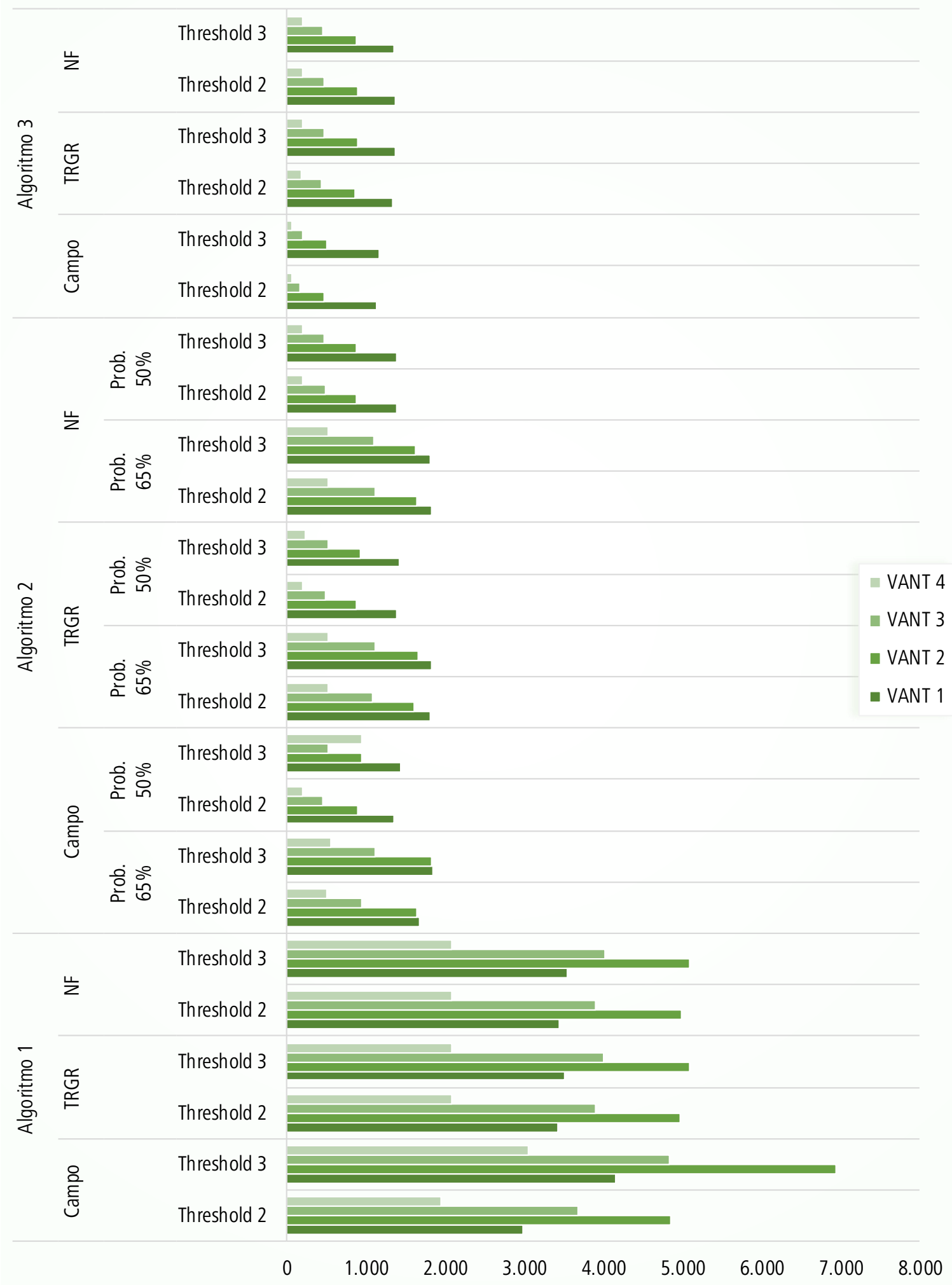


Figura 12 - Comparação dos resultados entre experimento de campo e os modelos de propagação Nakagami fading (NF) e Two-ray ground reflection (TRGR), na topologia 3. A métrica é a quantidade de mensagens recebidas por cada nodo.

\section{Comparação de modelos de propagação (Topologia 3)}

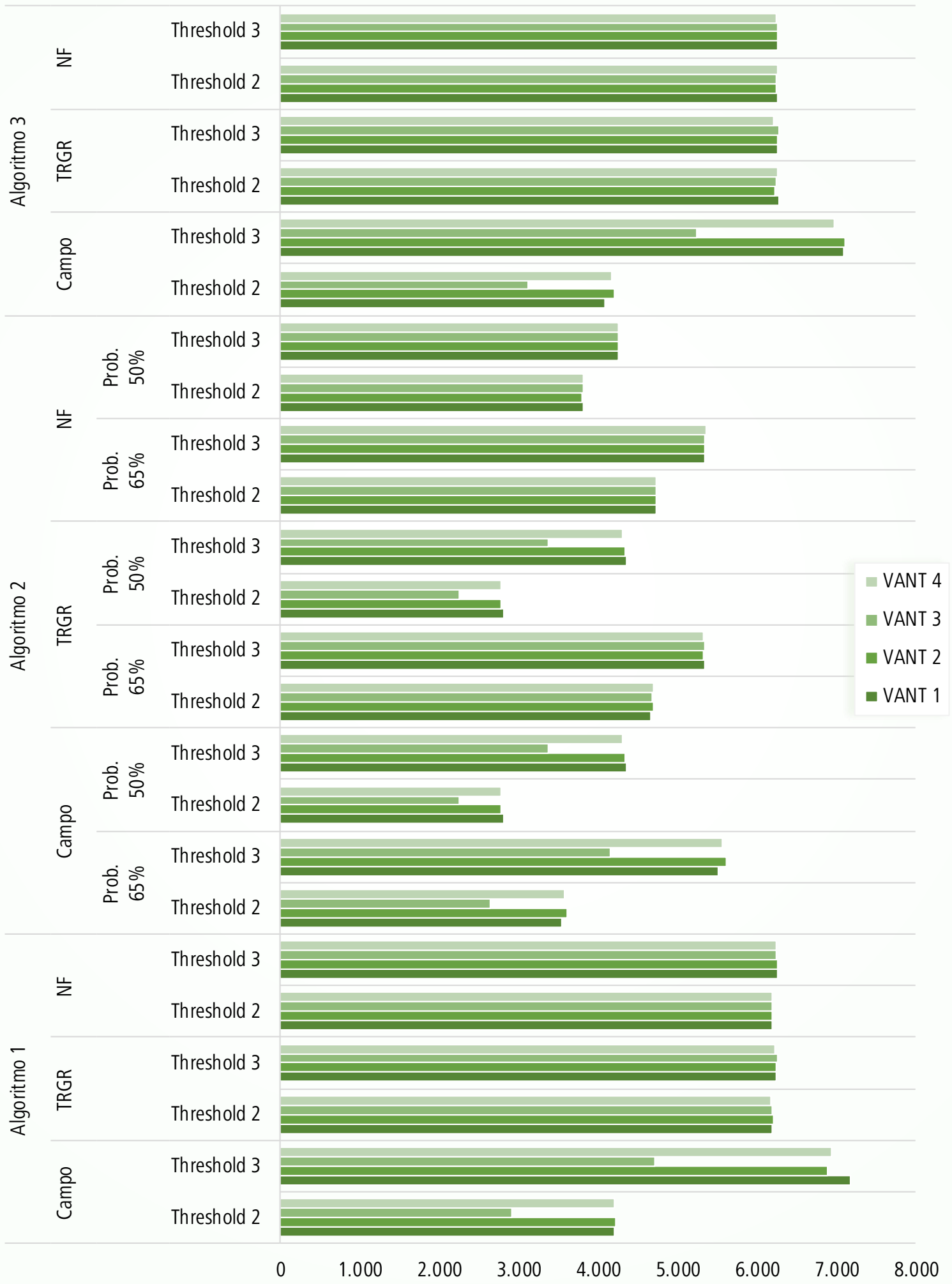


algoritmos avaliados por meio de outra métrica: o percentual de informação recebida por cada nodo da rede.

Essa medida é de grande importância pois reflete o impacto da mitigação dos algoritmos, por isso foi considerada para a decisão da adoção do modelo Two-ray ground reflection para o ambiente de simulação. A comparação dos percentuais de informação recebida nos experimentos reais e nas simulações com esse modelo de propagação, apresentados na Tabela 3, confirmam essa decisão.

Tabela 3 - Porcentagem de informação recebida por cada nodo da rede. As porcentagens mostradas no Algoritmo 1 são médias dos valores dos experimentos 1 e 2; as mostradas no Algoritmo 2 são médias dos valores dos experimentos 3, 4, 5 e 6; e as mostradas no Algoritmo 3 são médias dos valores de cada nodo nos experimentos 7 e 8 .

\begin{tabular}{lcccccc}
\hline & \multicolumn{2}{c}{ Algoritmo 1 } & \multicolumn{2}{c}{ Algoritmo 2 } & \multicolumn{2}{c}{ Algoritmo 3 } \\
& Campo & Simulação & Campo & Simulação & Campo & Simulação \\
\hline Topologia 1 & & & & & & \\
Nodo 1 & $99,9 \%$ & $100 \%$ & $100 \%$ & $100 \%$ & $99,9 \%$ & $99,9 \%$ \\
Nodo 2 & $97,7 \%$ & $100 \%$ & $100 \%$ & $100 \%$ & $97,7 \%$ & $99,9 \%$ \\
Nodo 3 & $96,9 \%$ & $100 \%$ & $82,5 \%$ & $81,3 \%$ & $60,8 \%$ & $75,2 \%$ \\
Nodo 4 & $91,4 \%$ & $99,7 \%$ & $49,9 \%$ & $49,4 \%$ & $21,3 \%$ & $31,4 \%$ \\
& & & & & & \\
Topologia 2 & & & & & & \\
Nodo 1 & $100 \%$ & $100 \%$ & $99,9 \%$ & $100 \%$ & $99,9 \%$ & $99,9 \%$ \\
Nodo 2 & $97,2 \%$ & $99,5 \%$ & $58,8 \%$ & $57,5 \%$ & $36,4 \%$ & $50,7 \%$ \\
Nodo 3 & $96,9 \%$ & $99,2 \%$ & $34,5 \%$ & $34 \%$ & $12,6 \%$ & $25 \%$ \\
Nodo 4 & $95,9 \%$ & $98,8 \%$ & $23,2 \%$ & $22,8 \%$ & $5,1 \%$ & $14,4 \%$ \\
& & & & & & \\
Topologia 3 & & & & & & \\
Nodo 1 & $99,95 \%$ & $100 \%$ & $99,83 \%$ & $100 \%$ & $100 \%$ & $99,98 \%$ \\
Nodo 2 & $100 \%$ & $100 \%$ & $100 \%$ & $100 \%$ & $100 \%$ & $99,98 \%$ \\
Nodo 3 & $100 \%$ & $100 \%$ & $99,98 \%$ & $100 \%$ & $100 \%$ & $99,98 \%$ \\
Nodo 4 & $100 \%$ & $100 \%$ & $99,98 \%$ & $100 \%$ & $100 \%$ & $99,98 \%$ \\
\hline
\end{tabular}

A seção a seguir apresenta uma explicação sobre modelos de mobilidade e qual foi o modelo adotado neste trabalho.

\subsection{Determinação do modelo de mobilidade}

O modelo de mobilidade provê duas funcionalidades básicas aos nodos da rede: moverem-se em torno da área da simulação e alterarem suas velocidades durante a execução da simulação. Ele é relevante por modificar a topologia da rede dinamicamente, por variar indiretamente a taxa de entrega de pacotes por meio da mudança das rotas dos pacotes, e por aproximar o comportamento dos objetos simulados do comportamento em 
ambiente real. Como aqui o modelo de mobilidade foi configurado com três dimensões, é de fato simulado os nodos como se estivessem voando ao invés de se deslocando no solo.

Vários são os trabalhos que propõem e investigam modelos de mobilidade. Os que são comumente adotados em trabalhos que envolvem FANETs são (CAMP; BOLENG; DAVIES, 2002; BAI; HELMY, 2004; KANG; ALDWAIRI; KIM, 2016; YASSEIN; DAMER, 2016): Mission Plan-based, Semi-Random Circular Movement, Random Waypoint Mobility e Gauss-Markov Mobility.

No modelo Mission Plan-based, o voo é predefinido e as aeronaves movem-se pelo caminho planejado sempre que são capazes de atingir o espaço da missão e a localização do waypoint.

No modelo Semi-Random Circular Movement, os VANTs voam em círculo em torno de uma área, capturando informação sobre a região abaixo deles.

O modelo Gauss-Markov Mobility é usado em simulações com comportamento de grupos (ou enxames), nos quais o movimento dos VANTs estão correlacionados uns com os outros e os nodos são forçados para longe das bordas da área da simulação.

O modelo adotado nas simulações com mobilidade foi o Random Waypoint Mobility, que é um modelo amplamente utilizado na simulação de redes ad hoc móveis (KO; VAIDYA, 1998; BETTSTETTER, 2001; CAMP; BOLENG; DAVIES, 2002; BETTSTETTER; SANTI; RESTA, 2003; BETTSTETTER, 2003; BAI; SADAGOPAN; HELMY, 2003; BAI; HELMY, 2004; SAHA; JOHNSON, 2004; ARIYAKHAJORN; WANNAWILAI; SATHITWIRIYAWONG, 2006; LASSILA; HYYTIÄ; KOSKINEN, 2006; SINGH; MAURYA; SARJE, 2011; YASSEIN; DAMER, 2016; KHAN et al., 2018; ZUCCHI; SILVEIRA, 2018). Esse modelo gera waypoints aleatórios dentro dos limites da área de simulação e traça uma trajetória linear entre um waypoint e o próximo (ROY, 2011). Ele foi escolhido pelo fato dos VANTs poderem voar seus trajetos independentemente das suas posições iniciais ou dos trajetos dos nodos vizinhos que estão na mesma área.

Neste modelo, os nodos móveis podem aguardar um período de tempo $t \geq 0 \mathrm{em}$ um ponto, mas nas simulações essa característica não foi utilizada $(t=0)$, pois estaria limitando as análises apenas a aeronaves que conseguem pairar no ar, o que não é desejado neste trabalho.

Na Figura 13 são ilustrados, no plano em três dimensões, caminhos percorridos por quatro VANTs utilizando o Random Waypoint Mobility durante uma rodada de simulação.

O modelo de mobilidade também altera a velocidade dos VANTs aleatoriamente, sempre que um novo waypoint é gerado. O valor foi gerado por uma distribuição uniforme no intervalo $[12 \mathrm{~m} / \mathrm{s}, 25 \mathrm{~m} / \mathrm{s}]$. Uma representação desta variação em uma replicação do 
primeiro experimento pode ser vista na Figura 14.

Figura 13 - Trajetória tridimensional dos VANTs durante uma execução da simulação, usando o modelo de mobilidade Random Waypoint Mobility. A movimentação dos VANTs foi limitada à área de um cuboide de lados $1.000 \mathrm{~m} \times 2.000 \mathrm{~m} \times 80 \mathrm{~m}$.

\begin{tabular}{|llllll|}
\hline & VANT 1 & VANT 2 & VANT 3 & VANT 4 \\
\hline
\end{tabular}

Eixo Z (metros)

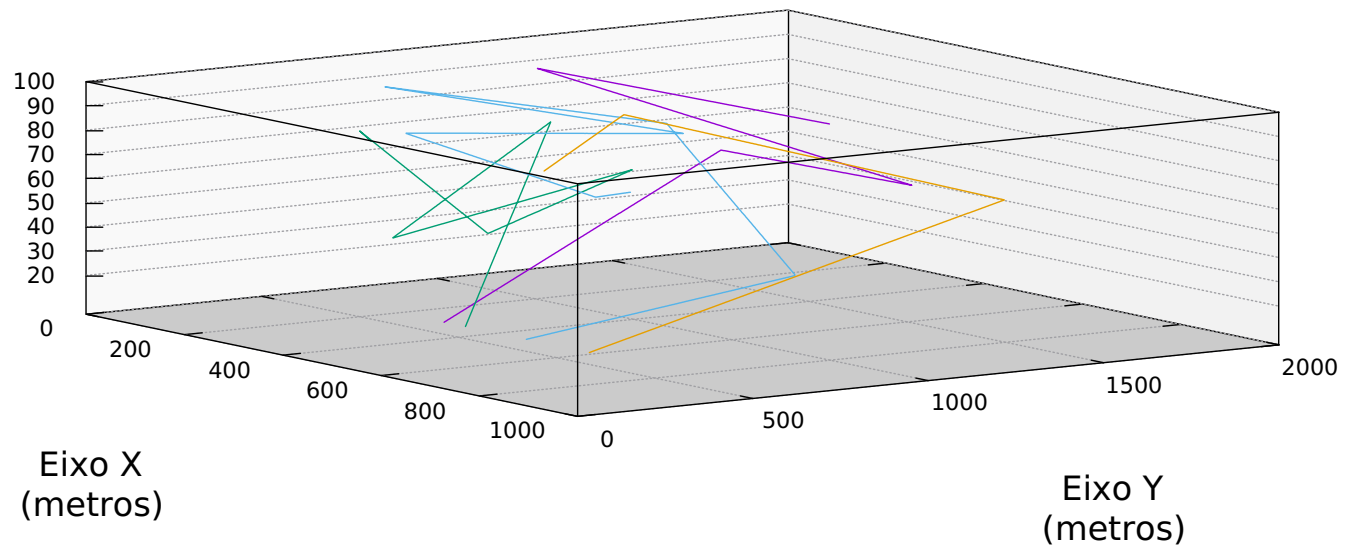

Figura 14 - Variação da velocidade dos VANTs durante as simulações, guiada pela função de distribuição uniforme $U(12 \mathrm{~m} / \mathrm{s}, 25 \mathrm{~m} / \mathrm{s})$.

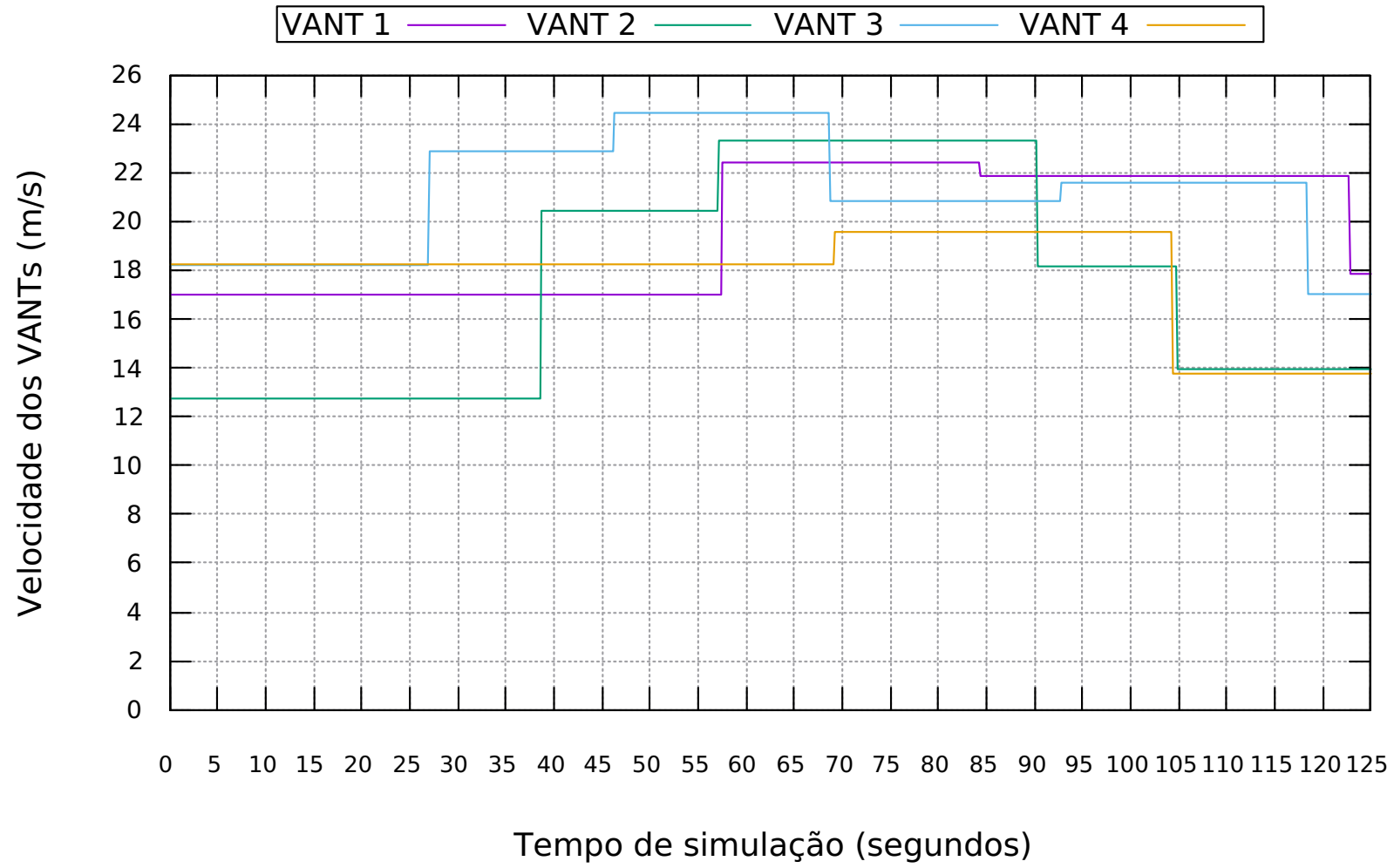


A variação de velocidade dos VANTs pode aumentar o consumo de combustível ou acelerar a descarga da bateria. O consumo de combustível ou de energia são processos estocásticos que estão fora do escopo deste trabalho. Trabalhos neste tema sugerem que a bateria de VANTs civis de pequeno porte ainda possui a maioria da sua carga quando o tempo de execução da missão atinge os 125 segundos (SAHA; QUACH; GOEBEL, 2012; SUZUKI; FILHO; MORRISON, 2012), mesmo os micro veículos aéreos, então não foi considerada neste trabalho uma fonte finita de energia. Ao invés disso, as missões simuladas tiveram duração de 125 segundos, pois assim pode ser considerado que os VANTs da FANET possuem energia ou combustível suficiente para completar a missão.

\subsection{Considerações finais}

Este capítulo foi iniciado com uma breve discussão sobre o conceito e a utilidade da simulação computacional para pesquisas. Como a simulação foi o método escolhido para a realização desta pesquisa de doutorado em redes sem fio entre VANTs, as características do meio sem fio e os aspectos da propagação de ondas de rádio também foram abordados, a fim de contextualizar a decisão sobre o modelo de propagação de ondas adotado.

Por se tratar de um trabalho com VANTs, também foram feitas considerações sobre modelos de mobilidade de nodos em redes móveis para fundamentar a escolha do modelo adotado nas simulações.

Uma característica essencial aos VANTs, bem como a todo veículo autônomo, e que não foi tratado neste capítulo, é o sistema de detecção de colisão. Apesar de ser desejável que modelos de mobilidade realistas para FANETs considerem esse aspecto, o comportamento de detecção de colisão não foi simulado neste trabalho. A pesquisa deste doutorado é sobre a comunicação entre VANTs em uma FANET, e considera-se que um sistema de detecção de colisão não influencia no desempenho da rede.

Com o ambiente de simulação definido, o passo seguinte foi demonstrar o problema BSP por meio de simulação computacional, como apresentado no Capítulo 6. 



\section{6}

(2)

\section{SIMULAÇÃO DO ALGORITMO DE FLOODING}

Com base na parametrização realista do ambiente de simulação, dois tipos de experimentação com flooding foram realizados para demonstrar a ocorrência do BSP e para mostrar seu impacto na rede: com mobilidade e sem mobilidade.

Os VANTs são inicialmente distribuídos uniformemente em um dos lados da área de simulação e, ao se movimentarem, ficam distribuídos de forma não uniforme, fazendo a rede ficar sob uma topologia diversa, com partes (ou partições) com diferentes densidades de nodos. Com o uso do modelo de mobilidade Random Waypoint Mobility e com a variação da densidade da rede torna-se impossível manter os VANTs fixados nas três topologias estáticas mencionadas anteriormente (Figura 5) - que suportavam somente quatro VANTs. Os resultados apresentados a partir daqui serão, então, divididos entre os resultados do experimento com quatro VANTs fixados nas três topologias estáticas e do experimento com mais de três VANTs movendo-se pela área da rede, em que a topologia é alterada dinamicamente (e chamada, a partir daqui, de topologia dinâmica).

O primeiro experimento de flooding foi realizado com quatro VANTs. No segundo, foram variados o número de VANTs, suas velocidades e seus posicionamentos tridimensionais. A Tabela 4 sumariza a configuração desses experimentos.

A aplicação da GCS gerou uma carga de 68 kilobits por segundo, o que representa apenas $0,12 \%$ da capacidade nominal da rede. Por causa dessa utilização irrelevante dos recursos da rede, o impacto da GCS não é considerado nas análises dos resultados desses experimentos.

A estação GCS das simulações difundiu mensagens periodicamente e todos os nodos intermediários retransmitiram as mensagens assim que elas foram recebidas. Esse é o modo de operação do algoritmo Flooding simples, como mencionado previamente na Seção 2.3 . 
Tabela 4 - Parâmetros da simulação do algoritmo de flooding.

\begin{tabular}{lll}
\hline PARÂMETROS VARIADOS & PRIMEIRO EXPERIMENTO & SEGUNDO EXPERIMENTO \\
\hline Quantidade de VANTs & 4 & $4,8,12,16,20,40,80$ \\
Tipo de topologias & Três topologias fixas & Topologia dinâmica \\
Posicionamento inicial dos nodos & Definido pela topologia & Em linha \\
Modelo de mobilidade & Stationary mobility & Random mobility \\
Velocidade relativa & 0 mps & 12 mps - 25 mps \\
TTL do frame & topologia 1: 3, & não definido \\
& topologia 2: 4, & \\
& topologia 3:2 & \\
\hline
\end{tabular}

Nos experimentos, uma aplicação sendo executada na GCS enviou 1.000 mensagens diferentes a uma taxa de 8 mensagens por segundo. A aplicação gerou mensagens com 1.024 bytes e 64 bytes foram adicionados pelo encapsulamento dos protocolos UDP, IP (Internet Protocol) e MAC (Medium Access Control). Ao final do empilhamento, o tamanho dos pacotes foi de 1.088 bytes. As aplicações dos nodos intermediários retransmitiram as mensagens imediatamente após serem recebidas na camada de aplicação.

O UDP foi escolhido como protocolo de transporte porque o TCP (Transmission Control Protocol) possui mecanismos de contenção de congestionamento que influenciariam nos resultados tanto dos experimentos de campo quanto dos simulados.

A rede FANET utilizou o padrão IEEE 802.11g, que tem uma capacidade de tráfego de 54 Mbps e um frame com tamanho máximo de 2.346 bytes (STALLINGS, 2006; KUROSE; ROSS, 2012b). Assim, cada frame foi capaz de carregar uma mensagem sem fragmentá-la. Este padrão Wi-Fi foi escolhido, tanto para o protótipo (mostrado na Figura 4) quanto para o ambiente de simulação, porque ele é amplamente utilizado em VANTs civis de pequeno porte.

Na Tabela 5 são ilustrados os parâmetros que definem o ambiente de simulação.

\subsection{Resultados da redundância de dados}

A primeira análise do impacto do flooding é sobre a redundância de dados na rede, um dos aspectos do problema BSP.

A estação GCS enviou, em 125 segundos, 1.000 mensagens únicas por broadcast e pode ser visto na Figura 15a que as retransmissões desmedidas multiplicaram este número para a ordem de centena de milhares.

A operação de broadcast é intrínseca às FANETs e às redes ad hoc móveis devido à natureza de radiodifusão de transmissão de rádio (LOU; WU, 2007; MURUGESAN; 
Tabela 5 - Parâmetros do sistema.

\begin{tabular}{ll}
\hline PARÂMETROS COMUNS & VALORES \\
\hline Simulador & OMNeT++5.0, INET Framework 4.3.0 \\
Área da rede & $1.000 m \times 2.000 \mathrm{~m} \times 80 \mathrm{~m}$ \\
Protocolo de transporte & $\mathrm{UDP}$ \\
Protocolo de rede & IPV4 \\
Taxa de dados da camada de enlace & $54 \mathrm{Mbps}$ \\
Modelo de camada física & Padrão: IEEE $802.11 \mathrm{~g}$, \\
& Frequência de operação: $2.4 \mathrm{GHz}$, \\
& Largura do canal: $20 \mathrm{MHz}$ \\
Modelo dos rádios & IEEE 802.11 dimensional radio \\
Modulação do rádio & QAM-64 \\
Tipo de path loss & Two-ray ground reflection \\
Quantidade e tipo de antena & 1 antena omnidirecional de $10 \mathrm{dbi}$ \\
Potência de transmissão & $20 \mathrm{dBm}$ \\
Potência de recepção & $-60 \mathrm{dBm}$ \\
Potência de interferência & $-60 \mathrm{dBm}$ \\
Ruído de fundo & $-90 \mathrm{dBm}$ \\
Tamanho do frame ethernet & 1.088 bytes \\
Duração das rodadas de simulação & 125 segundos \\
Intervalos de transmissão da GCS & 0,125 segundos \\
TTL das mensagens & 8 saltos \\
Quantidade de replicações dos experimentos & 10 \\
\hline
\end{tabular}

KRISHNAN, 2010; ROY, 2011). No entanto, a transmissão não é confiável porque nenhum tipo de confirmação é feita e ela pode interferir com outras transmissões, como nas topologias dadas na Figura 5, causando (i) o problema do terminal exposto (ou exposed terminal problem) e (ii) o problema do terminal encoberto (ou hidden terminal problem) (MURTHY; MANOJ, 2004; KUROSE; ROSS, 2012a).

O problema do terminal exposto ocorre quando um nodo fica impedido de enviar pacotes para outros nodos devido a um transmissor próximo, seja quando o nodo detecta a transmissão do vizinho e recua por algum tempo, ou quando pacotes transmitidos simultaneamente por vizinhos colidem e não podem ser recebidos com sucesso. $\mathrm{O}$ problema do terminal encoberto ocorre quando um nodo intermediário recebe, ao mesmo tempo, transmissões de dois vizinhos seus que estão fora do alcance um do outro.

Em FANETs baseadas na tecnologia Wi-Fi, os hosts são equipados com transceptores com capacidade CSMA/CA, mas não há uso de CSMA/CD (STALLINGS, 2006; KUMAR; MANJUNATH; KURI, 2008; KUROSE; ROSS, 2012b) para detectar o problema do nodo encoberto e as colisões de pacotes no meio sem fio. Também, o diálogo RTS/CTS e a confirmação de recebimento de frames não está presente porque são pertinentes apenas para unicast em redes infraestruturadas. 
Figura 15 - Quantidade média de mensagens recebidas por cada nodo da FANET. Estes valores são médias aritméticas entre as replicações do experimento do flooding. As áreas transparentes representam o número de frames que chegaram com erro e foram descartados pelo protocolo MAC, não tendo sido, então, computados pela camada de aplicação.

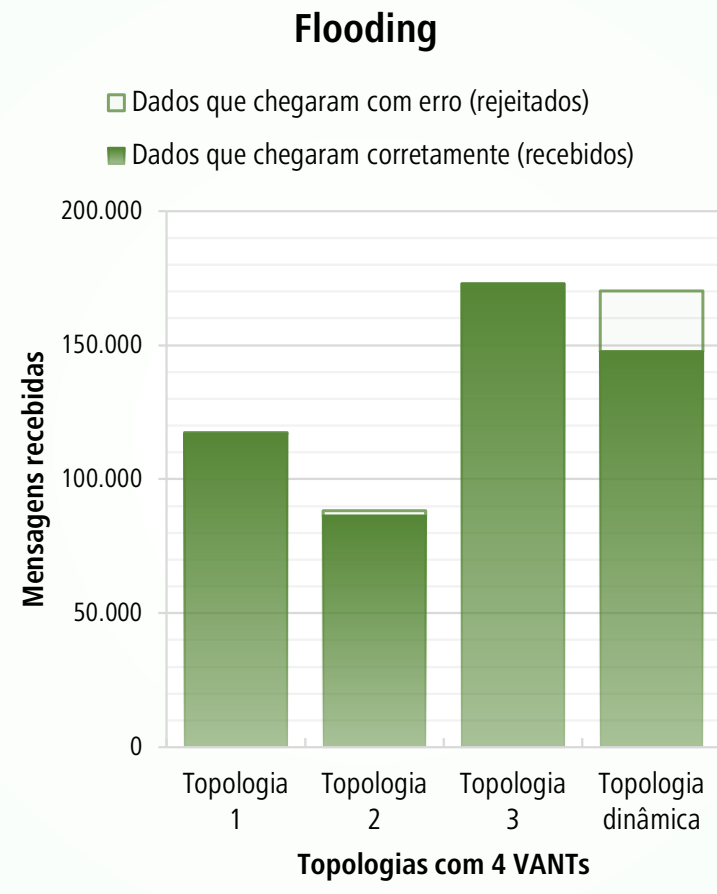

(a) Quatro VANTs

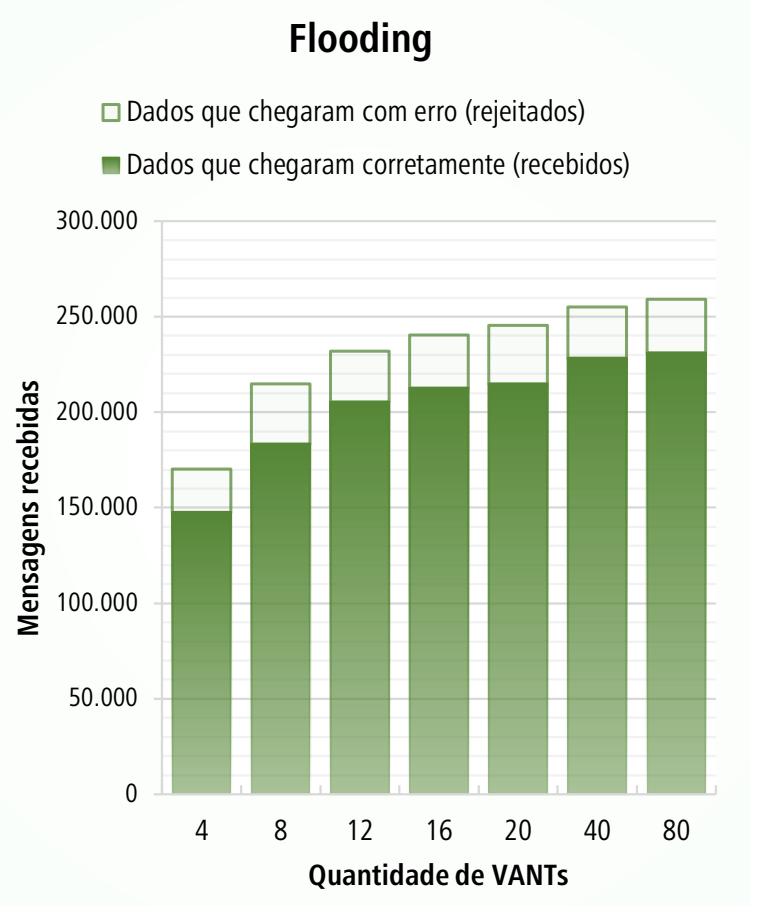

(b) Mais de três VANTs, em uma topologia dinâmica

A falta desses mecanismos torna o canal de rádio de uma FANET mais suscetível a erros quando há muitos broadcasts em um curto período de tempo, por isso todos os nodos receberam alguns dados com erro, mesmo quando estavam estáticos - nas topologias 1 e 2. Além desta susceptibilidade, os movimentos dos VANTs causam flutuação nas ondas de rádio e instabilidade no link de dados. Como consequência, pode-se notar na Figura 15b que a recepção errônea de dados foi mais severa nos experimentos com topologia dinâmica.

Uma visão diferente destes dados, mostrada na Tabela 6, revela a porcentagem excessiva de mensagens redundantes circulando pela rede. É uma prova do uso indiscriminado do canal sem fio, reduzindo a largura de banda útil, sobrecarregando o processador dos hosts e desperdiçando energia - um recurso que deve ser racionado para prolongar o tempo de voo.

É possível notar, até então, que a redundância de mensagens tende a crescer conforme a FANET fica mais densa. Isso acontece porque a área da rede é sempre a mesma, e o número de vizinhos aumenta sem que a distância entre eles mude. Com isso, o número de sinais sobrepostos também aumenta, fazendo com que muitos VANTs 
Tabela 6 - Porcentagem média de mensagens redundantes causada pelo flooding, em relação ao número inicial de mensagens.

\begin{tabular}{lr}
\hline \multicolumn{2}{c}{ TOPOLOGIAS ESTÁtICAS } \\
\multicolumn{2}{c}{ COM QUATRO VANTs } \\
\hline Topologia 1 & $11.599,11 \%$ \\
Topologia 2 & $8.526,99 \%$ \\
Topologia 3 & $17.197,66 \%$ \\
\hline
\end{tabular}

\begin{tabular}{|c|c|}
\hline \multicolumn{2}{|c|}{$\begin{array}{l}\text { TOPOLOGIAS DINÂMICAS } \\
\text { COM MÚLTIPLOS VANTS }\end{array}$} \\
\hline 4 VANTs & $14.658,60 \%$ \\
\hline 8 VANTs & $18.232,58 \%$ \\
\hline 12 VANTs & $20.435,31 \%$ \\
\hline 16 VANTs & $21.161,01 \%$ \\
\hline 20 VANTs & $21.380,11 \%$ \\
\hline 40 VANTs & $22.728,91 \%$ \\
\hline 80 VANTs & $23.004,00 \%$ \\
\hline
\end{tabular}

recebam e retransmitam em paralelo as mesmas mensagens.

Pode-se observar que a redundância não cresce na mesma taxa que o número de nodos da rede. Ou seja, a redundância não duplica ou triplica quando o número de VANTs é multiplicado por dois ou três. Este comportamento está relacionado com a disputa do canal e com a quantidade de dados recebidos com erro. Além da instabilidade da conexão, causada pela movimentação tridimensional dos VANTs, quanto mais densa a FANET fica, mais difícil se torna controlar o acesso ao meio, eventualmente ocorrendo interferências e aumentando o número de frames recebidos com erro. É por isso que o número de frames recebidos por cada nodo não cresce na mesma taxa que o número de nodos na FANET. Esse recurso só pode ser visto em um experimento realista e é uma das contribuições desta pesquisa.

Cada frame recebido corretamente na camada MAC subiu a pilha de protocolos até chegar à camada de aplicação, onde uma mensagem foi desencapsulada, registrada nos $\operatorname{logs}$, imediatamente re-encapsulada em um novo pacote UDP e desceu a pilha de protocolos para ser transmitida na rede. O diagrama de fluxo na Figura 16 ilustra esses passos. As mensagens que desceram da camada de aplicação são enfileiradas no buffer de saída enquanto o mecanismo CSMA/CA decide quando é o momento certo para transmiti-las. Enquanto esta área de memória não tem mais espaço livre, novas mensagens não podem ser enfileiradas e são descartadas automaticamente.

Quando o CSMA/CA detecta que o meio sem fio está ocioso, os frames são transmitidos. Quando esse mecanismo detecta que o meio está ocupado, novas transmissões são postergadas para evitar colisões de pacotes. Ao adiar os quadros enfileirados, o buffer de saída eventualmente fica cheio e novas mensagens vindas da camada de aplicação são descartadas sem serem despachadas do nodo. O impacto da contenção de transmissão pode ser visto nas figuras $17 \mathrm{a}$ e $17 \mathrm{~b}$. Nota-se que quanto mais sobreposições de sinais estão presentes, maior é a disputa pelo canal e menor é o número médio de mensagens retransmitidas por cada nodo. 
Figura 16 - Diagrama de fluxo do broadcast relay, ilustrando como frames são recebidos na camada MAC vindos da camada física e sobem a pilha de protocolos até atingirem a camada da aplicação. Essa última, por sua vez, inicia o processo reverso para retransmitir a mensagem para a vizinhança.

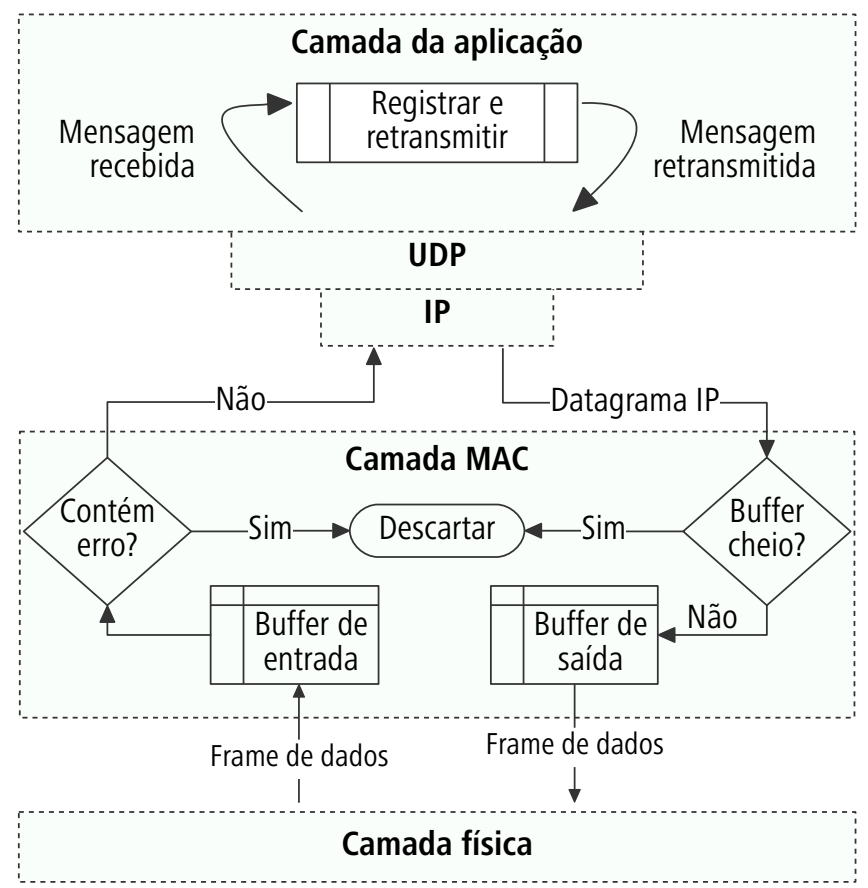

Fonte: Elaborada pelo autor.

\subsection{Resultados do alcance da informação}

Cada mensagem enviada pela estação GCS continha informações exclusivas, que não se repetiram em nenhuma outra mensagem. Os nodos replicam dados quando retransmitem mensagens e isso faz com que as informações se tornem redundantes para os nodos que recebem esses dados mais de uma vez. Portanto, ao retransmitirem uma mensagem, os nodos podem estar distribuindo dados, mas, devido à redundância, eles não estão necessariamente agregando novas informações ou conhecimento aos vizinhos.

Por essa razão, quando um nodo $A$ perde uma mensagem retransmitida por um nodo $B$, isso não significa que uma informação recente foi perdida, já que os dados transportados por essa mensagem poderiam ser redundantes para $A$.

Para analisar a alcançabilidade das informações geradas em uma missão, essa distinção entre "dados recebidos" e "informação recebida" deve estar clara.

Começando a análise com os cenários com quatro nodos, pode-se ver na Figura 18a que foi na topologia 3 que os VANTs receberam mais informações e no menor tempo, apesar da maior redundância apresentada na Figura 15a. Isso é explicado primeiramente pela estabilidade do link de comunicação nessa topologia e, em segundo lugar, pela maior chance de uma mensagem ser recebida quando há mais cópias disponíveis na 
Figura 17 - Quantidade média de mensagens difundidas por cada nodo da FANET. Estes valores são médias aritméticas entre as replicações do experimento do flooding. O número total de mensagens que saíram da aplicação e desceram pela pilha UDP/IP é igual ao número de mensagens recebidas com sucesso e está representado neste gráfico pela soma das áreas azuis e transparentes. As áreas transparentes representam a quantidade de frames descartados na camada MAC por falta de espaço no buffer de saída.

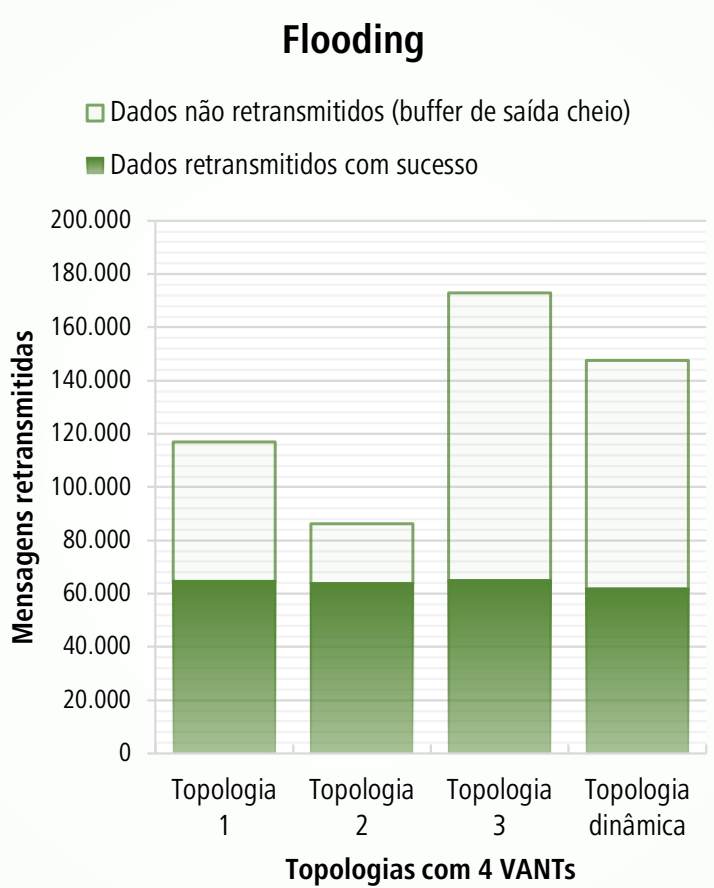

(a) Quatro VANTs

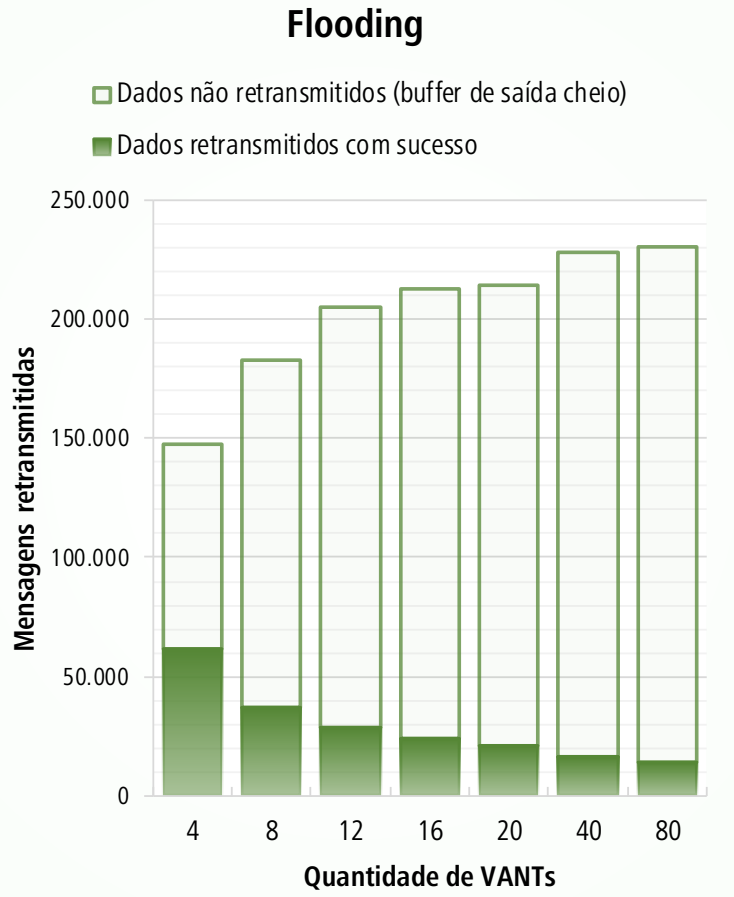

(b) Mais de três VANTs, em uma topologia dinâmica

rede.

Quando os VANTs estavam se movendo, a oscilação do link (causada pela variação da velocidade e das distâncias euclidianas entre os VANTs) ocasionava perdas de dados (ilustradas na Figura 15b) e manteve mensagens com informações redundantes em loop por longos períodos. Isso resultou em uma baixa porcentagem de informações recebidas, e um grande atraso fim-a-fim na entrega das informações, como ilustrado na Figura 18b.

O atraso médio na entrega de mensagens no melhor cenário (quatro VANTs na topologia 3) foi de 5,6 segundos e, dependendo da aplicação, esse tempo pode ser considerado aceitável para receber ou responder uma solicitação da GCS. No entanto, sabendo que os VANTs estavam voando a uma velocidade máxima de $25 \mathrm{mps}$, o atraso médio de ponta a ponta no experimento com a FANET mais densa (80 VANTs) permitiu que os VANTs voassem até 140 metros de distância, desde o momento em que a mensagem foi enviada até ser recebida. Se a aplicação da FANET estivesse usando broadcast como parte da estratégia de evitar colisões, o atraso médio nesse cenário (61,8 segundos) teria 
Figura 18 - Porcentagem média de informações recebidas por cada nodo e o atraso fim-a-fim (em segundos) da entrega de cada mensagem, em diferentes topologias de rede, na simulação do algoritmo de flooding.

\section{Flooding}

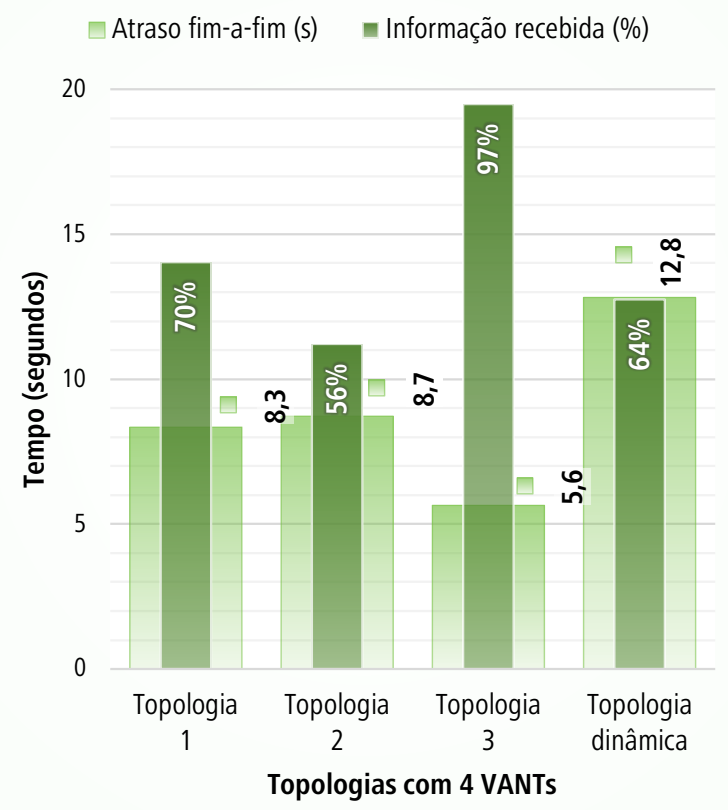

(a) Quatro VANTs

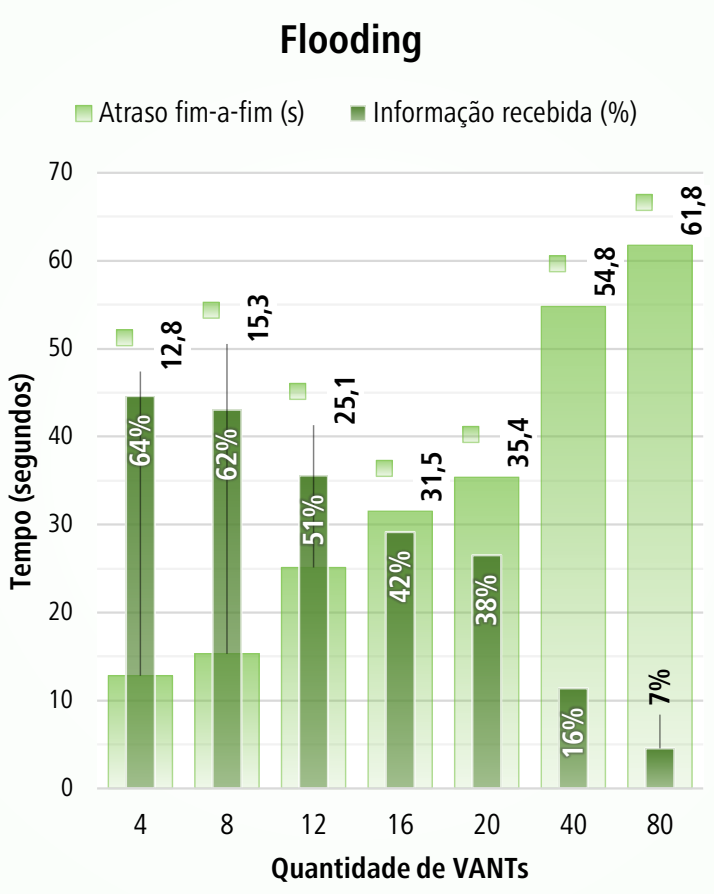

(b) Mais de três VANTs, com topologias dinâmicas.

impedido que essa estratégia funcionasse com segurança.

No início de cada missão, todos os VANTs estavam no alcance de transmissão da GCS, aumentando as sobreposições de sinal. Eles conseguiam receber com sucesso as primeiras mensagens enviadas pela GCS, retransmitindo-as amplamente.

O buffer de saída da camada MAC foi preenchido com duplicatas das primeiras mensagens e esvaziado em três situações: (i) quando as mensagens de saída eram descartadas devido à falta de espaço, (ii) quando frames enfileirados eram retransmitidos, ou (iii) quando o recebimento da mensagem era interrompido por quebra do link.

Quando os VANTs se aproximavam e a conexão era restabelecida, alguns dados eram mantidos em loop entre os nodos dentro da área do sinal, devido às retransmissões serem sem restrições e de modo imediato, impedindo a recepção de mensagens mais recentes - que eram enviadas pela GCS em uma frequência substancialmente menor. Esta circunstância desfavorável fez com que as 1.000 mensagens geradas na GCS não tivessem a mesma probabilidade de recepção.

É possível observar nos gráficos ilustrados na Figura 19 que poucos IDs foram excessivamente recebidos, porque estavam em um loop de retransmissão - o que explica os resultados de redundância - e que muitos IDs foram recebidos pouca ou nenhuma vez, 
Figura 19 - Gráficos de pontos representando as mensagens recebidas ao longo do tempo, nos experimentos com mobilidade, em que a densidade da rede foi variada. O eixo $\mathrm{X}$ representa o tempo de simulação, em segundos; e o eixo Y representa o identificador (ID) exclusivo de cada mensagem, um número inteiro no intervalo de 0 a 999 . Cada ponto $(x, y)$ representa uma mensagem $y$ recebida no tempo $x$ por um VANT. Cada VANT é representado por uma cor.

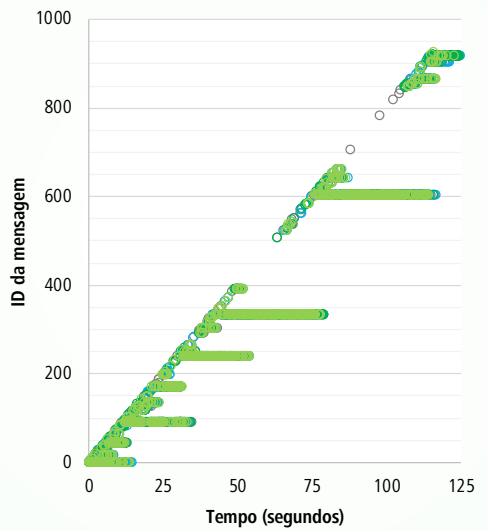

(a) 4 VANTs

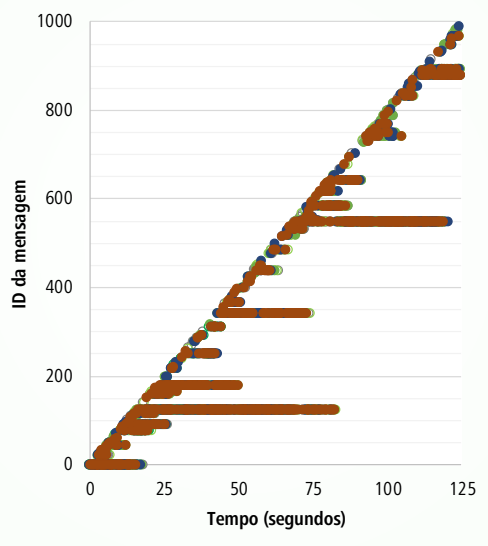

(b) 8 VANTs

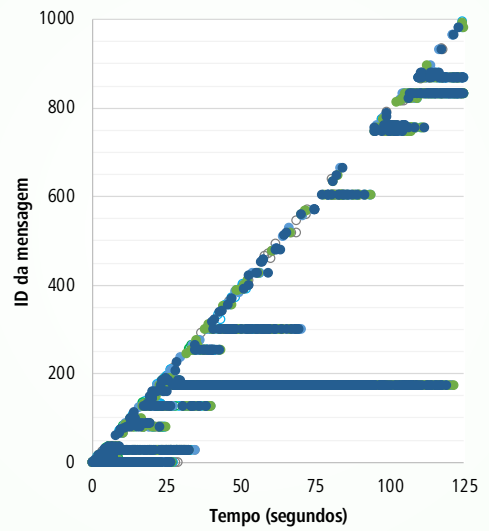

(c) 12 VANTs

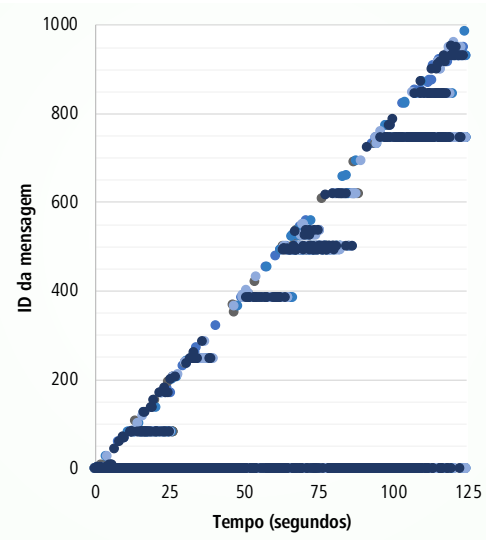

(d) 16 VANTs

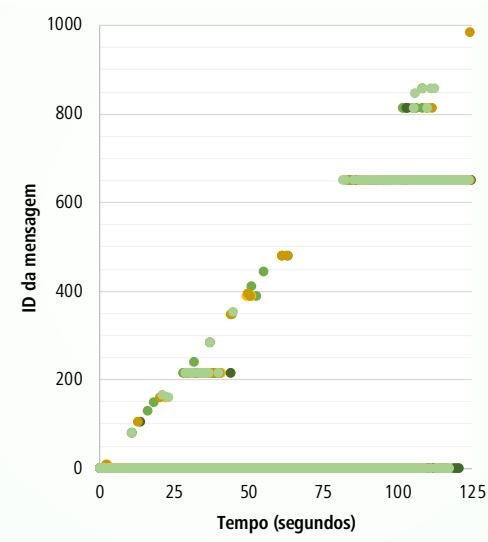

(f) 40 VANTs

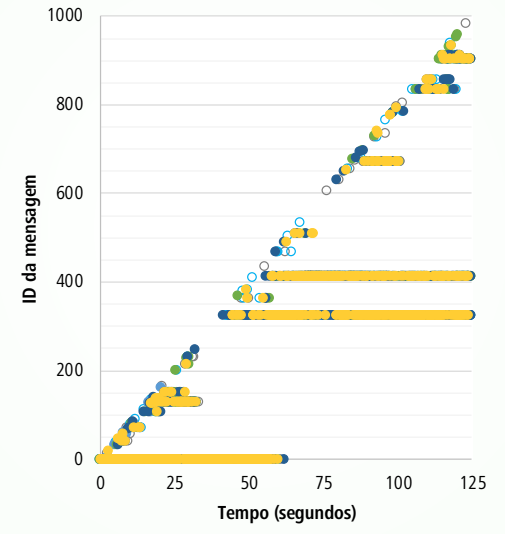

(e) 20 VANTs

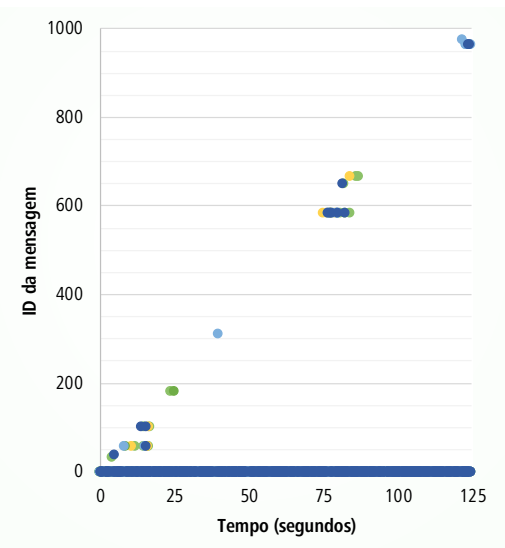

(g) 80 VANTs 
produzindo baixa variabilidade de informações - o que complementa as explicações sobre a porcentagem decrescente de informações recebidas nos experimentos com flooding, conforme a FANET fica mais densa.

\subsection{Considerações finais}

O propósito principal de uma aplicação que usa broadcast para disseminar mensagens é alcançar todos os nodos na rede. Sendo assim, fica provado que usar o flooding simples não é a estratégia ideal para alcançar este objetivo, devido à maior redundância de mensagens, ao aumento da perda de informação e ao atraso na entrega da mensagem, demonstrando o problema BSP nas FANETs e justificando a demanda por técnicas de mitigação.

O Capítulo 7 descreve a solução desenvolvida neste doutorado para o controle mais refinado do problema BSP em redes FANETs, bem como expõe a avaliação desta técnica, comparando-a com as técnicas já existentes na literatura e evidenciando os ganhos alcançados nos cenários em que a rede é mais densa e possui mobilidade dos nodos. 
CAPÍTULO

\section{7}

\section{SOLUÇÃO PARA O CONTROLE DO BSP EM FANETS: O ALGORITMO DNA-BSP}

Os algoritmos avaliados neste trabalho (Algoritmo 1, Algoritmo 2 e Algoritmo 3) (i) calculam a duplicação de mensagens dentro de um intervalo predefinido, ou (ii) adotam uma probabilidade predefinida de retransmissão, ou (iii) decidem com base em uma estimativa predefinida do tamanho da vizinhança.

Depois de analisar os resultados obtidos nas execuções desses algoritmos, foi possível notar que outros fatores poderiam ser levados em conta, como a (i) detecção contínua de sinais próximos, estimando o número de VANTs vizinhos e computando a cobertura adicional alcançada por uma retransmissão; (ii) ampliação do tempo de espera antes da decisão, para aumentar a eficácia do contador e diminuir o impacto do tempo de vida (TTL) da mensagem; (iii) armazenar informações sobre mensagens recebidas ou retransmitidas em vez de aceitar novamente uma mensagem após sua retransmissão; e (iv) armazenar informações sobre os vizinhos que estão duplicando as retransmissões. A estação GCS também poderia melhorar a parametrização das mensagens, modificando, por exemplo, o campo TTL de acordo com o número de nodos na rede.

Quando um nodo tem poucos vizinhos, a retransmissão de um pacote broadcast é mais importante por dois motivos. Primeiro, a redundância de sua retransmissão é menor porque o nodo é responsável por cobrir uma área maior. Isso também custa menos porque haverá menos contenção. Em segundo lugar, é mais provável que o nodo esteja localizado em uma posição crítica (por exemplo, um ponto de ligação entre duas partições da rede, cuja remoção desconectará a rede). A inibição de sua retransmissão pode fazer com que uma grande parte da rede não receba o pacote de transmissão.

Se a vizinhança de um nodo estiver densa o suficiente, pode-se concentrar mais em mitigar, porque usar um limite baixo não sacrificará o desempenho do alcance, mas 
poderá economizar muitas retransmissões (e, assim, amenizar os problemas de contenção e colisão).

Uma maneira de manter alta a porcentagem de informação recebida é não mitigar muitas mensagens. Contrariamente, quanto menos mensagens forem atenuadas, mais os nodos vizinhos incrementarão seu contador e, como consequência, mais mitigação ocorrerá posteriormente. Dessa forma, os nodos mais próximos da GCS retransmitem as mensagens recebidas, os nodos intermediários recebem e retransmitem parte delas e os nodos mais distantes são os que perdem a maior parte dos dados.

Com a finalidade de aprimorar a mitigação de broadcasts para o cenário das FANETs, um novo algoritmo de mitigação foi desenvolvido neste doutorado para melhorar o Simple Counter-based, denominado Dynamic Neighborhood-based Algorithm for the Broadcast Storm Problem (DNA-BSP). De forma sucinta, o DNA-BSP decide sobre a retransmissão ou descarte das mensagens verificando três condições: se o contador de duplicação é menor que o limiar; se a mensagem já foi retransmitida previamente, nos últimos 60 minutos; e se o número de vizinhos aumentou desde a última retransmissão.

Para detalhar esta nova técnica, o DNA-BSP é apresentado em duas partes. A parte I está descrita no Algoritmo 4 e leva em consideração a avaliação das mensagens recebidas.

Quando os VANTs recebem uma mensagem, a primeira tarefa é atualizar sua lista de vizinhos com o endereço do último salto da mensagem (linhas 2 e 3).

A segunda tarefa é verificar se uma retransmissão com o mesmo ID foi feita na última hora (linhas 5 e 6). Se esses dados tiverem sido transmitidos há menos de uma hora, a mensagem recebida é descartada (linha 9), porque considera-se que esses dados não adicionariam novas informações ao VANT local nem aos vizinhos, evitando usar o meio sem fio para transmissão redundante. Depois de descartar a mensagem recebida, o algoritmo retorna e aguarda o recebimento de novas mensagens. Se esse ID tiver sido retransmitido há mais de uma hora atrás, ele é removido da lista de mensagens enviadas (linha 7), a mensagem recebida não será descartada e a próxima etapa será executada.

A terceira e última etapa ao receber uma mensagem é verificar se já existe na fila de espera uma mensagem com o mesmo ID (linha 13). Nesse caso, o contador da mensagem em espera é incrementado, seu campo TTL é diminuído e a cópia recebida é descartada. Caso contrário, essa mensagem recebida é inserida na fila, seu contador é inicializado com 1, seu campo TTL não é alterado e um temporizador de retransmissão é iniciado.

Na camada de aplicação, os algoritmos de mitigação decrementam o campo TTL quando uma cópia de uma mensagem em espera é recebida, de modo que a vida útil da informação mantenha-se conforme o esperado pela GCS. Quando uma mensagem deixa 


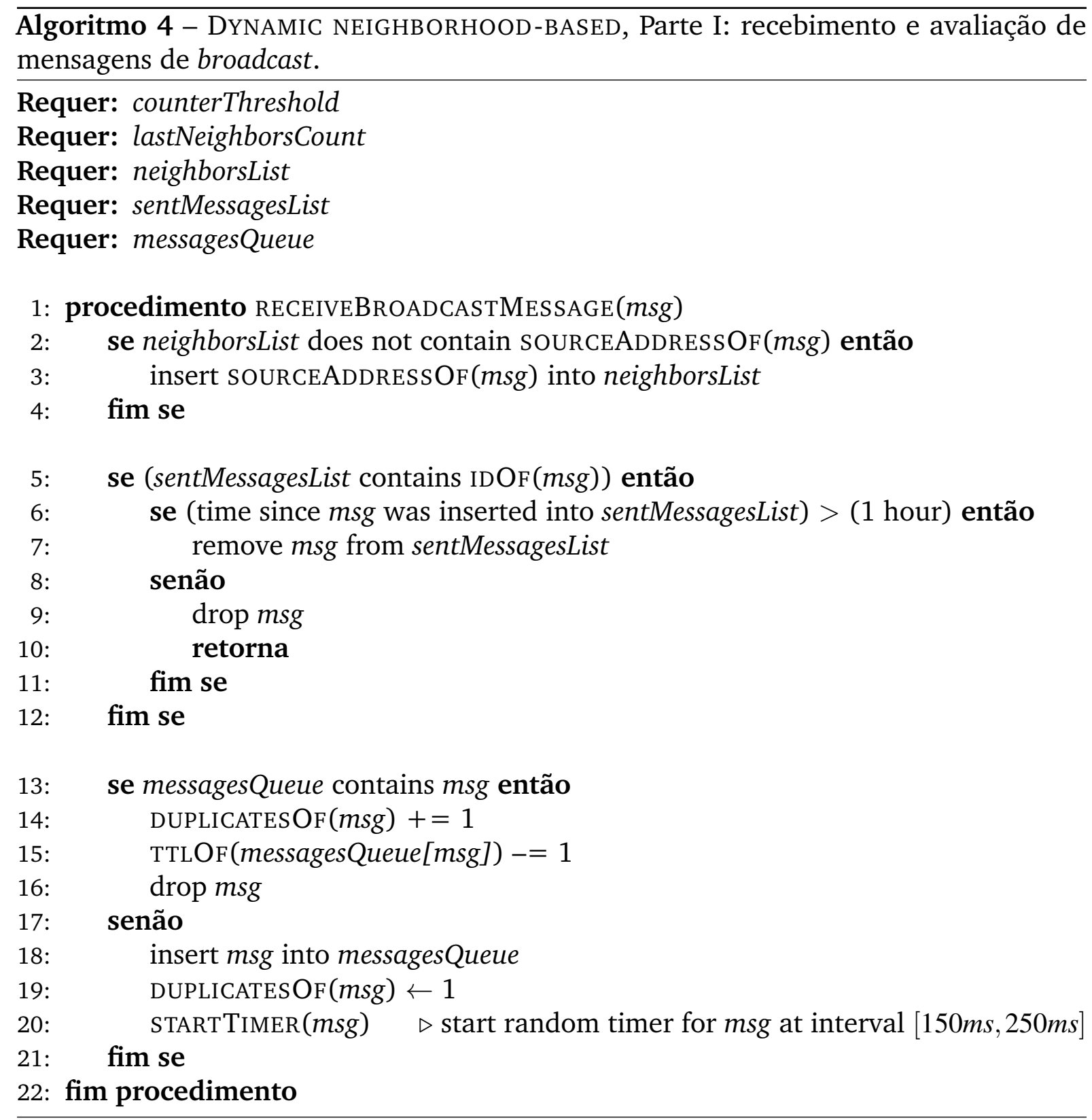

a aplicação e desce a pilha de protocolos, é responsabilidade do protocolo IP decrementar o campo TTL e, se o valor final for maior que zero, continuar a enviá-la para o protocolo MAC. Caso contrário, esse pacote IP é descartado e a mensagem original não deixa o nodo. Esse comportamento foi verificado e está implementado no módulo fornecido pelo framework INET.

Considerando o pior caso, em que um VANT recebe uma cópia de cada mensagem enviada nos últimos 3.600 segundos e todas elas são retransmitidas, 28.800 tuplas (ID, horario) seriam inseridas na lista de mensagens enviadas. Em uma arquitetura de 64 bits, essa lista ocuparia aproximadamente ${ }^{1} 450$ Kbytes de espaço de memória e esta é uma demanda aceitável para recursos de computadores embarcados em VANTs civis capazes de realizar missões com uma hora de duração, como o utilizado no protótipo da Figura 4. 
As simulações desse trabalho foram executadas por 125 segundos e a memória usada foi menor que 340 Kbytes. As medições são ilustradas na Figura 20.

Figura 20 - Estimativa ${ }^{1}$ da quantidade de memória utilizada (em bytes) para armazenar a lista de mensagens retransmitidas em cada VANT. Na plataforma de simulação, a sobrecarga do contêiner foi de 48 bytes, mais 8 bytes para os IDs, mais 8 bytes para o horário de transmissão das mensagens.

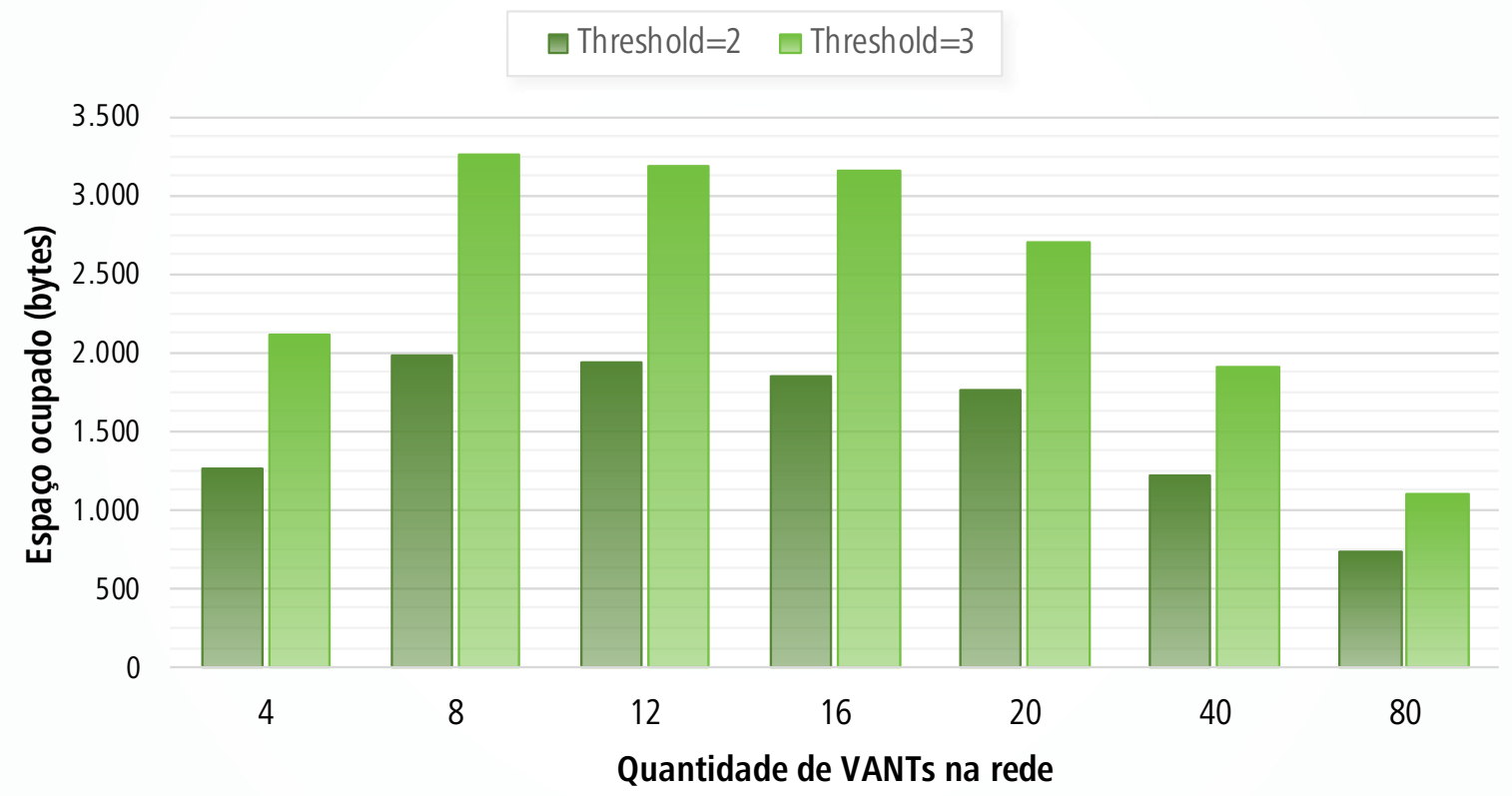

Fonte: Dados da pesquisa.

Nesta primeira parte do Algoritmo DNA-BSP, duas condições são avaliadas sobre as mensagens recebidas: (i) se já foram recebidas e retransmitidas na última hora da missão, ou (ii) se já estão presentes na fila de espera. Se alguma das condições acima for satisfeita, os dados recebidos serão descartados. Caso contrário, esses dados são aceitos e inseridos na fila de retransmissão. Nenhuma mensagem é removida desta fila na Parte I.

Quando o temporizador de uma mensagem termina, esta mensagem é removida da fila de espera e a decisão de retransmiti-la ou não é feita na Parte II (Algoritmo 5), levando em consideração se (i) o contador de duplicação da mensagem é menor que o

1 A estrutura de dados usada no código implementado para armazenar IDs de mensagens e os horários de transmissões é o contêiner std: : map, disponível na linguagem $\mathrm{C}++$. Ele usa a árvore rubro-negra, que por sua vez faz uso de ponteiros e outras variáveis para manter seus nós equilibrados. Sabe-se que nas implementações de árvores rubro-negras os nós folha não são relevantes e geralmente não contêm nenhum dado. Essas folhas não precisam residir na memória do computador e são comumente identificadas por um ponteiro nulo. Para economizar memória e tempo de execução, às vezes, um ponteiro para um único nó sentinela (em vez de um ponteiro nulo) desempenha o papel de todos os nós folha; todas as referências de nós internos para nós folha apontam para o nó sentinela. Por esse motivo, o espaço de memória real ocupado pela lista de mensagens enviadas pode variar ligeiramente, dependendo de como a biblioteca implementa essa estrutura. 
limiar, e se (ii) o número real de vizinhos aumentou desde que o último temporizador terminou (linha 26).

Em experimentos com threshold $=2$, uma cópia dos dados de uma mensagem em espera deve ter sido recebida apenas uma vez para que a retransmissão da mensagem seja aprovada. Com threshold $=3$, esses dados podem ter sido recebidos duas vezes enquanto a mensagem estava na fila.

Quando todas as condições são satisfeitas, a mensagem é então retransmitida (linha 27) e uma tupla composta do horário de retransmissão e o ID da mensagem é inserido na lista de mensagens enviadas (linha 28). Caso contrário, a mensagem em espera é descartada (linha 30).

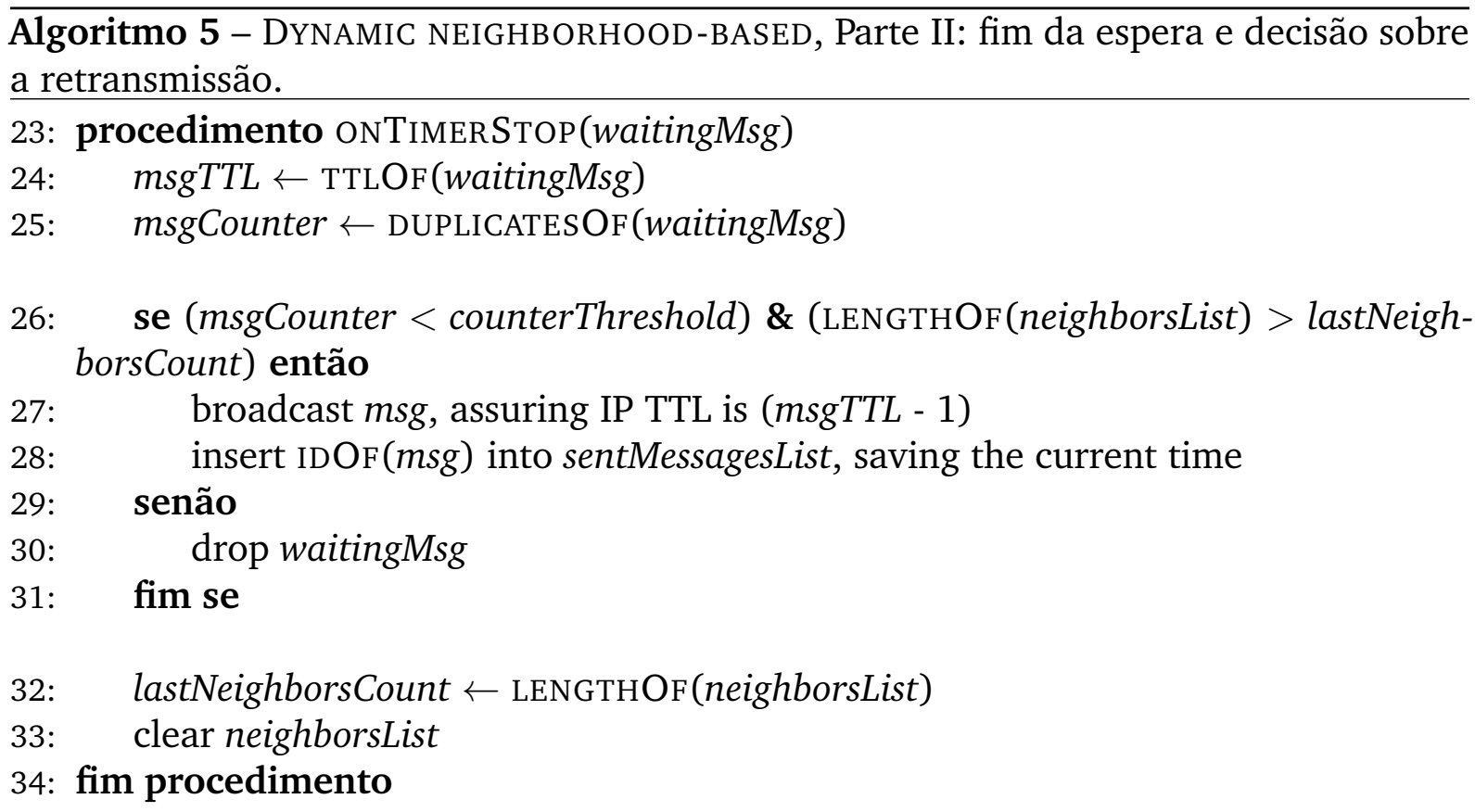

A última tarefa da Parte II é atualizar o número de vizinhos do VANT (linha 32) e apagar a lista de vizinhos (linha 33), obrigando que ela seja repopulada quando novas mensagens chegarem.

Valores de limiar maiores que 3 não foram considerados porque, de acordo com Tseng et al. (2002), eles produzem mais redundância na rede e não fornecem cobertura adicional.

\subsection{Resultados do Algoritmo DNA-BSP}

Resultados da simulação com os quatro algoritmos (Simple Counter-based, Fixed Probability-based, Dynamic Probability-based e DNA-BSP) e quatro VANTs fixados nas três topologias estáticas (Figura 5) são apresentados na Figura 21. O primeiro fato a ser observado é a drástica redução de dados redundantes que fluem pela rede. 
Figura 21 - Resultado da simulação dos quatro algoritmos em uma FANET com quatro VANTs, nas três topologias fixas. Os valores são a média aritmética entre cada replicação do experimento. Em (a), (b) e (c), menos é melhor. Em (d), mais é melhor.

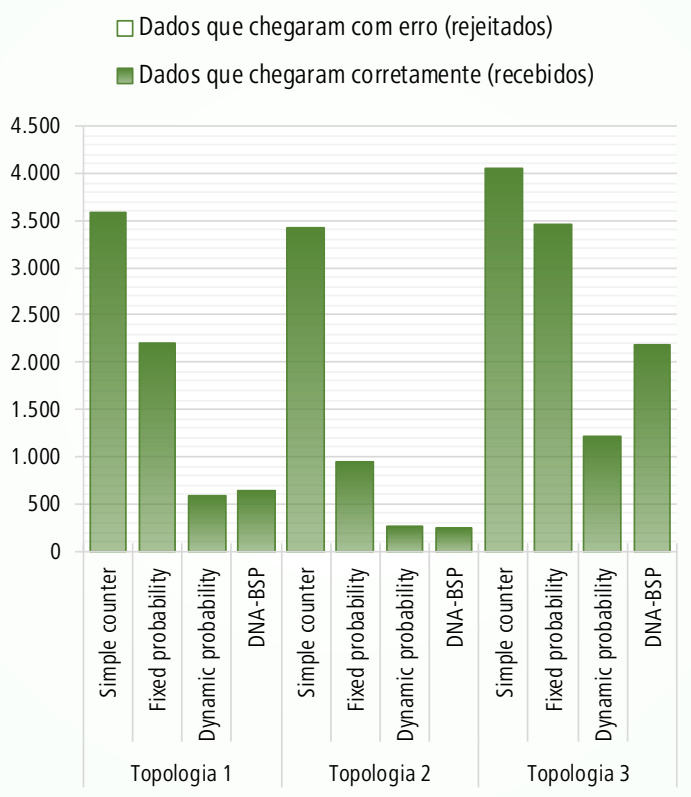

(a) Quantidade média de mensagens recebidas por cada um dos quatro VANTs da FANET. Não houve a ocorrência de frames com erro.

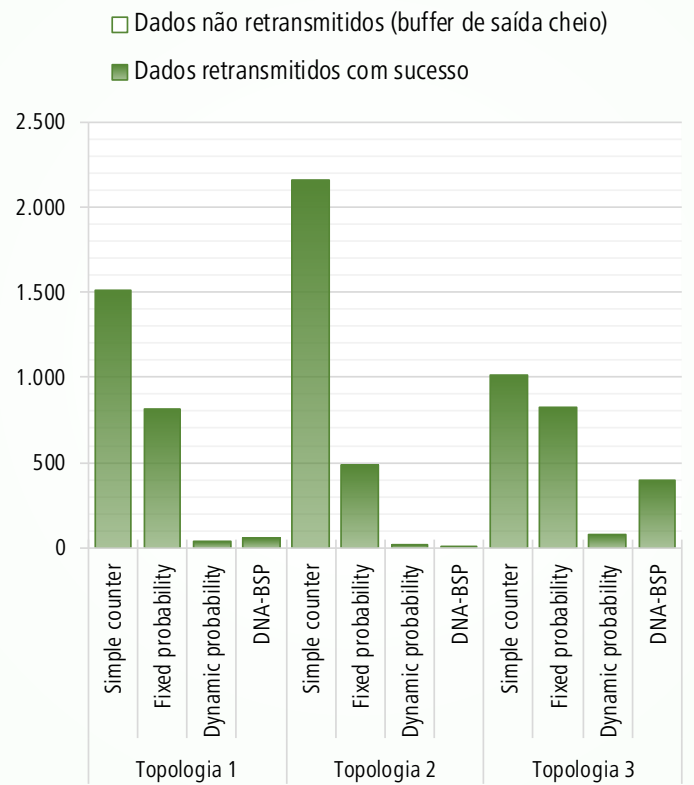

(c) Quantidade média de mensagens retransmitidas por cada um dos quatro VANTs da FANET. Todas as mensagens que saíram da aplicação e desceram a pilha UDP/IP foram transmitidas com sucesso.

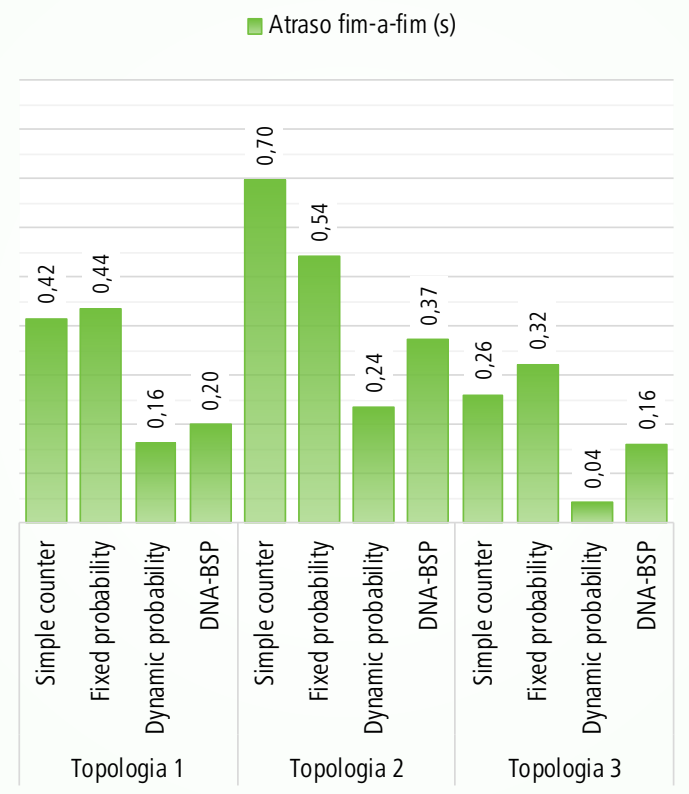

(b) Atraso fim-a-fim médio (em segundos) na entrega de cada mensagem para os VANTs.

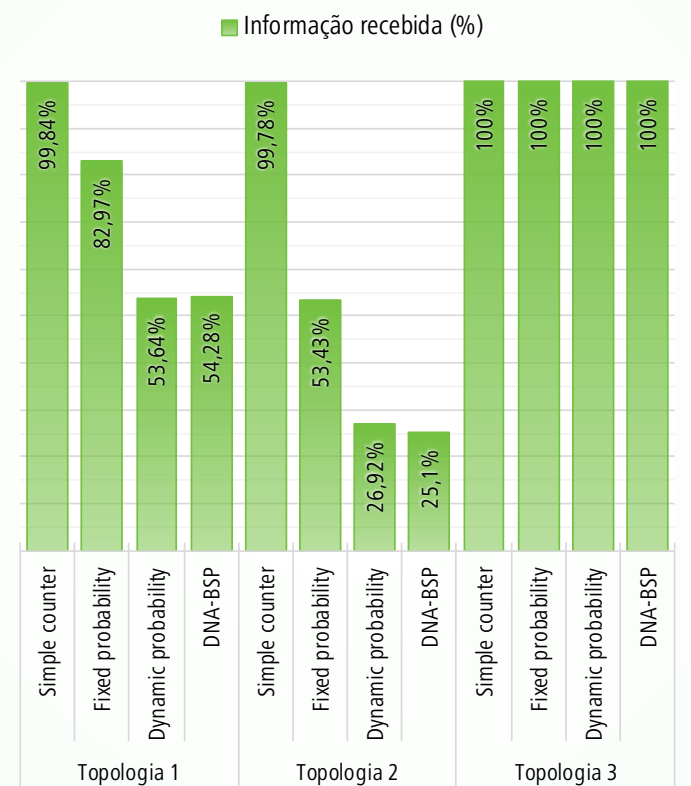

(d) Porcentagem média de informação recebida pelos VANTs. 
Os VANTs receberam menos de 4.500 mensagens quando as transmissões estavam restringidas (Figura 21a) e esse número ultrapassou a marca de 170.000 no cenário de flooding (Figura 15a). O Algoritmo DNA-BSP reduziu 99,46\% das mensagens recebidas na topologia $1,99,71 \%$ na topologia 2 e $98,73 \%$ na topologia 3 , quando comparado com os resultados do Flooding.

O número de retransmissões também diminuiu notavelmente. Os VANTs transmitiram mais de 60.000 mensagens quando estavam inundando a rede (Figura 17a), mas esse número caiu para menos de 2.500 quando os algoritmos de mitigação estavam em execução (Figura 21c). O Algoritmo DNA-BSP foi capaz de reduzir eficientemente $99,91 \%$ das mensagens transmitidas na topologia 1, 99,99\% na topologia 2 e 99,39\% na topologia 3. Isso significa que quase não foram feitas retransmissões redundantes quando o DNA-BSP estava em execução.

Pode-se notar também que, diferentemente do algoritmo de flooding, nenhum pacote recebido foi rejeitado pela camada MAC e os buffers de saída também não descartaram nenhuma mensagem (não há áreas transparentes na Figura 21a e na Figura 21c), mostrando que quatro VANTs estáticos transmitindo moderadamente não geraram tráfego suficiente para distorcer o desempenho do CSMA/CA.

Além da redução de redundância de dados, da colisão de pacotes e da contenção da rede, outro benefício é a menor latência dos dados. No caso do DNA-BSP, o atraso médio fim-a-fim diminuiu de 8,3, 8,7 e 5,6 segundos (Figura 18a) para 0,2, 0,37 e 0,16 segundos (Figura 21b) nas topologias 1, 2 e 3, respectivamente. Portanto, a entrega das mensagens foi até $97,6 \%$ mais rápida quando a redundância na rede era menor.

A comunicação por broadcast é frequentemente usada para controlar a formação do voo, evitar colisões entre VANTs, gerenciar o progresso da missão ou atualizar rotas IP dentro da rede. Logo, reduzir a disputa do canal sem fio é benéfico no sentido de que mais largura de banda fica disponível para o tráfego de outros tipos de dados, como imagens geradas ou dados coletados pelos VANTs.

Por outro lado, pode-se observar nas simulações com menos redundância, que os nodos receberam menos informação em alguns casos (Figura 21d). Isso acontece porque as informações não alcançaram os nodos mais distantes da GCS devido à mitigação dos nodos intermediários.

Os resultados dos experimentos com mobilidade são mais relevantes porque o cenário representa melhor as FANETs. Nas simulações dos algoritmos de mitigação aplicados a VANTs móveis também houve uma notória redução nos volumes de mensagens retransmitidas, de mensagens recebidas e no tempo de entrega das mensagens em comparação com os resultados do algoritmo de flooding, além de propiciarem uma maior porcentagem de informação recebida nos nodos e uma menor quantidade de frames que 
chegaram com erro, como pode ser visto nos gráficos da Figura 22.

Figura 22 - Resultados da simulação dos quatro algoritmos de mitigação em FANET com mais de três VANTs, na topologia dinâmica. O buffer de saída foi capaz de despachar todas as mensagens, então não houve descarte de mensagens. Em (a), (b), (c) e (d), menos é melhor. Em (e), mais é melhor.

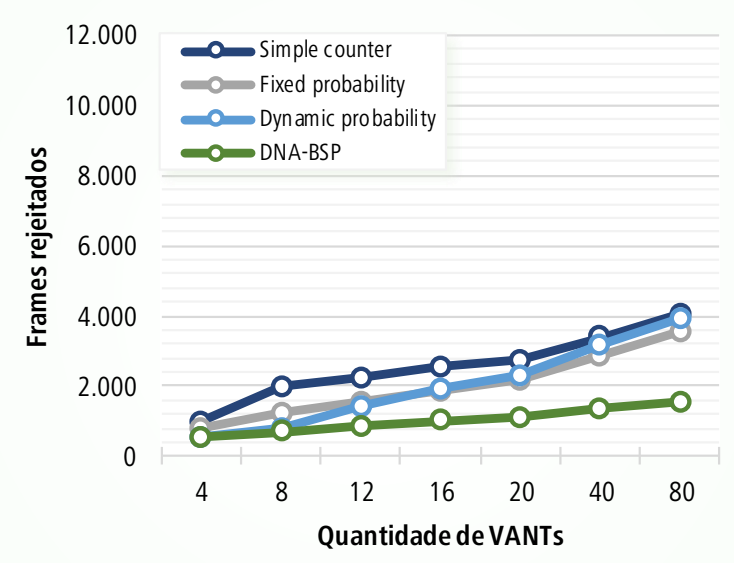

(a) Dados recebidos com erro (rejeitados).

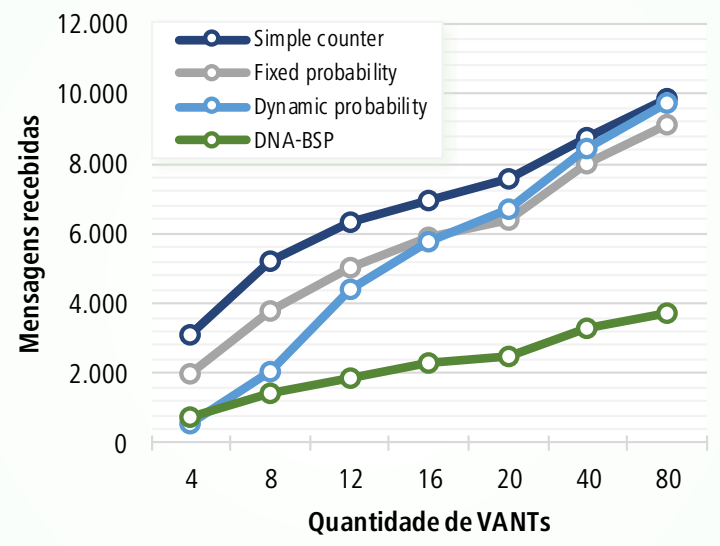

(b) Dados recebidos com sucesso.

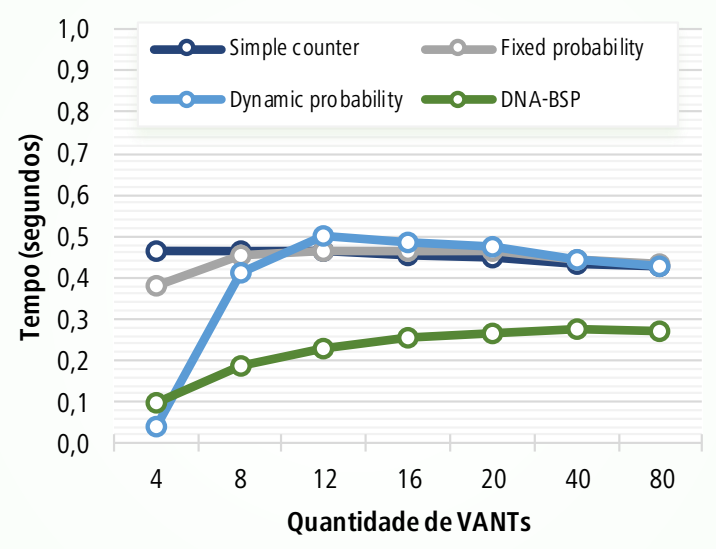

(c) Atraso fim-a-fim na entrega das mensagens.

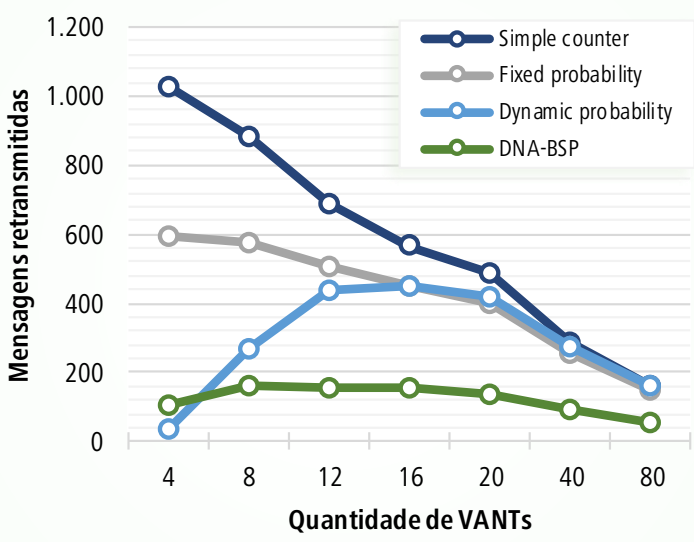

(d) Dados retransmitidos com sucesso.

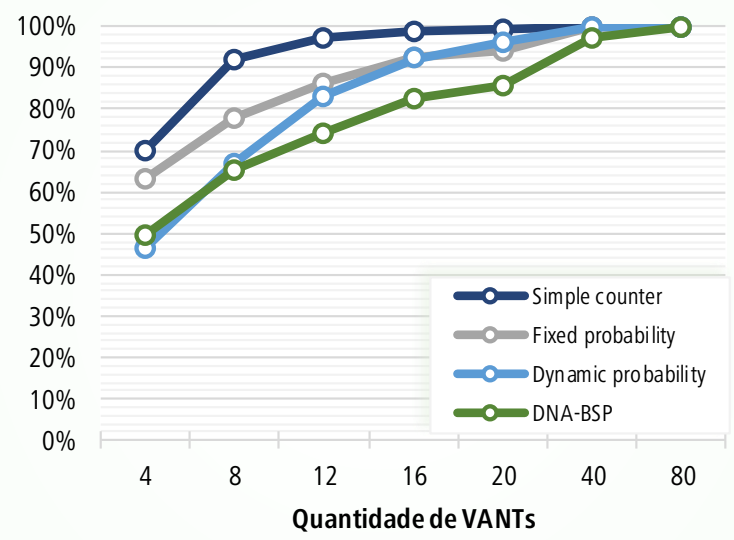

(e) Informação recebida. 
Comparando com os resultados do algoritmo de flooding, no cenário de mobilidade e nos piores casos, o DNA-BSP reduziu a quantidade máxima de retransmissões em 99,7\%. A quantidade máxima de mensagens recebidas foi reduzida por esse algoritmo em 98,3\%, mesmo aumentando a quantidade de informação recebida em 39,7\% e proporcionando um atraso fim-a-fim $99,5 \%$ menor.

O Algoritmo Dynamic Probability-based conseguiu resultados ligeiramente melhores que o DNA-BSP nos cenários com quatro nodos sob topologias fixas. Contudo, conforme foram sendo inseridos mais VANTs na FANET, sua capacidade de mitigação foi decaindo. Em alguns casos (vide figuras 22a, 22b, 22c e 22d) ele terminou pior, inclusive, do que os algoritmos Simple Counter-based e Fixed Probability-based, que são computacionalmente mais simples.

O DNA-BSP, por sua vez, tem uma eficiência melhor no cenário que mais representa uma FANET pelo fato de acumular mais conhecimento do que os outros algoritmos, exceto na métrica de informação recebida. Esse ponto fraco é congruente com a dualidade entre a restrição de retransmissões e a disseminação completa das informações.

\subsection{Considerações finais}

Os algoritmos de mitigação de tempestade de broadcast usam a técnica storecarry-forward para acumular conhecimento sobre os dados antes de decidir sobre a retransmissão. Esse modo de operação é mais adequado que o flooding em redes móveis sem fio de múltiplos saltos e com conectividade intermitente (como as FANETs) e leva a uma diminuição no número de mensagens redundantes na rede.

A interrupção dos loops que ocorreram nos experimentos de flooding permitiu que dados mais recentes tivessem uma maior chance de serem retransmitidos, aumentando assim a porcentagem de informações recebidas nos nodos.

A rede FANET é projetada para que uma missão possa ser executada em conjunto por múltiplos VANTs e ocupar parte da capacidade do meio sem fio com dados redundantes, e portanto irrelevantes, pode atrapalhar a realização da missão.

Dependendo do uso da técnica de broadcast, quando ocorrem perdas de informação - devido à excessiva mitigação ou falhas de transmissão - a aplicação pode repetir solicitações, como uma tentativa de corrigir tal perda. Esse aumento na demanda da rede seria consequência da ineficiência dos métodos de mitigação.

Neste capítulo, além de caracterizar o problema BSP e apresentar as vantagens do uso de algoritmos de mitigação, foi mostrado que quanto mais os algoritmos diminuíram as retransmissões, maior foi a perda de informação no nível da aplicação. Esse princípio de dualidade ainda é motivação para pesquisas futuras. 
O Capítulo 8 apresenta as conclusões sobre essa pesquisa de doutorado e também as sugestões para trabalhos futuros. 


\section{CONCLUSÕES}

Apesar dos diversos trabalhos encontrados na literatura sobre o problema da tempestade de broadcast em redes ad hoc móveis e dos avanços já conquistados, essa área continua sendo desafiadora visto que mitigar esse problema é a primeira solução buscada para alcançar a qualidade de serviço em MANETs que utilizam o broadcast para disseminar informação entre seus membros.

Neste trabalho foi abordado o problema da tempestade de broadcast que ocorre em redes FANETs quando informações de roteamento, controle de formação e gerenciamento de missão precisam ser disseminadas por toda a rede.

Como contribuições ao estado da arte na pesquisa sobre esse tópico, podem ser citadas as análises em ambientes realistas dos comportamentos dos algoritmos de disseminação já existentes e a criação de uma abordagem mais apropriada para o problema no cenário de redes ad hoc entre VANTs, que nos levam a responder a questão mais importante deste trabalho, ou seja, a questão que estuda o problema das tempestades de broadcast nas FANETs e uma contramedida adequada.

Primeiramente, os algoritmos de mitigação da literatura mais populares foram experimentados em campo, com uma rede de comunicação realista e equivalente à uma rede FANET.

Posteriormente, a pesquisa desse doutorado englobou experimentos empíricos e resultados de simulação de comunicação por broadcast em FANETs que operam com antenas omnidirecionais, entregando números para mostrar as consequências do problema BSP. Até onde foi possível analisar, esta é a primeira vez que o problema BSP é apresentado com esse nível de detalhe.

Apesar de ser uma demanda em redes FANETs, os resultados dos experimentos desse tipo de comunicação destacam que ele é realmente problemático e que a redun- 
dância de dados tende a aumentar à medida que a FANET se torna mais densa. Por meio de simulação computacional, foi mostrado o impacto negativo do algoritmo de flooding em FANETs densas, causando altas taxas de perda de informação e elevado atraso na entrega das mensagens, que são resultados diretos da contenção da rede. A demanda por técnicas de mitigação foi, então, explicada e justificada.

Os algoritmos de mitigação de retransmissões mais conhecidos da literatura foram avaliados e comparados entre si. Nenhum desses algoritmos é genérico o suficiente para ser aplicado em FANETs, especialmente quando o número de nodos aumenta. A razão é que esses algoritmos não formam conhecimento sobre dados antigos nem sobre o estado atual da topologia da rede.

Por fim, foi descrito o algoritmo Dynamic Neighborhood-based Algorithm for the Broadcast Storm Problem (DNA-BSP), considerando que, nas FANETs, os nodos estão voando - movendo-se livremente em três dimensões - e por isso a vizinhança muda continuamente. Este algoritmo visa realizar uma mitigação mais inteligente quando comparado aos algoritmos de mitigação da literatura. Ele melhora o algoritmo baseado em contador simples ao adicionar uma lista de mensagens retransmitidas no período de uma hora e ao usar o número dinâmico de vizinhos para decidir qual mensagem retransmitir, sem fazer uso de mensagens periódicas de saudação, as mensagens HELLO. O DNA-BSP foi experimentado por meio de simulação e, em seguida, seus resultados foram comparados com os resultados do flooding e dos algoritmos de mitigação da literatura.

O DNA-BSP soluciona o problema da tempestade de broadcast permitindo que informações desnecessárias sejam mitigadas e que o broadcast seja realizado de maneira controlada, apresentando melhores resultados que os algoritmos existentes e corroborando com a hipótese desta tese, constituindo, assim, um avanço ao estado da arte.

\subsection{Limitações}

A abordagem criada neste doutorado foi guiada (i) por dados reais, coletados em experimentos em ambiente externo para determinar um ambiente de simulação confiável; (ii) pelas técnicas mais conhecidas existentes na literatura (Baseada em Contador Simples, Baseada em Probabilidades Fixas e Baseada em Probabilidades Dinâmicas); e (iii) por decisão inteligente, uma vez que o DNA-BSP acumula conhecimento sobre a informação trafegada e sobre a vizinhança para aumentar sua eficiência, mesmo com um número maior de VANTs na rede.

Os resultados de simulação relativos ao atraso fim-a-fim e a eficiência de mitigação do algoritmo mostraram que o DNA-BSP supera os algoritmos comparados, melhorando a comunicação em tempo real. Quando comparado ao cenário problemático do BSP 
(o emprego do flooding para disseminação de informação em FANET com topologia dinâmica), esse algoritmo foi capaz de reduzir o atraso na entrega de mensagens em 99,5\% e também reduziu o uso do canal sem fio, transmitindo 99,7\% menos cópias de mensagens. Como o DNA-BSP também acumula conhecimento sobre os nodos vizinhos, a eficiência do algoritmo aumenta quando a FANET fica mais densa.

No entanto, equilibrar uma alta taxa de entrega de informações com uma baixa redundância de dados ainda é um grande desafio de disseminação de dados em FANETs e é a limitação da versão atual do algoritmo DNA-BSP. A abordagem ideal para que as mensagens sejam entregues a todos os nodos e que eles façam uma única retransmissão exige que os nodos armazenem todas as informações trocadas durante todo o período da missão, para que seja possível identificar qualquer dado duplicado e evitar sua retransmissão. Essa abordagem requer uma estratégia eficiente de armazenamento e acesso de informação, visto que o hardware comumente embarcado em VANTs, principalmente os civis de pequeno porte, possui limitações de recursos e potência computacional. A identificação de uma mensagem duplicada e a decisão sobre sua retransmissão ou descarte precisam, ainda, considerar que as mensagens trocadas via broadcast, geralmente, requerem respostas de tempo real, o que deixa mais complexa a modelagem dessa abordagem.

\subsection{Dificuldades encontradas}

A pesquisa deste doutorado envolveu conhecimentos multidisciplinares e trouxe consigo algumas dificuldades, tanto técnicas quanto científicas, elencadas a seguir:

- Determinação de comunicação em uma FANET: a primeira dificuldade encontrada foi na determinação de uma comunicação como nas FANETs em que o problema BSP acontecesse, visto que nenhum trabalho anterior sobre isso foi encontrado na literatura. O hardware construído com o protótipo (Figura 4) possui as mesmas configurações que o hardware utilizado em muitos modelos de VANTs civis de pequeno porte e ele não foi capaz de suportar o problema da inundação causado pelo algoritmo flooding. Os resultados dos experimentos do flooding no ambiente real demonstravam que apenas as primeiras mensagens haviam sido retransmitidas, pelo problema causado pelo loop incessante mostrado (por meio de simulação computacional) na Figura 19. Esses resultados não forneceram informações suficientes para a definição do ambiente de simulação e, por isso, a comunicação foi baseada nos experimentos reais com os algoritmos de controle de broadcast da literatura;

- Compreensão do framework de simulação: o OMNeT + + é um framework muito robusto, muito confiado por equipes de pesquisa do mundo todo e muito extenso. 
Programar nesse ambiente, reutilizando os módulos já validados é diferente de escrever o seu próprio código utilizando bibliotecas universais. Isso demandou um longo tempo para aprender como todos os elementos são modelados e como deve ser programado o fluxo de dados para que os resultados da simulação fossem confiáveis;

- Determinação dos modelos de simulação: Os modelos disponíveis no framework permitem uma variedade de customizações, o que foi, definitivamente, um dificuldade encontrada e disponibilizá-los agora é uma das contribuições desta pesquisa. O estudo sobre as características físicas e eletromagnéticas de um meio de transmissão sem fio foi necessário para a correta parametrização dos diversos modelos de propagação de ondas, de modo que não ficassem irreais, até se conseguir um comportamento estatisticamente idêntico à rede dos experimentos de campo.

- Limitação de recursos computacionais: A simulação de fenômenos físicos tais como path loss, fading, interferências de sinais e efeito Doppler (discutidos na Seção 5.2), em redes sem fio com alta densidade de nodos móveis, demanda muito recurso computacional, como capacidade de processamento e espaço em disco e memória. Uma dificuldade encontrada foi a realização das simulações em computador desktop como os utilizados no laboratório de pesquisa. Então, a solução foi migrar o framework pra nuvem e lá executar as simulações ${ }^{1}$, deixando somente as análises para serem feitas no laboratório.

\subsection{Contribuições}

A principal contribuição desta tese de doutorado é a concepção do algoritmo Dynamic Neighborhood-based Algorithm for the Broadcast Storm Problem para redes FANETs. Esse algoritmo vai de encontro ao objetivo desta tese, fornecendo um método de mitigação de broadcasts eficiente, capaz de amenizar os efeitos do problema BSP de modo distribuído e permitindo um melhor aproveitamento da rede.

Durante o processo da pesquisa e para a criação deste algoritmo, outras contribuições relevantes também foram obtidas:

- Levantamento de técnicas de controle de broadcast para redes ad hoc sem fio com nodos móveis no plano 2D (PIRES et al., 2016);

- Um protótipo de host para a comunicação ad hoc sem fio em redes FANETs (PIRES et al., 2016);

1 As simulações computacionais foram executadas na nuvem da Google, chamada Google Cloud Platform. 
- Adaptação dos algoritmos da literatura para o cenário dos sistemas embarcados em aeronaves não tripuladas de pequeno porte (PIRES et al., 2016);

- Análise das vantagens e desvantagens de cada técnica de mitigação (PIRES et al., 2016);

- Análise da influência de uma camada de segurança na camada de aplicação da comunicação (ARNOSTI; PIRES; BRANCO, 2017);

- Integração entre um simulador de voo e leis da física e o simulador de redes, com geração automática de códigos (MARCONATO et al., 2017);

- Análise e escolha dos modelos de mobilidade de nodos e propagação de ondas mais apropriado para o cenário das redes FANETs;

- Quantificação do problema da tempestade de broadcast em cenário realista de FANETs;

Como última contribuição fica o ambiente de simulação computacional definido neste trabalho e descrito no Capítulo 5 , que será disponibilizado para que novas pesquisas neste campo possam ser realizadas de maneira confiável e de modo mais célere.

\subsection{Trabalhos futuros}

O objetivo deste trabalho foi elucidar o problema do BSP em FANETs e apresentar uma solução eficiente para prover qualidade de serviço na rede. Como sugestão para trabalhos futuros fica:

- mensuração da qualidade de serviço do canal sem fio em uma FANET cujos VANTs usem o DNA-BSP para disseminar informação na rede, medindo, por exemplo, a eficiência de protocolos de roteamento que tenham suas mensagens HELLO mitigadas;

- melhorias no DNA-BSP considerando o emprego de técnicas de mitigação diferentes das probabilísticas, a dinamicidade dos vizinhos e o uso de prioridades nas mensagens, por exemplo;

- acréscimo de novos elementos ao meio ambiente, para a avaliação do comportamento do modelo de propagação de ondas, como obstáculos, terrenos irregulares, construções etc.;

- a integração do simulador de redes com um simulador realista de voo, responsável por prover aos VANTs movimentação considerando as cinéticas das aeronaves e suas limitações de movimentação. 


\subsection{Declaração de autoria}

Eu confirmo que esta tese de doutorado não foi apresentada como parte dos requisitos para obtenção de um outro grau nesta ou em qualquer outra instituição de ensino e pesquisa. Afirmo ainda que ela é o resultado do meu próprio trabalho e todo o material de outras fontes foi plenamente e adequadamente reconhecido/referenciado. Pesquisas realizadas em colaboração estão claramente indicadas. Trechos desta tese, quer tenham sido publicados ou submetidos à apreciação dos conselhos editoriais de revistas, conferências e workshops, são apresentados a seguir de acordo com a lista de publicações.

\subsection{Lista de publicações}

\subsubsection{Artigo aceito para publicação}

- Pires, R. M.; Pinto, A. S. R.; Branco, K. R. L. J. C.

The broadcast storm problem in FANETs and the Dynamic Neighborhood-based Algorithm as a countermeasure.

Revista: IEEE Access 2019, trilha especial: Network Resource Management in Flying Ad Hoc Networks: Challenges, Potentials, Future Applications, and Wayforward. Nível de contribuição: Alto - o aluno de doutorado é o principal pesquisador e conduziu os trabalhos em conjunto com os demais colaboradores.

\subsubsection{Artigos publicados}

- Marconato, E. A.; Rodrigues, M.; Pires, R. M.; Pigatto, D. F.; Querino Filho, L. C.; Pinto, A. S. R.; Branco, K. R. L. J. C.

AVENS - A Novel Flying Ad Hoc Network Simulator with Automatic Code Generation for Unmanned Aircraft System.

Evento: 50th Hawaii International Conference on System Sciences (HICSS), Waikoloa, Hawaii. 2017.

Nível de contribuição: Médio - o aluno de doutorado contribuiu com o desenvolvimento e a análise dos estudos de caso.

- Arnosti, S. Z.; Pires, R. M.; Branco, K. R. L. J. C.

Evaluation of cryptography applied to broadcast storm mitigation algorithms in FANETs.

Evento: International Conference on Unmanned Aircraft Systems (ICUAS), Miami. 2017. 
Nível de contribuição: Alto - o aluno de doutorado é o principal pesquisador e conduziu os trabalhos em conjunto com os demais colaboradores.

- Pires, R. M.; Arnosti, S. Z.; Pinto, A. S. R.; Branco, K. R. L. J. C. Experimenting Broadcast Storm Mitigation Techniques in FANETs.

Evento: 49th Hawaii International Conference on System Sciences (HICSS), Koloa, Hawaii. 2016.

Nível de contribuição: Alto - o aluno de doutorado é o principal pesquisador e conduziu os trabalhos em conjunto com os demais colaboradores. 



\section{REFERÊNCIAS}

ABDULLA, A.; FADLULLAH, Z.; NISHIYAMA, H.; KATO, N.; ONO, F.; MIURA, R. Toward fair maximization of energy efficiency in multiple UAS-Aided networks: A game-theoretic methodology. IEEE Transactions on Wireless Communications, v. 14, n. 1, p. 305-316, 2015. ISSN 1536-1276. Citado nas páginas 35 e 36.

AREM, B. van; DRIEL, C. J. G. van; VISSER, R. The Impact of Cooperative Adaptive Cruise Control on Traffic-Flow Characteristics. IEEE Transactions on Intelligent Transportation Systems, v. 7, n. 4, p. 429-436, 2006. ISSN 1524-9050. Citado na página 34.

ARIYAKHAJORN, J.; WANNAWILAI, P.; SATHITWIRIYAWONG, C. A comparative study of random waypoint and Gauss-Markov mobility models in the performance evaluation of MANET. In: IEEE. Communications and Information Technologies, 2006. ISCIT'06. International Symposium on. [S.1.], 2006. p. 894-899. Citado na página 79.

ARMOUSH, A.; SALEWSKI, F.; KOWALEWSKI, S. Design pattern representation for safetycritical embedded systems. Journal of Software Engineering \& Applications, v. 02, p. 1-12, 2009. ISSN 1945-3116. Citado na página 31.

ARNOSTI, S. Z.; PIRES, R. M.; BRANCO, K. R. L. J. C. Evaluation of cryptography applied to broadcast storm mitigation algorithms in FANETs. In: 2017 International Conference on Unmanned Aircraft Systems (ICUAS). Miami, FL, USA: IEEE, 2017. p. 1368-1377. ISBN 9781509044955. Citado nas páginas 28 e 107.

BAI, F.; HELMY, A. A survey of mobility models in wireless adhoc networks. In: Wireless Ad Hoc and Sensor Networks. [S.1.]: Kluwer Academic Publishers, 2004. cap. 1, p. 1-29. Citado na página 79.

BAI, F.; SADAGOPAN, N.; HELMY, A. IMPORTANT: a framework to systematically analyze the Impact of Mobility on Performance of Routing proTocols for Adhoc NeTworks. In: IEEE INFOCOM 2003. Twenty-second Annual Joint Conference of the IEEE Computer and Communications Societies (IEEE Cat. No.03CH37428). [S.1.: s.n.], 2003. v. 2, p. 825-835. ISSN 0743-166X. Citado na página 79.

BEAULIEU, N.; CHENG, C. Efficient Nakagami-m fading channel simulation. Vehicular Technology, IEEE Transactions on, v. 54, n. 2, p. 413-424, mar. 2005. ISSN 0018-9545. Citado na página 51.

BEKMEZCI, I.; ERMIS, M.; KAPLAN, S. Connected multi UAV task planning for Flying Ad hoc Networks. In: IEEE Int. Black Sea Conf. Commun. Networking (BlackSeaCom 2014). [S.l.: s.n.], 2014. p. 28-32. ISBN 9781479940677. Citado nas páginas 35 e 36.

BEKMEZCI, I.; SAHINGOZ, O. K.; TEMEL, S. Flying Ad hoc Networks (FANETs): A survey. Ad Hoc Networks, v. 11, n. 3, p. 1254-1270, maio 2013. ISSN 15708705. Citado nas páginas 35, 36 e 37 . 
BETTSTETTER, C. Smooth is better than sharp: a random mobility model for simulation of wireless networks. In: ACM. Proceedings of the $4^{\text {th }}$ ACM international workshop on Modeling, analysis and simulation of wireless and mobile systems. [S.1.], 2001. p. 19-27. Citado na página 79.

Topology properties of ad hoc networks with random waypoint mobility. ACM SIGMOBILE Mobile Computing and Communications Review, ACM, v. 7, n. 3, p. 50-52, 2003. Citado na página 79.

BETTSTETTER, C.; SANTI, P.; RESTA, G. The node distribution of the random waypoint mobility model for wireless ad hoc networks. IEEE Transactions on Mobile Computing, v. 2, p. 257-269, jul. 2003. ISSN 1536-1233. Citado na página 79.

BLAKELY, K.; LOWEKAMP, B. A Structured Group Mobility Model for the Simulation of Mobile Ad Hoc Networks. In: Proceedings of the Second International Workshop on Mobility Management \& Wireless Access Protocols. New York, NY, USA: ACM, 2004. (MobiWac '04), p. 111-118. ISBN 1581139209. Citado na página 47.

BOUKERCHE, A. (Ed.). Algorithms and Protocols for Wireless and Mobile Ad Hoc Networks. Hoboken, N.J.: Wiley-IEEE Press, 2008. (Wiley Series on Parallel and Distributed Computing). ISBN 9780470396377. Citado nas páginas 38 e 44.

BRANCO, K. R. L. J. C.; PELIZZONI, J. M.; NERIS, L. O.; TRINDADE JR, O.; OSÓRIO, F. S.; WOLF, D. F. Tiriba - a new approach of UAV based on model driven development and multiprocessors. In: 2011 IEEE International Conference on Robotics and Automation (ICRA). Shanghai, China: IEEE, 2011. p. 1-4. ISBN 9781612843858. ISSN 1050-4729. Citado na página 32.

BUJARI, A.; CALAFATE, C. T.; CANO, J.-C.; MANZONI, P.; PALAZZI, C. E.; RONZANI, D. Flying ad hoc network application scenarios and mobility models. International Journal of Distributed Sensor Networks, v. 13, n. 10, out. 2017. ISSN 1550-1477. Citado na página 26.

CAMP, T.; BOLENG, J.; DAVIES, V. A survey of mobility models for ad hoc network research. Wireless Communications and Mobile Computing, v. 2, n. 5, p. 483-502, ago. 2002. ISSN 1530-8669. Citado na página 79.

CHANDRASEKHARAN, S.; GOMEZ, K.; AL-HOURANI, A.; KANDEEPAN, S.; RASHEED, T.; GORATTI, L.; REYNAUD, L.; GRACE, D.; BUCAILLE, I.; WIRTH, T.; ALLSOPP, S. Designing and implementing future aerial communication networks. IEEE Communications Magazine, v. 54, n. 5, p. 26-34, maio 2016. ISSN 0163-6804. Citado na página 40.

CHAPMAN, R.; HAMILTON, D.; BOX, D.; KUHR, M.; MACDONALD, J.; HAMILTON, S. Simulation of army unmanned aerial vehicle communications. In: HENDERSON, S. G.; BILLER, B.; HSIEH, M.-H.; SHORTLE, J.; TEW, J. D.; BARTON, R. R. (Ed.). 2007 Winter Simulation Conference. Washington, DC, USA: IEEE, 2007. p. 1324-1327. ISBN 9781424413058. ISSN 0891-7736. Citado na página 40.

CHIARAMONTE, R. B.; BRANCO, K. R. L. J. C. Collision detection using received signal strength in FANETs. In: 2014 International Conference on Unmanned Aircraft Systems (ICUAS). Orlando, FL, USA: IEEE, 2014. ISBN 9781479923762. Citado nas páginas 35 e 36. 
CONRADT, L.; ROPER, T. J. Group decision-making in animals. Nature, Nature Publishing Group, v. 421, n. 6919, p. 155-158, 2003. Citado na página 34.

COUZIN, I. D.; KRAUSE, J.; FRANKS, N. R.; LEVIN, S. A. Effective leadership and decisionmaking in animal groups on the move. Nature, Nature Publishing Group, v. 433, n. 7025, p. 513-516, 2005. Citado na página 34.

DONLEY, M. B.; SCHWARTZ, N. A. United States Air Force Unmanned Aircraft Systems Flight Plan: 2009-2047. Whashington, DC, 2009. 82 p. Citado nas páginas 31 e 33 .

DRONEIMAGES. Aplicações filmagens e fotos aéreas com drone. DroneImages, 2013. Disponível em: < http://www.droneimages.com.br/aplicacoes-de-filmagens-efotos-aereas-com-drone $>$. Acesso em: 08/ago/2015. Citado na página 26.

FACEBOOK. Internet.org: Connecting the World from the Sky. 2014. Disponível em: <https://info.internet.org/en/wp-content/uploads/sites/4/2016/07/ 851574_611544752265540_1262758947_n.pdf >. Acesso em: 28/jan/2019. Citado na página 40.

FEDERAL AVIATION ADMINISTRATION. FAA Aerospace Forecast FY 2018-2038. USA, 2018. 101 p. Citado na página 40.

FERREIRA, A.; GALTIER, J.; PENNA, P. Topological design, routing, and handover in satellite networks. In: STOJMENOVIć, I. (Ed.). Handbook of Wireless Networks and Mobile Computing. [S.1.]: John Wiley \& Sons, Inc., 2002, (Wiley Series on Parallel and Distributed Computing). cap. 22. ISBN 0471224561. Citado na página 59.

FEUKEU, E.; SNYMAN, L. An improved dynamic broadcast storm mitigation for VANETs. Procedia Computer Science, v. 130, p. 180-187, 2018. ISSN 1877-0509. The $9^{\text {th }}$ International Conference on Ambient Systems, Networks and Technologies (ANT 2018) / The $8^{\text {th }}$ International Conference on Sustainable Energy Information Technology (SEIT-2018) / Affiliated Workshops. Citado nas páginas 26, 40 e 43.

FINN, A.; SCHEDING, S. Developments and Challenges for Autonomous Unmanned Vehicles: A Compendium. [S.1.]: Springer Berlin Heidelberg, 2010. v. 3. (Intelligent Systems Reference Library, v. 3). ISBN 9783642107047. Citado na página 33.

FISHER, J. A.; FARABOSCHI, P.; YOUNG, C. Embedded computing: a VLIW approach to architecture, compilers and tools. San Francisco, CA: Elsevier, 2005. 671 p. ISBN 1558607668. Citado na página 31 .

FUCHS, C.; HENNIGER, H.; EPPLE, B.; GIGGENBACH, D.; AMIRFEIZ, M.; JENTILE, M.; NEPI, G. D.; MAZZI, F.; MARTINI, G. Broadband communications for aeronautical networks: the ATENAA outer optical link validation. In: Proceedings of the $\mathbf{1}^{\text {st }}$ CEAS European Air and Space Conference. Berlin, Germany: [s.n.], 2007. Citado na página 40.

GANKHUYAG, G.; SHRESTHA, A. P.; YOO, S.-J. Robust and Reliable Predictive Routing Strategy for Flying Ad Hoc Networks. IEEE Access, v. 5, p. 643-654, jan. 2017. ISSN 2169-3536. Citado na página 40. 
GAZETA DO POVO. Brasil reforça segurança da Copa com drone de R\$ 18 milhões. Gazeta do Povo, 2014. Disponível em: < http://www.gazetadopovo.com.br/ esportes/copa/2014/brasil-reforca-seguranca-da-copa-com-drone-de-r-18-milhoes24j0kbm3ks63um2jbsauhd83y > . Acesso em: 31/mar/2014. Citado na página 26.

GERLA, M.; YI, Y. Team communications among autonomous sensor swarms. ACM SIGMOD Rec., v. 33, n. 1, p. 20, mar. 2004. ISSN 01635808. Citado nas páginas 45, 46, 47 e 53.

GU, D. L.; PEI, G.; LY, H.; GERLA, M.; HONG, X. Hierarchical routing for multi-layer ad hoc wireless networks with UAVs. In: MILCOM 2000 Proceedings. $21^{\text {st }}$ Century Military Communications. Architectures and Technologies for Information Superiority (Cat. No.00CH37155). Los Angeles, CA, USA: IEEE, 2000. v. 1, p. 310-314. ISBN 0780365216. Citado na página 40.

GUAN, Y. L.; TURNER, L. F. Generalised FSMC model for radio channels with correlated fading. IEE Proceedings - Communications, v. 146, n. 2, p. 133-137, abr. 1999. ISSN 1350-2425. Citado nas páginas 71 e 72.

HAAS, Z. J.; PEARLMAN, M. R. ZRP: A Hybrid Framework for Routing in Ad Hoc Networks. In: Ad Hoc Networking. Boston, MA, USA: Addison-Wesley Longman Publishing Co., Inc., 2001. cap. 7, p. 221-253. ISBN 0201309769. Citado na página 38.

HAN, X.; ROSSI, L. F.; SHEN, C.-C. Autonomous Navigation of Wireless Robot Swarms with Covert Leaders. In: Proc. $1^{\text {st }}$ Int. Conf. Robot Commun. Coord. (RoboComm '07). Piscataway, NJ, USA: IEEE Press, 2007. (RoboComm '07), p. 27:1-27:8. ISBN 9789639799080. Citado nas páginas 48 e 53.

HARTMANN, K.; STEUP, C. The vulnerability of UAVs to cyber attacks - an approach to the risk assessment. In: $20135^{\text {th }}$ International Conference on Cyber Conflict (CYCON 2013). Tallinn, Estonia: IEEE, 2013. ISBN 9789949921157. ISSN 2325-5374. Citado na página 40.

HAYAT, S.; YANMAZ, E. Multi-Hop Aerial 802.11 Network: An Experimental Performance Analysis. In: INSTITUTE OF NETWORKED AND EMBEDDED SYSTEMS, ALPEN-ADRIA UNIVERSITäT KLAGENFURT. Proc. 2015 Austrian Robot. Work. Klagenfurt, Austria, 2015. p. 20-21. Citado nas páginas 50, 51, 52 e 53.

HAYAT, S.; YANMAZ, E.; MUZAFFAR, R. Survey on unmanned aerial vehicle networks for civil applications: A communications viewpoint. IEEE Communications Surveys \& Tutorials, v. 18, n. 4, p. 2624-2661, 2016. ISSN 1553-877X. Citado nas páginas 26, 37 e 43.

HEINZELMAN, W. R.; KULIK, J.; BALAKRISHNAN, H. Adaptive protocols for information dissemination in wireless sensor networks. In: Proceedings of the $5^{\text {th }}$ annual ACM/IEEE international conference on mobile computing and networking - MobiCom'99. New York, NY, USA: ACM Press, 1999. ISBN 1581131429. Citado na página 38.

HO, C.; OBRACZKA, K.; TSUDIK, G.; VISWANATH, K. Flooding for reliable multicast in multi-hop ad hoc networks. In: Proceedings of the $3^{\text {rd }}$ international workshop on Discrete algorithms and methods for mobile computing and communications DIALM'99. [S.1.]: ACM Press, 1999. p. 64-71. Citado na página 38. 
HONG, X.; GERLA, M.; PEI, G.; CHIANG, C.-C. A Group Mobility Model for Ad Hoc Wireless Networks. In: Proceedings of the $2^{\text {nd }}$ ACM International Workshop on Modeling, Analysis and Simulation of Wireless and Mobile Systems. New York, NY, USA: ACM, 1999. (MSWiM '99), p. 53-60. ISBN 1581131739. Citado na página 47.

HYLAND, M. T.; MULLINS, B. E.; BALDWIN, R. O.; TEMPLE, M. A. Simulation-based performance evaluation of mobile ad hoc routing protocols in a swarm of unmanned aerial vehicles. In: $21^{\text {st }}$ International Conference on Advanced Information Networking and Applications Workshops (AINAW'07). Niagara Falls, Ont., Canada: IEEE, 2007. p. 249-256. ISBN 9780769528472. Citado na página 40.

IEEE. IEEE Standard Definitions of Terms for Radio Wave Propagation. 1997. IEEE Std 211-1997. Citado na página 71.

JANUZAJ, V.; KUGELE, S.; LANGER, B.; SCHALLHART, C.; VEITH, H. New Challenges in the Development of Critical Embedded Systems - An "aeromotive" Perspective. In: MARGARIA, T.; STEFFEN, B. (Ed.). Leveraging Applications of Formal Methods, Verification, and Validation. [S.1.]: Springer Berlin Heidelberg, 2010, (Lecture Notes in Computer Science, v. 6415). p. 1-2. ISBN 9783642165573. Citado na página 31.

JIANG, J.; HAN, G. Routing protocols for unmanned aerial vehicles. IEEE Communications Magazine, v. 56, n. 1, p. 58-63, jan. 2018. ISSN 0163-6804. Citado na página 40.

JOHNSON, D. B.; MALTZ, D. A.; BROCH, J. DSR: the dynamic source routing protocol for multihop wireless ad hoc networks. In: Ad hoc Networking. Boston, MA, USA: AddisonWesley Longman Publishing Co., Inc., 2001. cap. 5, p. 139-172. ISBN 0201309769. Citado na página 38.

KANG, S.; ALDWAIRI, M.; KIM, K.-I. A survey on network simulators in three-dimensional wireless ad hoc and sensor networks. International Journal of Distributed Sensor Networks, v. 12, n. 9, set. 2016. Citado na página 79.

KARAM, A. G. M. S. Development of an Efficient Ad Hoc Broadcasting Scheme for Critical Networking Environments. Tese (phdthesis) - College of Information Technology, United Arab Emirates University (UAEU), maio 2016. Citado na página 26.

KARRAS, K.; KYRITSIS, T.; AMIRFEIZ, M.; BAIOTTI, S. Aeronautical mobile ad hoc networks. In: 2008 14 $^{\text {th }}$ European Wireless Conference. Prague, Czech Republic: IEEE, 2008. ISBN 9783800731022. Citado na página 40.

KESHAVARZ-HADDAD, A.; RIBEIRO, V.; RIEDI, R. Color-based broadcasting for ad hoc networks. In: $20064^{\text {th }}$ International Symposium on Modeling and Optimization in Mobile, Ad Hoc and Wireless Networks. Boston, MA, USA: IEEE, 2006. p. 1-10. ISBN 0780395492. Citado nas páginas 48 e 53.

KHAN, M. A.; KHAN, I. U.; SAFI, A.; QUERSHI, I. M. Dynamic routing in flying ad hoc networks using topology-based routing protocols. Drones, v. 2, n. 3, ago. 2018. ISSN 2504-446X. Citado na página 79.

KHAN, M. A.; QURESHI, I. M.; SAFI, A.; KHAN, I. U.; QURESHI, I. M.; KHAN, I. U. Flying Ad hoc Networks (FANETs): A review of communication architectures, and routing 
protocols. In: 2017 First International Conference on Latest Trends in Electrical Engineering and Computing Technologies (INTELLECT). Karachi, Pakistan: IEEE, 2017. ISBN 9781538629697. Citado na página 26.

KIM Seong-Woo; GWON Gi-Poong; CHOI Seung-Tak; KANG Seung-Nam; SHIN MyoungOk; YOO In-Sub; LEE Eun-Dong; FRAZZOLI, E.; SEO Seung-Woo. Multiple vehicle driving control for traffic flow efficiency. In: Intelligent Vehicles Symposium (IV), 2012 IEEE. [S.1.: s.n.], 2012. p. 462-468. ISSN 1931-0587. Citado nas páginas 26 e 34.

KIM Seong-Woo; SEO Seung-Woo. Cooperative Unmanned Autonomous Vehicle Control for Spatially Secure Group Communications. IEEE Journal on Selected Areas in Communications, v. 30, n. 5, p. 870-882, 2012. ISSN 0733-8716. Citado na página 34.

KO, Y.-B.; VAIDYA, N. H. Location-aided routing (LAR) in mobile ad hoc networks. In: Proceedings of the $4^{\text {th }}$ Annual ACM/IEEE International Conference on Mobile Computing and Networking. New York, NY, USA: ACM, 1998. (MobiCom '98), p. 66-75. ISBN 1-58113-035-X. Citado na página 79.

KUMAR, A.; MANJUNATH, D.; KURI, J. Random Access and Wireless LANs. In: CLARK, D. (Ed.). Wireless Networking. [S.1.]: Morgan Kaufmann/Elsevier, 2008, (The Morgan Kaufmann Series in Networking). cap. 7. ISBN 9780123742544. Citado na página 85.

KUMAR, A. S.; RAMASWAMI, K. A New Density Based Probabilistic Counter Based Scheme for Solving Broadcast Storm in Mobile Ad hoc Networks. Journal of Theoretical and Applied Information Technology, v. 59, n. 2, p. 451-459, jan. 2014. ISSN 18173195. Citado na página 26.

KUMAR, R.; DAVE, M. A Framework for Handling Local Broadcast Storm Using Probabilistic Data Aggregation in VANET. Wirel. Pers. Commun., Springer US, v. 72, n. 1, p. 315-341, fev. 2013. ISSN 0929-6212. Citado nas páginas 26, 40 e 43.

KUROSE, J. F.; ROSS, K. W. Computer networking: a top-down approach featuring the Internet. $6^{\text {th }}$. ed. Harlow: Pearson Education, 2012. ISBN 9780273768968. Citado na página 85.

. Wireless and Mobile Networks. In: Computer networking: a top-down approach featuring the Internet. $6^{\text {th }}$. ed. Harlow: Pearson Education, 2012. cap. 6. ISBN 9780273768968. Citado nas páginas 38, 84 e 85.

LAI, W. K.; CHUNG, W.-K.; TSAI, J.-B.; SHIEH, C.-S. Spray and hop: Efficient utilitymobility routing for intermittently connected mobile networks. In: 2009 Fourth International Conference on Communications and Networking in China. [S.1.]: IEEE, 2009. p. 1-5. ISBN 9781424443376. Citado na página 40.

LASSILA, P.; HYYTIÄ, E.; KOSKINEN, H. Connectivity properties of random waypoint mobility model for ad hoc networks. In: AGHA, K. A.; LASSOUS, I. G.; PUJOLLE, G. (Ed.). Challenges in Ad Hoc Networking. Boston, MA: Springer US, 2006. p. 159-168. ISBN 9780387311739. Citado na página 79.

LOON. Google Project Loon. 2011. Disponível em: < https://loon.co/technology/>. Acesso em: 28/jan/2019. Citado na página 40. 
LOU, W.; WU, J. Toward broadcast reliability in mobile ad hoc networks with double coverage. IEEE Transactions on Mobile Computing, v. 6, n. 2, p. 148-163, fev. 2007. ISSN 1536-1233. Citado nas páginas 84 e 85.

MA, X. Data collection of mobile sensor networks by drones. Tese (phdthesis) Université de Toulouse, Institut National Polytechnique de Toulouse - INPT, France, nov. 2017. Citado na página 26.

MARCONATO, E. A.; MAXA, J. A.; PIGATTO, D. F.; PINTO, A. S. R.; LARRIEU, N.; BRANCO, K. R. L. J. C. IEEE 802.11n vs. IEEE 802.15.4: A study on communication QoS to provide safe FANETs. In: 2016 46 ${ }^{\text {th }}$ Annual IEEE/IFIP International Conference on Dependable Systems and Networks Workshop (DSN-W). Toulouse, France: IEEE, 2016. p. 184-191. ISBN 9781467388917. Citado nas páginas 35, 36 e 40.

MARCONATO, E. A.; PIGATTO, D. F.; BRANCO, K. R. L. J. C.; BRANCO, L. H. C. LARISSA: Layered architecture model for interconnection of systems in UAS. In: International Conference on Unmanned Aircraft Systems (ICUAS 2014). [S.1.: s.n.], 2014. p. 20-31. Citado nas páginas 35 e 36.

MARCONATO, E. A.; RODRIGUES, M.; PIRES, R. M.; PIGATTO, D. F.; FILHO, L. C. Q.; PINTO, A. R.; BRANCO, K. R. L. J. C. AVENS - a novel flying ad hoc network simulator with automatic code generation for unmanned aircraft system. In: Proceedings of the $50^{\text {th }}$ Hawaii International Conference on System Sciences (HICSS'17). Waikoloa Village, Hawaii: Hawaii International Conference on System Sciences, 2017. ISBN 9780998133102. Citado nas páginas 28, 35, 36 e 107.

MENEGUETTE, R. I.; MAIA, G.; MADEIRA, E. R. M.; PINTO, A. R.; LOUREIRO, A. A. F.; VILLAS, L. A. A new solution to perform data dissemination in vehicular networks. In: 2014 Brazilian Symposium on Computer Networks and Distributed Systems. [S.1.]: IEEE, 2014. p. 443-450. ISBN 9781479956128. Citado nas páginas 26, 40 e 43.

MENEGUETTE, R. I.; VILLAS, L. A. An Autonomic Algorithm for Data Dissemination in Vehicular Ad Hoc Networks. IEEE Latin America Transactions, v. 12, n. 3, p. 430-435, maio 2014. ISSN 1548-0992. Citado na página 26.

MOHAMMED, A.; OULD-KHAOUA, M.; MACKENZIE, L. An efficient counter-based broadcast scheme for mobile ad hoc networks. In: WOLTER, K. (Ed.). Formal Methods and Stochastic Models for Performance Evaluation. [S.1.]: Springer Berlin, Heidelberg, 2007, (Lecture Notes in Computer Science, v. 4748). p. 275-283. ISBN 9783540752103. Citado nas páginas 26, 40, 43, 49, 50, 53, 55, 56 e 57.

. Improvement to Efficient Counter-Based Broadcast Scheme through Random Assessment Delay Adaptation for MANETs. In: Computer Modeling and Simulation, 2008. EMS '08. Second UKSIM European Symposium on. [S.1.: s.n.], 2008. p. 536541. Citado nas páginas $26,40,43,50,53,55,56$ e 57.

. An improved rebroadcast probability function for an efficient counter-based broadcast scheme in MANETs. In: $\mathbf{2 5}^{\text {th }}$ Annual UK Performance Engineering Workshop (UKPEW'09). [S.1.: s.n.], 2009. Citado nas páginas 26, 40, 43, 50, 53, 55, 57 e 58.

MOHAMMED, A.; OULD-KHAOUA, M.; MACKENZIE, L.; ABDULAI, J. Improving the performance of counter-based broadcast scheme for mobile ad hoc networks. In: IEEE 
International Conference on Signal Processing and Communications (ICSPC 2007). [S.1.: s.n.], 2007. p. 1403-1406. Citado na página 26.

MUNDOGEO. Fórum VANTs \& Drones: Aplicações e Resultados. In: MUNDOGEO. MundoGEO\#Connect LatinAmerica 2015. São Paulo-SP, Brasil, 2015. Citado na página 26.

MURTHY, C. S. R.; MANOJ, B. S. Ad hoc Wireless Networks: Architectures and Protocols. [S.1.]: Prentice Hall PTR, 2004. (Prentice Hall Communications Engineering and Emergin Technologies). ISBN 0-13-147023-X. Citado nas páginas 37, 38, 70, 71, 72 e 85.

MURUGESAN, M.; KRISHNAN, A. Efficient forward node list algorithm for broadcasting in asymmetric mobile ad hoc networks. International Journal on Computer Science and Engineering (IJCSE), v. 02, n. 04, p. 1219-1222, 2010. ISSN 0975-3397. Citado nas páginas 84 e 85 .

MYLONAS, Y.; LESTAS, M.; PITSILLIDES, A.; IOANNOU, P.; PAPADOPOULOU, V. Speed adaptive probabilistic flooding for vehicular ad hoc networks. IEEE Transactions on Vehicular Technology, v. 64, n. 5, p. 1973-1990, maio 2015. ISSN 0018-9545. Citado nas páginas 26, 40 e 43.

NAJAFZADEH, S.; ITHNIN, N.; RAZAK, S. A.; KARIMI, R. BSM: Broadcasting of Safety Messages in Vehicular Ad Hoc Networks. Arabian Journal for Science and Engineering, Springer Berlin Heidelberg, v. 39, n. 2, p. 777-782, set. 2013. ISSN 1319-8025. Citado na página 26.

NAYYAR, A. Flying ad hoc network (FANETs): Simulation based performance comparison of routing protocols: AODV, DSDV, DSR, OLSR, AOMDV and HWMP. In: 2018 International Conference on Advances in Big Data, Computing and Data Communication Systems (icABCD). Durban, South Africa: IEEE, 2018. p. 1-9. ISBN 9781538630600. Citado na página 40.

OUBBATI, O. S.; LAKAS, A.; ZHOU, F.; GÜNEŞ, M.; YAGOUBI, M. B. A survey on positionbased routing protocols for flying ad hoc networks (FANETs). Vehicular Communications, v. 10, p. 29-56, out. 2017. ISSN 2214-2096. Citado na página 40.

PARRISH, J. K.; EDELSTEIN-KESHET, L. Complexity, Pattern, and Evolutionary TradeOffs in Animal Aggregation. Science, v. 284, n. 5411, p. 99-101, 1999. Citado na página 33.

PERKINS, C. E.; BHAGWAT, P. Highly dynamic destination-sequenced distance-vector routing (DSDV) for mobile computers. ACM SIGCOMM Computer Communication Review, Association for Computing Machinery (ACM), v. 24, n. 4, p. 234-244, out. 1994. Citado na página 38 .

PETERSEN, A. C. Simulating Nature: A Philosophical Study of Computer-Simulation Uncertainties and Their Role in Climate Science and Policy Advice. $2^{\text {nd }}$. ed. [S.1.]: Chapman and Hall/CRC, 2012. ISBN 9781466500679. Citado na página 70.

PIRES, R. M.; ARNOSTI, S. Z.; PINTO, A. S. R.; BRANCO, K. R. L. J. C. Experimenting broadcast storm mitigation techniques in FANETs. In: $201649^{\text {th }}$ Hawaii International 
Conference on System Sciences (HICSS). [S.1.: s.n.], 2016. p. 5868-5877. ISSN 15301605. Citado nas páginas 26, 28, 35, 36, 40, 43, 106 e 107.

PIRES, R. M.; CHAVES, A. A.; BRANCO, K. R. L. J. C. Smart Sensor Protocol - a new standard for UAV and payload integration. In: International Conference on Unmanned Aircraft Systems (ICUAS). Orlando, FL, USA: IEEE, 2014. p. 1300-1310. ISBN 9781479923762. Citado na página 33.

QUISPE, L. E.; GALAN, L. M. Behavior of ad hoc routing protocols, analyzed for emergency and rescue scenarios, on a real urban area. Expert Systems with Applications, v. 41, n. 5, p. 2565-2573, abr. 2014. ISSN 0957-4174. Citado na página 40.

RAPPAPORT, T. S. Wireless Communications Principles and Practice. $2^{\text {nd }}$. ed. London: Prentice Hall PTR, 2001. (Prentice Hall Communications Engineering and Emerging Technologies Series). ISBN 0130422320. Citado nas páginas 34, 71 e 72.

RAY, S.; CARRUTHERS, J. B.; STAROBINSKI, D. RTS/CTS-induced congestion in ad hoc wireless LANs. In: Wireless Communications and Networking (WCNC) 2003. [S.1.]: IEEE, 2003. v. 3, p. 1516-1521. ISSN 1525-3511. Citado na página 39.

RAZZAQI, A. A.; MUSTAQIM, M.; KHAWAJA, B. A. Antenna array design for multiUAVs communication in next generation Flying Ad hoc Networks (FANETs). In: $\mathbf{1 1}^{\text {th }}$ Annu. High Capacit. Opt. Networks Emerging/Enabling Technol. (Photonics Energy 2014). [S.1.: s.n.], 2014. p. 25-28. ISBN 9781479969401. Citado nas páginas 35 e 36.

REINA, D. G.; TORAL, S. L.; JOHNSON, P.; BARRERO, F. A survey on probabilistic broadcast schemes for wireless ad hoc networks. Ad Hoc Networks, Elsevier BV, v. 25, p. 263-292, fev. 2015. Citado nas páginas 25, 26, 37, 43 e 44.

REUTERS. Drone mostra imagens de destruição após terremoto no Nepal. 2015. Disponível em: < http://g1.globo.com/mundo/noticia/2015/04/drone-mostra-imagensde-destruicao-apos-terremoto-no-nepal.html $>$. Acesso em: 27/abr/2015. Citado na página 26.

ROSATI, S.; KRUŻELECKI, K.; HEITZ, G.; FLOREANO, D.; RIMOLDI, B. Dynamic routing for flying ad hoc networks. IEEE Transactions on Vehicular Technology, v. 65, n. 3, p. 1690-1700, mar. 2015. ISSN 1939-9359. Citado na página 40.

ROY, R. R. Handbook of Mobile Ad Hoc Networks for Mobility Models. [S.1.]: Springer US, 2011. ISBN 9781441960481. Citado nas páginas 79, 84 e 85.

SAHA, A. K.; JOHNSON, D. B. Modeling mobility for vehicular ad hoc networks. In: Proceedings of the $1^{\text {st }}$ ACM International Workshop on Vehicular Ad Hoc Networks. New York, NY, USA: ACM, 2004. (VANET '04), p. 91-92. ISBN 1581139225. Citado na página 79.

SAHA, B.; QUACH, C. C.; GOEBEL, K. Optimizing battery life for electric UAVs using a Bayesian framework. In: 2012 IEEE Aerospace Conference. Big Sky, MT, USA: IEEE, 2012. p. 1-7. ISBN 9781457705571. ISSN 1095-323X. Citado na página 81.

SAHINGOZ, O. K. Mobile networking with UAVs: Opportunities and challenges. In: Proc. of Int. Conf. Unmanned Aircr. Syst. (ICUAS 2013). Atlanta, GA: IEEE, 2013. p. 933-941. ISBN 9781479908172. Citado nas páginas 35 e 36. 
. Networking models in flying ad hoc networks (FANETs): Concepts and challenges. Journal of Intelligent and Robotic Systems: Theory and Applications, v. 74, n. 1-2, p. 513-527, out. 2014. ISSN 0921-0296. Citado nas páginas 35 e 36.

SCHWARTZ, R. S.; SCHOLTEN, H.; HAVINGA, P. A scalable data dissemination protocol for both highway and urban vehicular environments. EURASIP J. Wirel. Commun. Netw., Springer, v. 2013, n. 1, p. 257, nov. 2013. ISSN 1687-1499. Citado nas páginas 26 e 41.

SHAKHATREH, H.; SAWALMEH, A.; AL-FUQAHA, A. I.; DOU, Z.; ALMAITA, E.; KHALIL, I.; OTHMAN, N. S.; KHREISHAH, A.; GUIZANI, M. Unmanned aerial vehicles: A survey on civil applications and key research challenges. Preprint. 2018. Disponível em: < https: //arxiv.org/abs/1805.00881>. Citado na página 26.

SHARMA, V.; KUMAR, R. A Cooperative Network Framework for Multi-UAV Guided Ground Ad Hoc Networks. J. Intell. Robot. Syst., v. 77, n. 3-4, p. 629-652, mar. 2014. ISSN 0921-0296. Citado nas páginas 35 e 36.

SHI, N.; LUO, X. A novel cluster-based location-aided routing protocol for UAV fleet networks. International Journal of Digital Content Technology and its Applications(JDCTA), v. 6, n. 18, p. 376-383, out. 2012. ISSN 1975-9339. Citado na página 40 .

SHIRANI, R.; ST-HILAIRE, M.; KUNZ, T.; ZHOU, Y.; LI, J.; LAMONT, L. On the delay of reactive-greedy-reactive routing in unmanned aeronautical ad hoc networks. Procedia Computer Science, v. 10, p. 535-542, 2012. ISSN 1877-0509. Citado na página 40.

SIMON, M. K.; ALOUINI, M.-S. Digital Communication Over Fading Channels: A Unified Approach to Performance Analysis. [S.1.]: John Wiley \& Sons, Inc., 2000. (Wiley Series in Telecommunications and Signal Processing). ISBN 0471200697. Citado na página 72.

SINGH, D.; MAURYA, A. K.; SARJE, A. K. Comparative performance analysis of LANMAR, LAR1, DYMO and ZRP routing protocols in MANET using Random Waypoint Mobility Model. In: $20113^{\text {rd }}$ International Conference on Electronics Computer Technology. [S.1.: s.n.], 2011. v. 6, p. 62-66. Citado na página 79.

SINGH, K.; VERMA, A. K. Experimental analysis of AODV, DSDV and OLSR routing protocol for flying ad hoc networks (FANETs). In: 2015 IEEE International Conference on Electrical, Computer and Communication Technologies (ICECCT). Coimbatore, India: IEEE, 2015. p. 1-4. ISBN 9781479960859. Citado na página 40.

SKYDRONE. VANTs - Skydrone. 2015. Disponível em: < http://www.skydrones.com.br/ content/skydrones/aplicacao.aspx>. Acesso em: 08/ago/2015. Citado na página 26.

STALLINGS, W. Wireless LANs. In: Data and Computer Communications. $8^{\text {th }}$. ed. [S.1.]: Prentice Hall, 2006. cap. 17. ISBN 0132433109. Citado nas páginas 84 e 85.

STOJMENOVIC, I.; WU, J. Broadcasting and activity scheduling in ad hoc networks. In: BASAGNI, S.; CONTI, M.; GIORDANO, S.; STOJMENOVIC, I. (Ed.). Mobile Ad Hoc Networking. New York, Chichester: Willey, 2004. cap. 7, p. 205-229. ISBN 9780471373131. Citado nas páginas 26 e 45. 
SUZUKI, K. A. O.; FILHO, P. K.; MORRISON, J. R. Automatic battery replacement system for UAVs: Analysis and design. Journal of Intelligent \& Robotic Systems, v. 65, n. 1, p. 563-586, jan. 2012. ISSN 1573-0409. Citado na página 81.

TANENBAUM, A. Computer Networks. $4^{\text {th }}$ illustrated. ed. [S.1.]: Prentice Hall PTR, 2003. 891 p. (Computer Networks). ISBN 9780130661029. Citado na página 38.

TAREQUE, M. H.; HOSSAIN, M. S.; ATIQUZZAMAN, M. On the routing in flying ad hoc networks. In: 2015 Federated Conference on Computer Science and Information Systems (FedCSIS). Lodz, Poland: [s.n.], 2015. p. 1-9. ISBN 9788360810651. Citado na página 40.

TEMEL, S.; BEKMEZCi, I. On the performance of flying ad hoc networks (FANETs) utilizing near space high altitude platforms (HAPs). In: Proceedings of $6^{\text {th }}$ International Conference on Recent Advances in Space Technologies (RAST 2013). Istanbul, Turkey: [s.n.], 2013. p. 461-465. ISBN 9781467363938. Citado nas páginas 35, 36 e 40 .

TRINDADE JR, O.; BARBOSA, L. C. P.; NERIS, L. O.; JORGE, L. A. C. A Mission Planner and Navigation System for the ARARA Project. In: $23^{\text {rd }}$ ICAS - Congress of International Council of the Aeronautical Sciences. Toronto, Canada: [s.n.], 2002. p. 682.1-682.8. Citado na página 32 .

TRINDADE JR, O.; JORGE, L. A. C.; AGUIAR, J. G. B. Field of Dreams - Using UAVs for Precision Farming. Unmanned Systems Magazine, p. 35-39, nov. 2004. Citado na página 26.

TRINDADE JR, O.; NERIS, L. O.; BARBOSA, L. C. P.; BRANCO, K. R. L. J. C. A layered approach to design autopilots. In: IEEE International Conference on Industrial Technology - ICIT. [S.1.: s.n.], 2010. p. 1415-1420. Citado na página 32.

TSENG, Y.-C.; NI, S.-Y.; CHEN, Y.-S.; SHEU, J.-P. The broadcast storm problem in a mobile ad hoc network. Wireless Networks, Kluwer Academic Publishers, v. 8, n. 2-3, p. 153-167, mar. 2002. ISSN 1572-8196. Citado nas páginas 26, 38, 39, 40, 43, 44, 53, 55 e 97.

TSENG, Y.-C.; NI, S.-Y.; SHIH, E.-Y. Adaptive approaches to relieving broadcast storms in a wireless multihop mobile ad hoc network. IEEE Transactions on Computers, v. 52, n. 5, p. 545-557, maio 2003. ISSN 0018-9340. Citado nas páginas 26, 40, 43, 45, 53 e 55 .

TUNA, G.; NEFZI, B.; CONTE, G. Unmanned aerial vehicle-aided communications system for disaster recovery. Journal of Network and Computer Applications, v. 41, p. 27-36, maio 2014. ISSN 1084-8045. Citado na página 26.

USA Army UAS Center of Excelence. Unmanned Aircraft Systems Roadmap 2010-2035: Eyes of the Army. Roadmap. 2010. Disponível em: < https://apps.dtic.mil/docs/citations/ ADA518437>. Citado nas páginas 32 e 33.

USA Government Accountability Office. Unmanned Aircraft Systems: federal actions needed to ensure safety and expand their potential uses within the national airspace system. 2008. Report to congressional requesters. GAO-08-511. Disponível em: 
< https://www.gao.gov/products/GAO-08-511>. Acesso em: 04/fev/2019. Citado na página 32 .

VALAVANIS, K. P. (Ed.). Advances in Unmanned Aerial Vehicles. [S.1.]: Springer, Dordrecht, 2007. v. 33. (Intelligent Systems, Control and Automation: Science and Engineering, v. 33). ISBN 9781402061141. Citado nas páginas 26 e 40.

VARGA Andras. OMNeT+ + Academic Public License. 2010. Acessado em 30/jul/2015. Disponível em: < https://omnetpp.org/intro/license>. Citado nas páginas 73 e 74.

WEBBER, F.; HIROMOTO, R. Assessing the Communication Issues Involved in Implementing High-Level Behaviors in Unmanned Aerial Vehicles. In: MILCOM 2006. [S.1.]: IEEE, 2006. p. 1-7. ISBN 1-4244-0617-X. Citado nas páginas 46, 47 e 53.

WENZHUN, H.; YONGSHENG, W.; XIANGYANG, Y. Studies on novel anti-jamming technique of unmanned aerial vehicle data link. Chinese Journal of Aeronautics, v. 21, n. 2, p. 141-148, abr. 2008. ISSN 1000-9361. Citado na página 40.

WILLIAMS, B.; CAMP, T. Comparison of broadcasting techniques for mobile ad hoc networks. In: Proceedings of the $3^{\text {rd }}$ ACM International Symposium on Mobile Ad Hoc Networking \& Computing. New York, NY, USA: ACM, 2002. (MobiHoc '02), p. 194-205. ISBN 1581135017. Citado nas páginas 43 e 44.

WINSBERG, E. Computer simulations in science. In: ZALTA, E. N. (Ed.). The Stanford Encyclopedia of Philosophy. Summer 2018. Metaphysics Research Lab, Stanford University, 2018. Disponível em: < https://plato.stanford.edu/archives/sum2018/entries/ simulations-science/ $>$. Citado nas páginas 69 e 70.

WISITPONGPHAN, N.; TONGUZ, O. K.; PARIKH, J. S.; MUDALIGE, P.; BAI, F.; SADEKAR, V. Broadcast storm mitigation techniques in vehicular ad hoc networks. IEEE Wireless Communications, v. 14, n. 6, p. 84-94, dez. 2007. ISSN 1536-1284. Citado nas páginas 26, 40, 43, 49 e 53.

YANMAZ, E.; KUSCHNIG, R.; BETTSTETTER, C. Achieving air-ground communications in 802.11 networks with three-dimensional aerial mobility. In: 2013 Proc. IEEE INFOCOM. [S.1.]: IEEE, 2013. p. 120-124. ISBN 9781467359467. ISSN 0743166X. Citado nas páginas 50, 51, 52 e 53.

YANMAZ, E.; QUARITSCH, M.; YAHYANEJAD, S.; RINNER, B.; HELLWAGNER, H.; BETTSTETTER, C. Communication and coordination for drone networks. In: ZHOU, Y.; KUNZ, T. (Ed.). Ad Hoc Networks. [S.1.]: Springer, Cham, 2017. (Lecture Notes of the Institute for Computer Sciences, Social Informatics and Telecommunications Engineering, v. 184), p. 79-91. ISBN 9783319512044. Citado na página 26.

YASSEIN, M. B.; DAMER, N. A. Flying Ad Hoc Networks: Routing protocols, mobility models, issues. International Journal of Advanced Computer Science and Applications, The Science and Information Organization, v. 7, n. 6, 2016. Citado nas páginas 40 e 79.

ZHANG, C.; KOVACS, J. M. The application of small unmanned aerial systems for precision agriculture: a review. Precision Agriculture, v. 13, n. 6, p. 693-712, jul. 2012. ISSN 1385-2256. Citado nas páginas 26 e 32. 
ZHENG, Y.; JIANG, Y.; DONG, L.; WANG, Y.; LI, Z.; ZHANG, H. A mobility and load aware OLSR routing protocol for UAV mobile ad hoc networks. In: 2014 International Conference on Information and Communications Technologies (ICT 2014). [S.1.]: Institution of Engineering and Technology (IET), 2014. ISBN 9781849198431. Citado na página 40.

ZUCCHI, A. C.; SILVEIRA, R. M. Performance analysis of routing protocol for ad hoc UAV network. In: LANC'2018 Proceedings of the 10 ${ }^{\text {th }}$ Latin America Networking Conference. São Paulo, Brazil: ACM Press, 2018. p. 73-80. ISBN 9781450359221. Citado na página 79. 


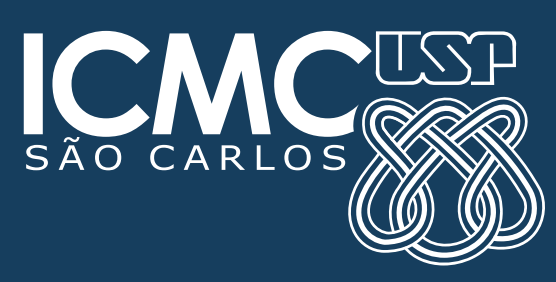

